\title{
21. OLIGOCENE AND NEOGENE RADIOLARIANS FROM THE LABRADOR SEA, ODP LEG 105 ${ }^{1}$
}

\author{
David Lazarus ${ }^{2}$ and Amy Pallant ${ }^{3}$
}

\begin{abstract}
Two sites in the Labrador Sea and one site in Baffin Bay were drilled during Leg 105. Radiolarians were recovered at all three sites, although at Site 645 (Baffin Bay), radiolarians were present in useful numbers only in the mudline sample. Radiolarians of late Neogene age were recovered at Site 646 south of Greenland, while early Oligocene and early Miocene radiolarians were recovered from the Labrador Sea at Site 647. In Site 646, radiolarian and other coarse-fraction abundances vary dramatically from sample to sample and may reflect deep-water depositional processes as well as changes in surface-water conditions. Site 647 siliceous microfossils reach their peak abundance and preservation in Core 105-647A-25R and decline gradually upward into the lower Miocene (Cores 105-647A-13R and -14R). Siliceous microfossil abundances in counts of the $>38-\mu \mathrm{m}$ carbonate-free coarse fraction from the siliceous interval are correlated to each other, but not to the abundance of nonbiogenic coarse-fraction components. Radiolarian abundances in specimens per gram (but not diatom abundances) are correlated to bulk opal concentration and to the organic carbon content of the sediment. The abundance of radiolarians and other siliceous microfossils within the lower Oligocene to lower Miocene is interpreted as reflecting changes in surface-water productivity. With only a few exceptions, no stratigraphic indicator species were seen in samples from either Site 646 or Site 647 . The absence of both tropical/subtropical and Norwegian-Greenland Sea stratigraphic forms is due to the dominance of subarctic North Atlantic taxa in Leg 105 assemblages. The early Oligocene and early Miocene assemblages recovered at Site 647 are of particular interest, as very little material of these ages has previously been recovered from the subarctic North Atlantic region, and virtually no descriptive work has been conducted on the more endemic components of the radiolarian assemblages from these time intervals. Thus, this report concentrates on providing, at least in part, the first comprehensive documentation of early Oligocene and early Miocene radiolarians from the subarctic North Atlantic, with emphasis on basic descriptions, measurements, and photographic documentation. However, synonymic work and formal designation of new species names has been deferred until additional material from other regions can be examined. The sole exception is the emendation of Theocalyptra tetracantha Bjørklund and Kellogg 1972 to Cycladophora tetracantha $\mathrm{n}$. comb.
\end{abstract}

\section{INTRODUCTION}

Cenozoic paleoceanographic changes were dominated by the cooling of high-latitude regions of the earth and, in particular, by oceanographic changes in the Antarctic and North Atlantic (including the Norwegian-Greenland Sea). Although much has been learned indirectly about the history of these regions from low-latitude benthic isotope data, only fragmentary data have been available until recently from the high-latitudes themselves. Recent deep-sea drilling provided important new material for paleoceanographic study. Radiolarians are potentially useful for stratigraphic and paleoceanographic analyses of North Atlantic sediments, given their high diversity, known association with surface-water productivity, and frequent occurrence in sections lacking useful calcareous microfossil taxa (a fairly common attribute of high-latitude sediments).

Radiolarians from these sediments are also of importance for evolutionary studies. Many Cenozoic species are seen in polar regions that are not found in the tropics and vice versa. The origin of these diverse Cenozoic endemic polar assemblages represents one of the best opportunities to study how changing climatic conditions affect biologic evolution, a topic of considerable importance in evolutionary biology. Bipolar taxa and lowlatitude/high-latitude species pairs also provide many opportunities to study how geographic variation affects species-level evolutionary change and thus to help test competing theories of speciation (Lazarus, 1983).

\footnotetext{
${ }^{1}$ Srivastava, S. P., Arthur, M., Clement, B., et al., 1989. Proc. ODP, Final Repts. (Pt. B), 105: College Station, TX (Ocean Drilling Program).

${ }^{2}$ ETH-Zurich, Gelogisches Institut, Sonneggstrasse 5, CH-8092 Zurich, Switzerland.

${ }^{3}$ Woods Hole Oceanographic Institution, Woods Hole, MA 02543.
}

Because North Atlantic radiolarians are endemic to the region, the taxonomy and biostratigraphy developed for Cenozoic radiolarians from tropical and subtropical regions cannot be used as the basis for North Atlantic radiolarian studies. Successful utilization of polar North Atlantic radiolarians in both paleoceanographic and evolutionary research thus requires independent development of an adequate taxonomic and biostratigraphic framework.

\section{Previous Studies}

Radiolarians from North Atlantic surficial sediments have been studied for many years (Haeckel, 1887; Jørgensen, 1900, 1905; Goll and Bjørklund, 1971; Petrushevskaya and Bjørklund, 1974). These studies established the endemic nature of polar radiolarian assemblages and delineated two major endemic polar radiolarian biogeographic provinces: the Norwegian-Greenland Sea province and the subarctic North Atlantic province. By contrast, relatively little is known about earlier Cenozoic radiolarians. Several studies of shallow-water Cenozoic radiolarian assemblages from the Siberian platform were conducted by Russian scientists (Lipman, 1950; Krasheninnikov, 1960; Borisenko, 1960a, 1960b; Kozlova and Gorbovets, 1966), but these studies were limited by low diversity and poor preservation. More recently, diverse, well-preserved assemblages have been obtained by the Deep Sea Drilling Project and Ocean Drilling Program (Legs 12, 38, 81, 104, and 105). Important taxonomic studies of these assemblages include Bjørklund (1976a), Dzinoridze et al. (1978), and Westberg-Smith and Riedel (1984). These taxonomic studies provide a much clearer picture of radiolarian taxonomy and stratigraphy than was previously available. However, our knowledge of polar North Atlantic radiolarians is still incomplete. Many taxa encountered in sediments recovered by these previous drilling legs have not yet been described, let alone formally named, and the nomenclature used by each author for the 
same or similar species is often quite different. Furthermore, several stratigraphic gaps exist in the radiolarian sequences recovered during these legs due to variable preservation, hiatuses, and, frequently, poor core recovery.

\section{Leg 105 Coring and Scope of Present Radiolarian Studies}

Two sites in the Labrador Sea and one site in Baffin Bay were drilled from September to October, 1985 during Leg 105. Radiolarians were recovered at all three sites, although at Site 645 $\left(65^{\circ} 28^{\prime} \mathrm{N}, 64^{\circ} 39^{\prime} \mathrm{W}\right.$; Baffin Bay) radiolarians were present in useful numbers only in the mudline sample. Radiolarians of late Neogene age were recovered at Site 646 south of Greenland $\left(58^{\circ} 13^{\prime} \mathrm{N}, 48^{\circ} 22^{\prime} \mathrm{W}\right)$, while early Oligocene and early Miocene radiolarians were recovered from the Labrador Sea at Site 647 $\left(53^{\circ} 20^{\prime} \mathrm{N}, 45^{\circ} 16^{\prime} \mathrm{W}\right)$.

With only a few exceptions (noted below), no stratigraphic indicator species were seen in either Site 646 or Site 647. The absence of both tropical/subtropical and Norwegian-Greenland Sea stratigraphic forms is because of the dominance of subarctic North Atlantic taxa in Leg 105 assemblages. Biostratigraphic subdivision of Labrador Sea sediments by radiolarians will require a separate zonation scheme. We were unable to construct a zonation at this time because too few sections were available from this region with well-preserved radiolarians to permit stratigraphic analysis. Thus, Leg 105 radiolarians are most useful as material for basic taxonomic analysis. The early Oligocene and early Miocene assemblages recovered at Site 647 are of particular interest because little material of these ages has previously been recovered from the subarctic North Atlantic region and virtually no descriptive work has been performed on the more endemic components of the radiolarian assemblages from these time intervals. Thus, this report concentrates on providing, at least in part, the first comprehensive documentation of early Oligocene and early Miocene radiolarians from the subarctic North Atlantic, with emphasis on basic descriptions, measurements, and photographic documentation. Synonymic work and formal designation of new species names have been deferred until additional material from other regions can be examined. Subsequent studies will provide detailed descriptions of the late $\mathrm{Ne}$ ogene radiolarian assemblages recovered from Sites 645 and 646.

\section{METHODS}

Samples were processed from each core catcher on board ship, and strewn slides were prepared for study. Shore-based sample preparation included drying and weighing each sample and preparing random settled slides using the method outlined by Moore (1973). All samples examined were prepared using $38-\mu \mathrm{m}$ sieves because many of the most common radiolarian species seen in Leg 105 sediments cannot be retained on the larger $63-\mu \mathrm{m}$ sieves commonly used in other radiolarian studies. Each sample was scanned to determine the general composition of the carbonate-free coarse fraction. The relative abundance of radiolarians, pennate and centric diatoms, silicoflagellates, lithic fragments, and sponge spicules was qualitatively determined (i.e., Abundant, Common, Few, Rare) in addition to qualitative estimates of the preservation of radiolarians (Excellent, Good, Fair, Poor). The abundances of these components also were determined quantitatively in selected samples by counting areas of the microscope slide and converting the values obtained to numbers per gram of dry sediment, as explained in Moore (1973). Since the material examined in this study is from a single geographic locality and represents two separate, short intervals of time, geographic and temporal variation in morphology is, respectively, absent and minimal. Taxonomic analysis thus was based on the simple premise that groups of specimens displaying continuous morphologic variation constitute a single species, while gaps in the spectrum of morphologic variation represent species boundaries. Generally, a dozen or more video-print images per putative taxon (Mitsubishi video-printer model P-50U) were used to determine the limits of within-species variation. Video prints, in comparison to photographs, are quickly and eas- ily made, provide a copy of whatever is seen on the televison monitor at the press of a button, and print the image in a few seconds for only a few cents per copy. Measurements of gross characteristics were obtained from these video prints by using a ruler. However, video prints do not provide images of sufficient quality for publication $(256 \times 256$ pixels $\times$ 16 fairly low-contrast gray levels). Thus, photographs documenting each taxon were taken with a Zeiss Standard microscope with $25 \mathrm{X}$ and $40 \mathrm{X}$ objectives, a Nikon F3 35mm camera, and Kodak Tech-Pan film. Preliminary synonomies were performed only after the primary taxonomic definitions were completed, thus insuring that the taxon definitions reflect as much as possible the actual patterns of morphologic variation, not externally imposed prior taxonomic concepts.

\section{RADIOLARIANS FROM EACH SITE}

\section{Site 645}

Aside from a single radiolarian-bearing sample (Sample 105$645 \mathrm{~F}-1 \mathrm{H}-1,0-2 \mathrm{~cm}$ ) taken from near the sediment/water interface, Site 645 core-catcher samples were barren of radiolarians. Core-catcher results from this site were so uniformly negative that we decided to forego any further downcore sampling. Details of the core-catcher results and a preliminary taxonomic survey of the radiolarians recovered from the mudline sample are given in the Site 645 chapter (Srivastava, Arthur, et al., 1987).

\section{Site 646}

Preliminary shipboard results from core-catcher samples indicated that radiolarians are common and well preserved in Site 646 sediments above $\sim 330 \mathrm{~m}$ (mid-Pliocene). More detailed shore-based sampling, at about one sample per section, was conducted for the $0-350$-mbsf interval to determine better the stratigraphic distribution of radiolarians and other coarse-fraction components. Relative abundance determinations, together with radiolarian preservation estimates for these samples, are indicated in Figure 1 and in the Appendix. Radiolarian and other siliceous microfossil abundances vary dramatically in the $330-0$-mbsf interval, even between closely spaced adjacent samples, with many samples being dominated by abundant lithic fragments. This rapid variation in coarse-fraction composition may be caused by variations in the productivity of surface waters; however, given the location of Site 646 near the Gloria Drift, this variation may also represent depositional control by varying bottom currents.

Radiolarian assemblages from Site 646 are of a cool temperate or subarctic nature (see taxonomic list given in the Site 647 chapter in Srivastava, Arthur, et al., 1987), and were devoid of stratigraphically significant species. The sole exception is the middle Pliocene to Holocene (FAD at $2.5 \mathrm{Ma}$, Hays, pers. comm., 1987) species Cycladophora davisiana, which first appears between Section 105-646B-25X, CC and Sample 105-646B$26 \mathrm{X}-2,20-22 \mathrm{~cm}$. The low reliability of this FAD results from poor core recovery in this interval and the erratic occurrence of C. davisiana, which varied between abundant and absent on a sample-to-sample basis. However, this FAD is in good agreement with age estimates provided by other microfossil groups and by magnetostratigraphy.

\section{Site 647}

Site 647 penetrated a stratigraphic sequence that begins with middle Pliocene to Holocene, glacial, debris-laden calcareous muds and that terminates in calcareous claystones of early Eocene age. Several hiatuses are present in Site 647, including ones separating the middle Pliocene from the upper Miocene, the upper Miocene from the lower Miocene, and the lower Miocene from the lower Oligocene. Siliceous microfossil recovery is also limited by preservation, with well-preserved material present only in the lower Miocene and uppermost Eocene to lower Oligocene interval. Sediments above and below this interval are 


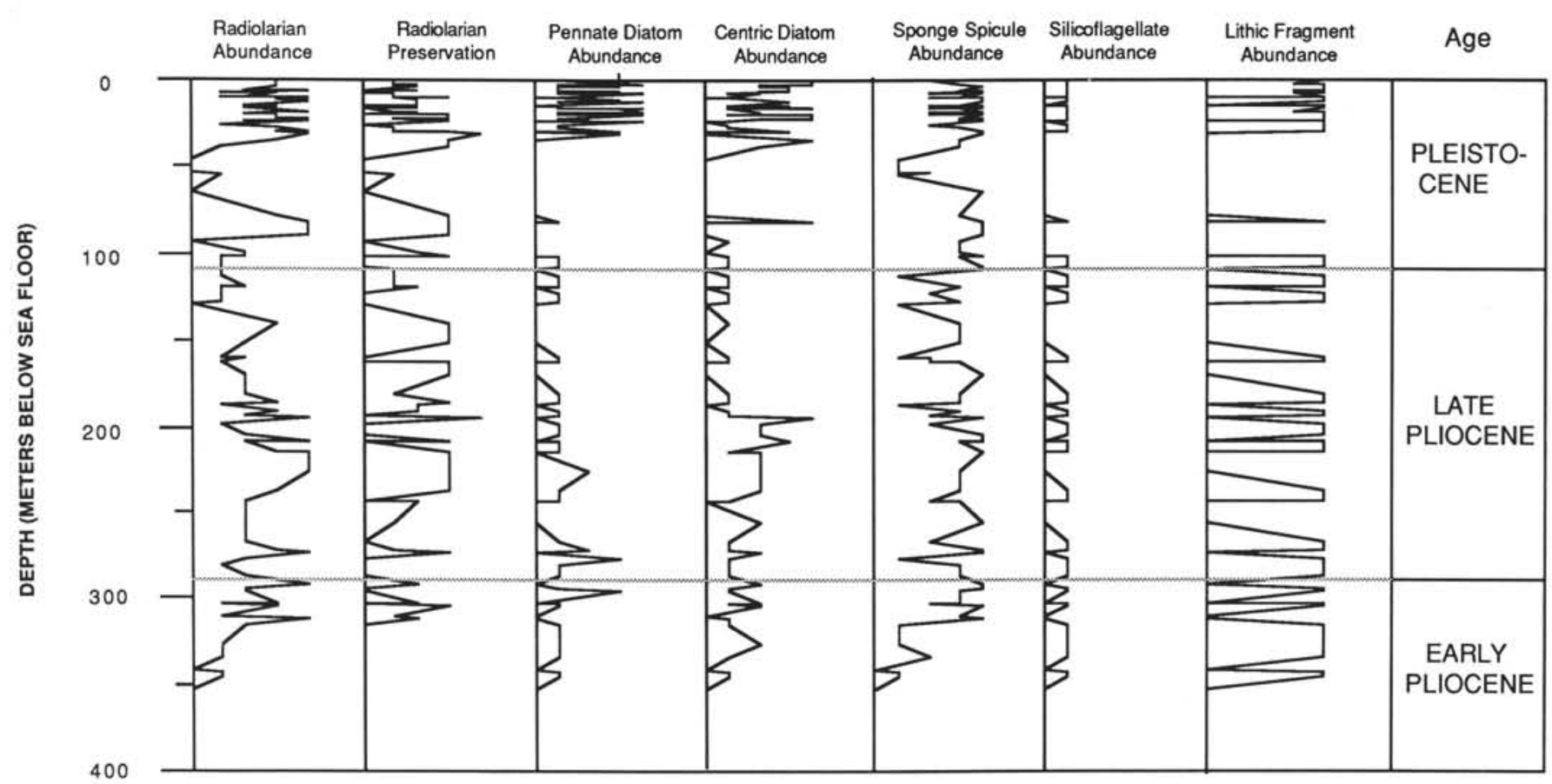

Figure 1. Qualitative relative abundance estimates of components in the $>38-\mu \mathrm{m}$ carbonate-free, coarse-fraction, $0-352 \mathrm{~m}$, Site 646 . Data taken from the Appendix. The actual range of the data plotted in each case is from absent on the left to abundant on the right, except for silicoflagellates, which are either rare or absent throughout, and radiolarian preservation, which ranges in the data plotted from poor (on the left) to excellent (on the right).

barren of radiolarians or, at most, contain rare, poorly preserved specimens (see Site 647 chapter in Srivastava, Arthur, et al., 1987).

Although individual samples with poor preservation were encountered, radiolarians within this interval are generally common to abundant, with good, and occasionally excellent, preservation (Fig. 2; Appendix). Other coarse-fraction components also show relatively consistent levels of abundance during this interval, including diatoms, sponge spicules, and lithic fragments (Fig. 2; Appendix). Site 647 patterns of preservation thus differ from the patterns of preservation and abundance seen in the late Neogene sediments of Site 646 and are thought to indicate relatively high productivity with only minor short-term variation in depositional and/or environmental conditions, compared to Site 646.

The abundance and preservation of siliceous microfossils in Holocene oceanic sediments strongly correlates with the productivity of overlying surface waters, and the abundance of biogenic silica in sediments is often used as an indicator for paleoproductivity (Siebold and Berger, 1982; Kennett, 1982). Counts of the abundance of major coarse-fraction components in the biosiliceous interval of Site 647 (Table 1) were conducted to determine if siliceous microfossil abundance variations reflect variations in surface-water productivity or other processes instead, such as diagenesis and depositional mechanisms at the seafloor. Radiolarian abundances in the lower Oligocene-lower Miocene interval often reach several tens of thousands per gram. Radiolarians reach peak abundance levels in excess of 100,000 specimens/gram in lower Oligocene Cores 105-647A-23 through -25 (Fig. 3), values seen in the modern ocean only in regions of high productivity (Petrushevskaya, 1971; Goll and Bjørklund, 1971). Diatom abundances show similar patterns of change (Fig. 3), although the maximum in Cores 105-647A-23 through -25 is more marked and the decrease in the upper part of the section more rapid.

The data collected in this study were compared to the results of Bohrmann and Stein (this volume). For each core in the stud- ied interval, the average value of biogenic opal, organic carbon, and percentage composition of different siliceous microfossil groups in the $>63-\mu \mathrm{m}$ fraction was computed from the data (Bohrmann and Stein's Table 1 [this volume]), and from total organic carbon (TOC) values from the Site 647 chapter (Srivastava, Arthur, et al., 1987). These values were compared with the average values in each core of the coarse-fraction components counted in this study (Table 1 of this report). Regression analyses were performed for each possible pairwise comparison; the results are summarized in a matrix of correlation coefficients in Table 2. Because average values per core were used rather than data collected for stratigraphically paired samples, a certain amount of error is expected in the computed results. However, these errors are conservative in the sense that they most likely reduce the degree of correlation between variables, rather than produce spurious correlations. Also, because only a relatively small number of values are used in each comparison, care has been taken to detect correlations due primarily to a single highly variant data point. This is done by examining scatterplots for all pairwise comparisons. Correlation coefficients that are statistically significant but are based on single variant data points are shown in Table 2 by parentheses.

Radiolarian abundances in early Oligocene-early Miocene aged samples from Site 647 strongly correlate to independent estimates of productivity: TOC concentration in the sediments and bulk opal concentrations (Table 2; Figs. 4 and 5). The latter two variables also correlate to each other. The covariation among these three variables is thought to represent a general measure of surface-water productivity, particularly since no significant relationship exists between these productivity indicators and variables such as sponge spicules and lithic fragments, which may be more influenced by bottom-water conditions and benthic sedimentation mechanisms (Table 1). Curiously, diatom abundance (per gram in the $>38-\mu \mathrm{m}$ fraction) does not correlate significantly with either $C_{\text {org }}$ or with opal concentration, although the lack of correlation may be due to the lack of properly paired samples. Diatom and radiolarian abundance data from this 


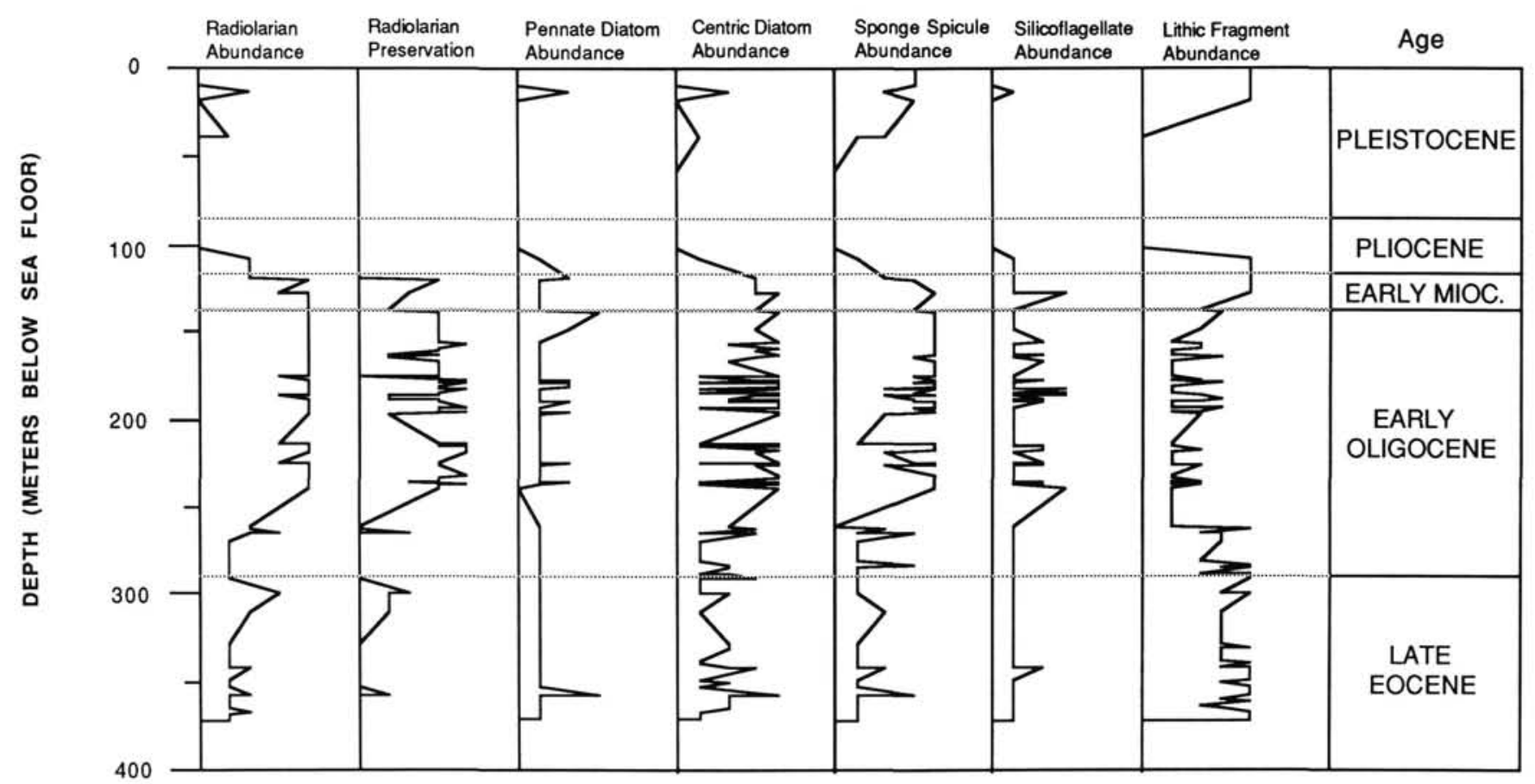

Figure 2. Qualitative relative abundance estimates of components in the $>38-\mu \mathrm{m}$ carbonate-free, coarse-fraction, 0-370 m, Site 647 . Data taken from the Appendix. See Figure 1 caption for plotting conventions.

Table 1. Abundances of major components in the acidized $>38 \mu \mathrm{m}$ coarse-fraction of selected Site 647 samples.

\begin{tabular}{|c|c|c|c|c|c|c|c|}
\hline \multirow{2}{*}{$\begin{array}{l}\text { Core/section } \\
\text { interval }(\mathrm{cm})\end{array}$} & \multirow{2}{*}{$\begin{array}{l}\text { Number of } \\
\text { radiolarians } \\
\text { scanned }\end{array}$} & \multirow{2}{*}{$\begin{array}{l}\text { Radiolarian } \\
\text { abundance }\end{array}$} & \multicolumn{2}{|c|}{ Diatoms } & \multirow{2}{*}{$\begin{array}{c}\text { Silico- } \\
\text { flagellates }\end{array}$} & \multirow{2}{*}{$\begin{array}{l}\text { Sponge } \\
\text { spicules }\end{array}$} & \multirow[b]{2}{*}{ Lithics } \\
\hline & & & Pennates & Centrics & & & \\
\hline $105-647 A-13-4,91-93 \# 1$ & 5024 & 23.7 & 0 & 2.9 & 0 & 8.8 & 10.4 \\
\hline $14-2,7-9 \# 1$ & 3349 & 11.6 & 0 & 3.2 & 0 & 8.7 & 91.6 \\
\hline $14-2,145-147 \# 3$ & 6280 & 22.1 & 0 & 0 & 0 & 25.8 & 72 \\
\hline $15-2,16-18 \# 1$ & 64 & 2.2 & 3 & 2.1 & 0 & 1.9 & 6.7 \\
\hline $15-3,65-67 \# 2$ & 488 & 37.2 & 1.9 & 28.6 & 0 & 20.6 & 11.9 \\
\hline $16-2,54-59 \# 1$ & 2856 & 63.8 & 0 & 15.0 & 0 & 22.5 & 58.0 \\
\hline $17-4,88-93$ & 2196 & 11.2 & 0.6 & 4.3 & 0 & 1.9 & 3.7 \\
\hline $18-2,78-82$ & 1306 & 30.5 & 0 & 6.9 & 0 & 1.8 & 1.1 \\
\hline $19-4,115-119 \# 1$ & 2016 & 39.7 & 2.7 & 18.7 & 0 & 21.4 & 4.4 \\
\hline $20-4,84-89 \# 1$ & 1932 & 63.8 & 0 & 27.4 & 1.0 & 62.7 & 9.5 \\
\hline $21-3,13-17 \# 1$ & 2016 & 61.6 & 0 & 23.9 & 2.2 & 29.1 & 3.7 \\
\hline $23-4,75-79 \# 3$ & 3276 & 121.2 & 0 & 116.4 & 1.0 & 16.0 & 17.1 \\
\hline $24-4,31-34 \# 2$ & 6300 & 70.2 & 0.5 & 31.6 & 0.8 & 35.9 & 8.1 \\
\hline $25-5,107-110 \# 1$ & 2100 & 134.4 & 0 & 388.5 & 16.7 & 29.2 & 66.8 \\
\hline $28-1,105-108 \# 1$ & 84 & 0.06 & 0 & 0.5 & 0 & 0 & 0.1 \\
\hline $28-3,102-105 \# 3$ & 29 & 0.04 & 0 & 0 & 0 & 0.04 & 0.8 \\
\hline $30-5,18-22 \# 3$ & 10 & 0.08 & 0.5 & 0 & 0 & 0 & 2.3 \\
\hline $31-1,132-136 \# 1$ & 112 & 0.2 & 0 & 4.2 & 0.8 & 0 & 12.3 \\
\hline $32-1,89-93 \# 2$ & 426 & 0.3 & 0.03 & 0.01 & 0 & 0.01 & 0.7 \\
\hline $33-2,26-28 \# 1$ & 135 & 0.3 & 0.05 & 0 & 0 & 0.2 & 9.8 \\
\hline
\end{tabular}

Note: The number of radiolarians counted in each sample is given, along with the abundances of siliceous microfossil groups, including sponge spicules, silicoflagellates, pennate and centric diatoms, and rock fragments ('Lithics'). All values are in 1000/g sediment (dry wt).

study, which were counted from the same samples, are significantly correlated to each other (Fig. 6).

As is true of other sediments recovered during Leg 105, few stratigraphic indicators are present in the radiolarian assemblages from Site 647, except for Cores 105-647A-13 and -14, which contain several diagnostic species allowing these cores to be dated as early Miocene age (between 17-23 Ma; for species list and discussion, see Site 647 chapter, Srivistava, Arthur, et al., 1987). The occurrence of these low-latitude stratigraphic indicators in the early Miocene indicates somewhat 'warmer' sur- face-water conditions during this interval than in the preceding early Oligocene.

\section{PRELIMINARY DESCRIPTIONS OF RADIOLARIAN SPECIES FROM ODP SITE 647, LEG 105, LABRADOR SEA}

Preliminary descriptions and photographs are given for the radiolarian species encountered to date in Leg 105 Site 647 sediments; these emphasize common taxa that we believe are new or not yet well described. In this initial survey, no new species 


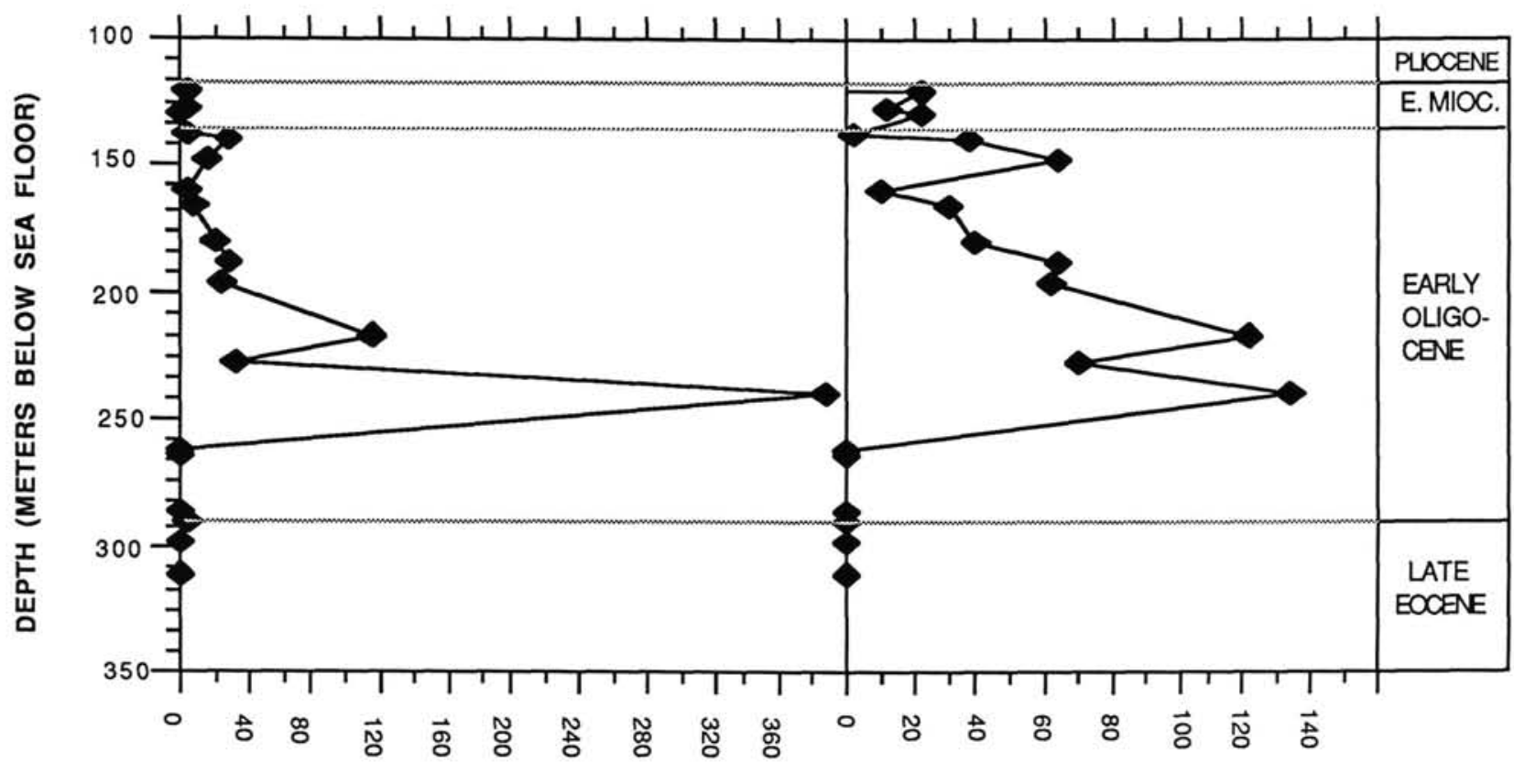

DIATOMS, X 1000/Gram

RADIOLARIANS, X 1000/Gram

Figure 3. Quantitative abundance data for diatoms and radiolarians in the $>38-\mu \mathrm{m}$ carbonate-free, coarse-fraction in samples of late Eocene through early Miocene age, Site 647 . Data from Table 1.

Table 2. Correlation matrix showing covariation in the abundances of different components in the biosiliceous interval of Site 647.

\begin{tabular}{|c|c|c|c|c|c|c|c|c|c|c|}
\hline & $\begin{array}{c}\text { Organic } \\
\text { carbon } \\
(\%)\end{array}$ & $\begin{array}{l}\text { Radiolarians } \\
\qquad(\mathrm{K} / \mathrm{g})\end{array}$ & $\begin{array}{c}\text { Diatoms } \\
(\mathrm{K} / \mathrm{g})\end{array}$ & $\begin{array}{c}\text { Sponge } \\
\text { spicules } \\
(\mathrm{K} / \mathrm{g})\end{array}$ & $\begin{array}{l}\text { Lithics } \\
(\mathrm{K} / \mathrm{g})\end{array}$ & $\begin{array}{c}\text { Radiolarians } \\
(\%)\end{array}$ & $\begin{array}{c}\text { Diatoms } \\
(\%)\end{array}$ & $\begin{array}{c}\text { Sponge } \\
\text { spicules } \\
(\%)\end{array}$ & $\begin{array}{l}\text { Bulk } \\
\text { opal } \\
(\%)\end{array}$ & $\begin{array}{c}\text { Carbonate-free } \\
\text { opal } \\
(\%)\end{array}$ \\
\hline Organic carbon $(\%)$ & 1 & & & & & & & & & \\
\hline $\begin{array}{l}\text { Radiolarians }(\mathrm{K} / \mathrm{g} \text {, } \\
>38)\end{array}$ & 0.783 & 1 & & & & & & & & \\
\hline $\begin{array}{l}\text { Diatoms }(\mathrm{K} / \mathrm{g} \text {, } \\
>38)\end{array}$ & 0.439 & 0.812 & 1 & & & & & & & \\
\hline Sponge Spicules & 0.443 & 0.426 & 0.186 & 1 & & & & & & \\
\hline Lithic fragments & 0.198 & 0.249 & 0.52 & 0.064 & 1 & & & & & \\
\hline $\begin{array}{l}\text { Radiolarians }(\%, \\
>63)\end{array}$ & 0.071 & 0.283 & 0.084 & 0.396 & 0.03 & 1 & & & & \\
\hline Diatoms $(\%,>63)$ & 0.164 & 0.65 & $(0.729)$ & 0.468 & 0.222 & 0.41 & 1 & & & \\
\hline $\begin{array}{l}\text { Sponge Spicules } \\
(\%,>63)\end{array}$ & 0.083 & 0.45 & 0.37 & 0.108 & 0.39 & $(0.852)$ & 0.019 & 1 & & \\
\hline Bulk opal (\%) & 0.89 & 0.766 & 0.38 & 0.362 & 0.364 & 0.21 & 0.042 & 0.014 & 1 & \\
\hline $\begin{array}{l}\text { Carbonate-free opal } \\
(\%)\end{array}$ & 0.485 & 0.366 & 0.03 & 0.218 & 0.073 & 0.04 & 0.28 & 0.361 & 0.573 & 1 \\
\hline
\end{tabular}

Correlations significant at the $5 \%$ level are shown in boldface. Correlations that are statistically significant, but based primarily on a single point, are shown in parentheses.

names are introduced and with the single exception of Cycladophora tetracantha n. comb., no formal taxonomic changes or emendations are made. We make no attempt to place species into a formal higher-level taxonomic framework other than Nassellaria and Spumellaria, since the higher-level systematics of radiolarians are still mostly conjectural and incomplete. Instead, species are listed in the text in such a way as to group together (as much as possible) morphologically similar forms. For example, the Nassellaria are more or less ordered in a progression from one-segmented, to two-segmented, to multisegmented forms. The order followed in the plates is similar to that followed in the text, although some rearrangements in the ordering were made to use the space in each plate efficiently. The informal synonymic lists indicate the relationship of other authors' illustrations to the species described in this report. In these syn- onymies, a question mark denotes possible, but uncertain, equivalence, and 'cf.' indicates that the illustrated form is not conspecific but closely related to the species of this report. Summary statistics are given in tabular form for measurements (in micrometers) of selected characters for most species. In these tables the following abbreviations are used: $\mathrm{A}=$ abdomen, $\mathrm{B}=$ bar, $\mathrm{Ce}=$ cephalis, Coeff. Var. = Coefflcient of Variation in percent $(100 *$ [Std. Dev $\div$ Mean] $), \mathrm{Ct}=$ cortical shell, $\mathrm{D}=$ diameter, $\mathrm{F}=$ foot, $\mathrm{H}=$ height, $\mathrm{L}=$ length, $\mathrm{M}=$ medullary shell, $\mathrm{Max}=$ maximum, $\mathrm{Min}=$ minimum, $\mathrm{P}=$ pore, $\mathrm{S}=$ spine, Std. Dev. = sample standard deviation $S, \mathrm{~T}=$ thorax, Tot $=$ total, and $\mathrm{W}=$ width. The descriptive terminology used here follows that used in Lombari and Lazarus (1988). Table 3 gives, for all but the very rare species, occurrence and qualitative abundance data in a representative set of samples. 


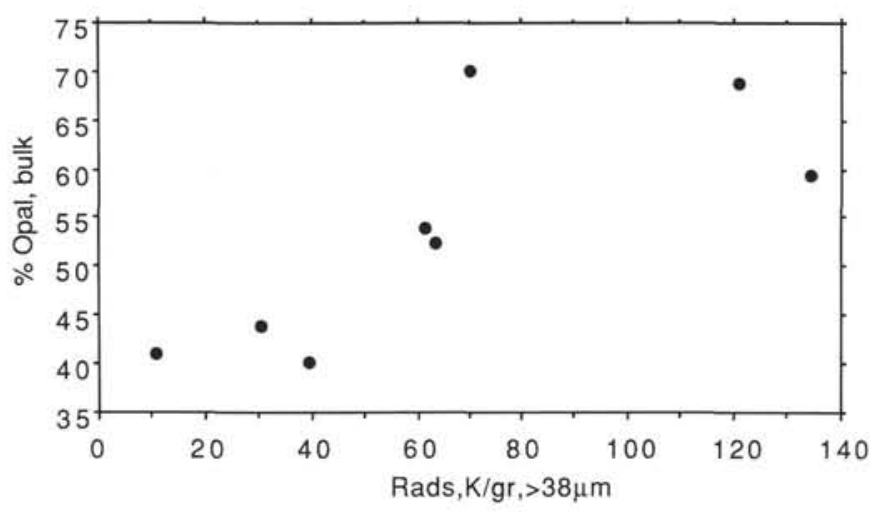

Figure 4. Comparison of radiolarian abundance to percentage of opal in bulk sediment for Cores 105-647A-15 through -25. Values are averages for each core, as explained in text. Sources of data also are explained in text.

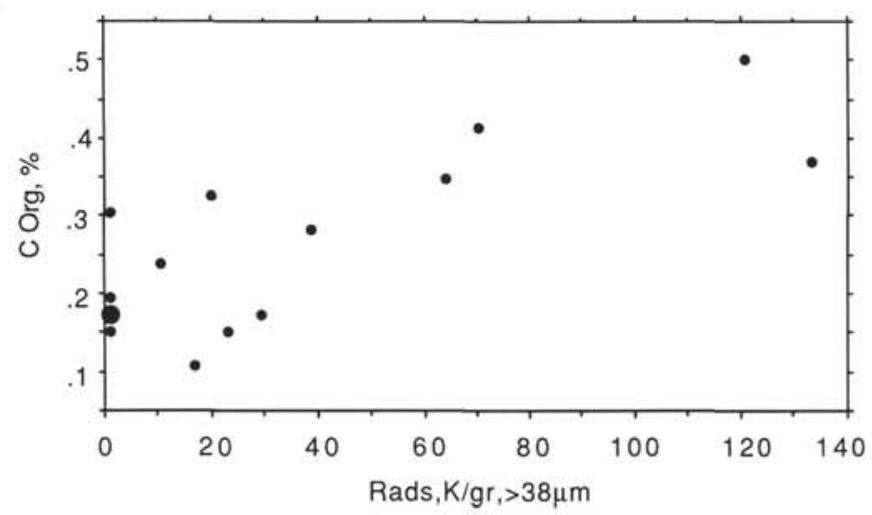

Figure 5. Comparison of radiolarian abundance to total organic carbon in bulk sediment for Cores $105-647 \mathrm{~A}-13$ through -28 . Values are averages for each core, as explained in text. Sources of data also are explained in text. Overlapping data points shown by larger dots.

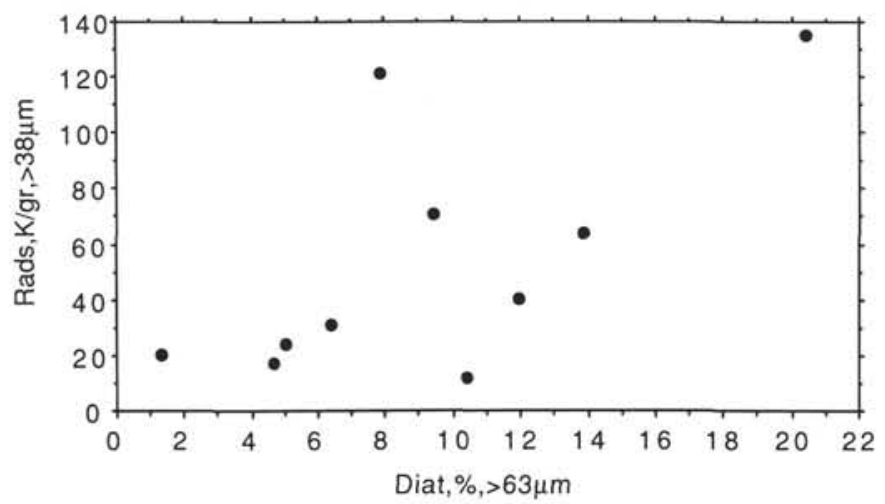

Figure 6. Comparison of radiolarian abundance with diatom abundance for Cores 105-647A-13 through -25. Values are averages for each core, as explained in text. Sources of data also are explained in text.

\section{NASSELLARIA}

Trissocyclid sp. A

(Plate 1, Figs. 16-18)

? Tholospyris mammalaris (Haeckel), Goll, 1969, Pl. 55, Figs. 5,6,8, and 9, text Fig. 1.
? Ceratospyris group of Mullineaux and Westberg-Smith, 1986 (in part), Pl. 2, Fig. 8a.

? Nephrospyris group of Mullineaux and Westberg-Smith, 1986 (in part), Pl. 2, Fig. 10a and 10b.

? Acanthodesmid gen. et. sp. indet. of Caulet, 1986 (in part), Pl. 6, Fig. 9.

Description. Robustly silicified, laterally elongate shell with noticable constriction at saggital ring. Very large saggital pores, large pores in lattice wall, and thick elliptical bars. Nodes often elevated, occasionally with well-developed lattice spines. Some specimens with shallow depressions at nodes, as in Liriospyris stauropora Goll (1968). Vertical and apical spines inconspicuous. Basal feet usually absent, but when present are fairly short, robust, and terminated by distal thorns.

Measurements.

\begin{tabular}{lclccc} 
& CeW & CeH & Saggital PD & Lattice PD & BD \\
\hline Number & 25 & 25 & 24 & 25 & 25 \\
Mean & 91.1 & 65.6 & 20.2 & 13.1 & 3.7 \\
Std.Dev. & 14.3 & 11.2 & 4.8 & 3.3 & 1.2 \\
Coeff. Var. & 15.7 & 17.0 & 23.6 & 25.2 & 32.5 \\
Minimum & 62 & 51 & 11 & 7 & 2 \\
Maximum & 122 & 89 & 32 & 20 & 7
\end{tabular}

Occurrence. Fairly common in Cores $105-647 \mathrm{~A}-13$ and -14 (earliest Miocene). Two specimens were seen in core-catcher Sections 105-647A15 and -34 . These latter specimens are thought to be downhole contamination.

Trissocyclid sp. B

(Plate 1, Figs. 1 and 2)

Description. Small cephalis without marked constriction at saggital ring. Saggital and lattice-wall pores similar, medium to small, somewhat irregular shape. Bars thick, circular; nodes moderately elevated. Latticewall extends as flaring skirt below basal ring on some specimens. Basal feet usually absent.

Measurements.

\begin{tabular}{lcccc} 
& CeW & $\mathrm{CeH}$ & $\mathrm{PD}$ & $\mathrm{BD}$ \\
\hline Number & 16 & 16 & 16 & 16 \\
Mean & 58.8 & 43.0 & 5.3 & 3.3 \\
Std.Dev. & 7.6 & 4.2 & 1.1 & 1.3 \\
Coeff. Var. & 12.9 & 9.8 & 21.0 & 40.9 \\
Minimum & 49 & 35 & 3 & 1 \\
Maximum & 73 & 50 & 7 & 6
\end{tabular}

Occurrence. Rare and intermittent in Oligocene and early Miocene.

Trissocyclid sp. C

(Plate 1, Figs. 3-5)

Two groups are recognized; each bears similar features but differs in detail and stratigraphic occurrence.

Group 1 (Plate 1, Fig. 3). Medium-to-small lightly silicified hemispherical to somewhat irregularly shaped cephalis having medium-sized pores and thin bars. Three long feet extend at wide angle from base of cephalis. Feet are three-bladed, thin, basally fenestrated, and bear lateral thorns or branches.

Measurements.

\begin{tabular}{lccccc} 
& $\mathrm{CeW}$ & $\mathrm{CeH}$ & $\mathrm{PD}$ & $\mathrm{BD}$ & $\mathrm{FL}$ \\
\hline Number & 10 & 10 & 10 & 10 & 9 \\
Mean & 51.6 & 46.2 & 6.7 & 2.1 & 87.8 \\
Std.Dev. & 5.9 & 6.9 & 1.3 & 0.9 & 26.5 \\
Coeff. Var. & 11.4 & 14.8 & 18.7 & 41.7 & 30.2 \\
Minimum & 40 & 35 & 5 & 1 & 40 \\
Maximum & 60 & 55 & 8 & 4 & 120
\end{tabular}

Occurrence. Rare in Cores 105-647A-33 through -20 (Oligocene).

Group 2 (Plate 1, Figs. 4 and 5). Small, heavily silicified equant cephalis with hemispherical outline to upper surface, without constriction at saggital ring. Pores small, irregular to circular, bars thick, circu- 
lar. Three well-developed, moderately flared, basal feet extending below basal ring. Feet distally branched. Some specimens bear a large, vertical, distally branched three-bladed spine projecting from the apex of the cephalis.

Measurements.

\begin{tabular}{lccccc} 
& $\mathrm{CeW}$ & $\mathrm{CeH}$ & $\mathrm{PD}$ & $\mathrm{BD}$ & $\mathrm{FL}$ \\
\hline Number & 13 & 12 & 9 & 9 & 12 \\
Mean & 48.5 & 42.8 & 4.3 & 1.9 & 35.2 \\
Std.Dev. & 5.5 & 5.1 & 0.5 & 0.9 & 12.1 \\
Coeff. Var. & 11.3 & 11.8 & 11.5 & 49.1 & 34.3 \\
Minimum & 43 & 35 & 4 & 1 & 15 \\
Maximum & 60 & 52 & 5 & 3 & 50
\end{tabular}

Occurrence. Group 2 is few to common in Cores 105-647A-13 and -14 (earliest Miocene). A single specimen was seen in Section 105-647A33, CC.

Trissocyclid sp. D

(Plate 1, Figs. 7 and 8)

? Lophospyris pentagona pentagona (Ehrenberg), Goll, 1976, Pl. 10, Figs. 1-7, Pl. 11, Figs. 1-3, 5.

Ceratospyris group C of Westberg-Smith and Riedel, 1984, Pl. 3,

Fig. 10.

Description. Bilobed, laterally elongate cephalis. Saggital and lattice-wall pores very large, slightly irregular to circular in shape, framed by strongly bladed triangular bars. Nodes elevated and are often marked by lattice spines of varying length. Four feet project below basal ring in some specimens.

Measurements.

\begin{tabular}{lccccc} 
& CeW & CeH & PD & BD & FL \\
\hline Number & 5 & 4 & 5 & 5 & 3 \\
Mean & 101.6 & 70.3 & 24.2 & 6.2 & 12.7 \\
Std.Dev. & 17.5 & 9.5 & 3.0 & 0.8 & 6.7 \\
Coeff. Var. & 17.3 & 13.5 & 12.5 & 13.5 & 52.6 \\
Minimum & 78 & 60 & 20 & 5 & 7 \\
Maximum & 127 & 82 & 27 & 7 & 20
\end{tabular}

Occurrence. Rare to few in Cores 105-647A-13 and -14 (earliest Miocene), very rare and intermittent occurrences in Oligocene.

Trissocyclid sp. E

(Plate 1, Figs. 6 and 10)

Description. Laterally elongate cephalis without saggital constriction. Saggital and lattice-wall pores very large, irregular polygonal in shape. Bars elliptical, thin, bearing a few short lattice-spines. Lattice wall often incomplete. Short feet extending from base on some specimens.

Measurements.

\begin{tabular}{lllccc} 
& CeW & CeH & PD & BD & FL \\
\hline Number & 10 & 10 & 9 & 9 & 7 \\
Mean & 90.1 & 73.3 & 33.8 & 5.1 & 21.4 \\
Std.Dev. & 12.2 & 8.9 & 6.0 & 1.3 & 10.4 \\
Coeff. Var. & 13.5 & 12.1 & 17.7 & 24.8 & 48.3 \\
Minimum & 75 & 60 & 23 & 4 & 5 \\
Maximum & 113 & 90 & 42 & 7 & 40
\end{tabular}

Occurrence. Rare; individual specimens seen in Cores 105-647A-24, -17 , and -14 (Oligocene thru early Miocene).

\section{Dorcadospyris sp.}

(Plate 1, Figs. 9, 12, and 13)

Description. Laterally elongate cephalis without saggital constriction. Saggital and lattice-wall pores similar, small, circular. Bars thick, circular, with elevated nodes. Some areas of lattice wall hyaline (infilling?). Two very large thick circular feet extend nearly horizontally from basal ring. In all specimens seen, the feet were broken off fairly near their base, thus preventing unambiguous assignment to previously described species.
Measurements.

\begin{tabular}{lccccc} 
& CeW & CeH & PD & BD & FD \\
\hline Number & 12 & 10 & 10 & 11 & 12 \\
Mean & 81.7 & 66.8 & 7.6 & 5.4 & 11.1 \\
Std.Dev. & 8.4 & 7.1 & 2.3 & 1.3 & 2.3 \\
Coeff. Var. & 10.3 & 10.6 & 30.0 & 24.0 & 20.5 \\
Minimum & 73 & 56 & 5 & 3 & 8 \\
Maximum & 100 & 78 & 12 & 7 & 15
\end{tabular}

Occurrence. Rare to few in Cores 105-647A-13 and -14 (earliest Miocene), sporadic in Oligocene.

\section{Corythospyris sp.}

(Plate 1, Figs. 14 and 19).

Description. Laterally elongate small cephalis, sometimes with saggital constriction. Saggital and lattice-wall pores irregular shape, medium-to-small. Saggital and lattice-wall pores are sometimes very similar, on other specimens more distinct. Bars of varying width are elliptical in cross section, moderate thickness, nodes generally not elevated. Lattice spines absent. Three bladed feet extend from basal ring, one from junction of saggital ring and basal ring in front, two from lateral positions on basal ring in back.

Measurements.

\begin{tabular}{lccccc} 
& CeW & CeH & PD & BD & FL \\
\hline Number & 14 & 14 & 14 & 14 & 14 \\
Mean & 62.7 & 43.8 & 8.3 & 3.2 & 17.7 \\
Std.Dev. & 5.9 & 3.1 & 3.0 & 1.0 & 6.4 \\
Coeff. Var. & 9.4 & 7.2 & 36.1 & 29.7 & 35.9 \\
Minimum & 56 & 38 & 3 & 2 & 8 \\
Maximum & 75 & 48 & 15 & 5 & 30
\end{tabular}

Occurrence. Few to common in Oligocene-early Miocene.

$$
\begin{gathered}
\text { Nassellarian gen. et sp. indet. \#3 } \\
\text { (Plate 1, Figs. } 11 \text { and 15) }
\end{gathered}
$$

Description. Approximately equant bilobed cephalis without saggital constriction. Lattice-wall pores similar, irregular shape, medium-tosmall. Bars elliptical, medium-to-narrow. Two to four bladed feet extend nearly horizontally from base, then curve downward. Three prominent bladed spines extend upward from median bar at base, piercing cephalis lattice-wall and extending outward-one vertically, the other two diagonally through cephalic lobes. Lattice-wall continues below cephalis as subcylindrical thorax of varying length in some specimens. Termination of thorax ragged.

Note: Despite superficial similarity to a trissocyclid, no true D-ring seen. Enormous lobate cephalis and prominent spines fit no known genus of nassellarian, but similar in some respects to Spongomelissa sensu Chen (1975) and Bjørklund (1976a). However, Bjørklund's specimens have only one (axial) cephalic spine and a heavier lattice-wall. Also somewhat similar to Lithomelissa tricornis Chen (1975), but this latter species has a smaller, more equant cephalis, shorter external cephalic spines and a well-developed thorax that is larger than the cephalis.

Measurements.

\begin{tabular}{lcclccl} 
& CeW & CeH & TL & PD & BW & SL \\
\hline Number & 15 & 15 & 15 & 11 & 11 & 15 \\
Mean & 49.0 & 36.4 & 41.4 & 5.9 & 2.5 & 36.7 \\
Std.Dev. & 6.4 & 5.8 & 18.0 & 1.9 & 1.1 & 14.8 \\
Coeff. Var. & 13.1 & 16.0 & 43.5 & 32.5 & 46.0 & 40.2 \\
Minimum & 38 & 28 & 18 & 4 & 1 & 20 \\
Maximum & 63 & 48 & 89 & 10 & 5 & 68
\end{tabular}

Occurrence. Few, occasionally common in Oligocene.

Lithomelissa (?) sp. A

(Plate 2, Figs. 1 and 2).

cf. Tripilidium (?) clavipes advena (Clark and Campbell) Bjørklund, 1976a, Pl. 22, Fig. 10.

? Cladoscenium advena (Clark and Campbell) group, Petrushevskaya, 1975, Pl. 24, Fig. 7. 
Table 3. Qualitative abundance estimates for all but very rare species of radiolarians in selected samples from Site 647.

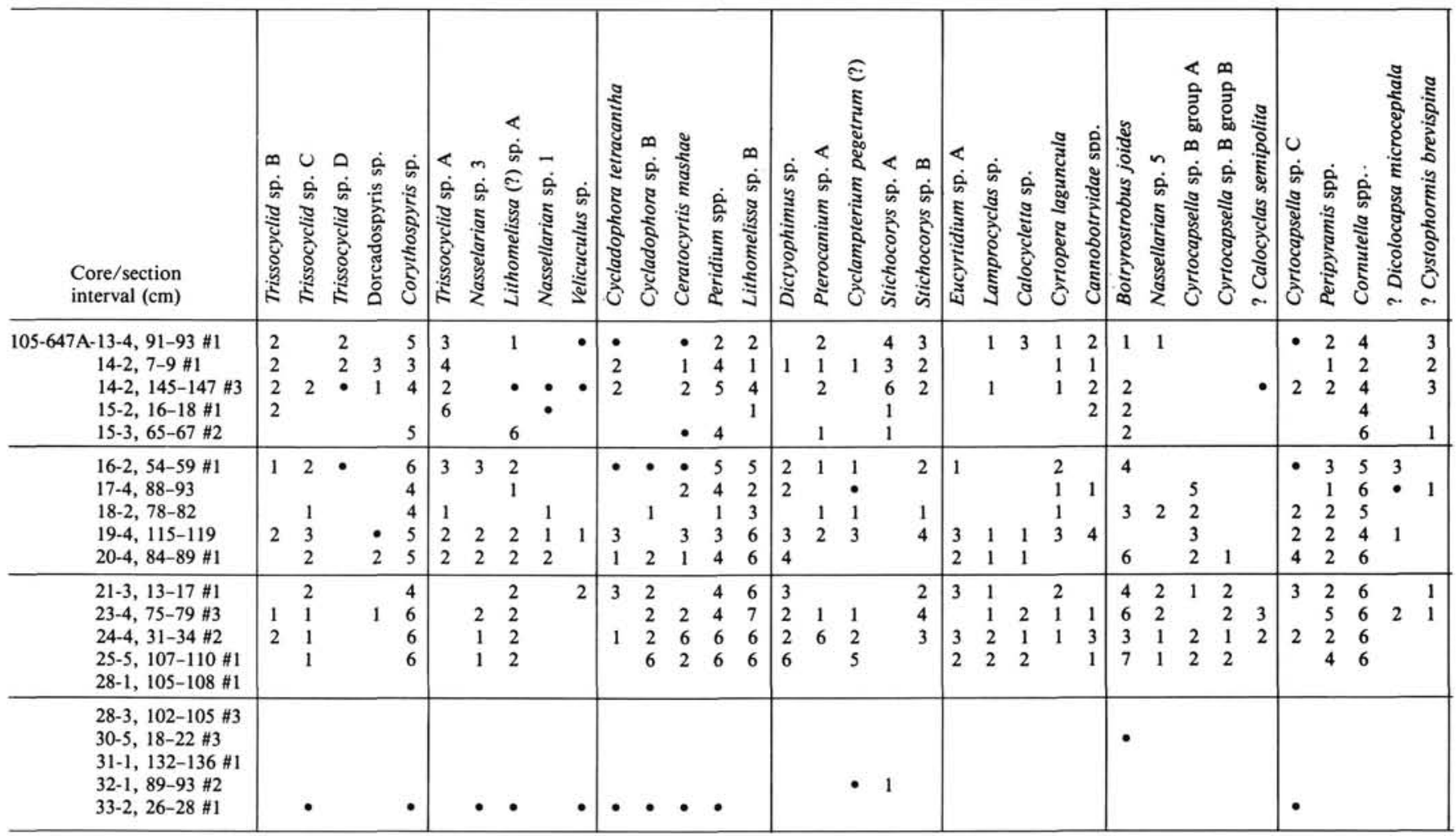

Note: Numbers in the table indicate relative abundance and range from very rare (1) to few (4) to common (6) to abundant (8). Dots indicate that the species was seen in the course of taxonomic works in an adjacent sample, although it was not seen in the sample indicated in the table. A minimum of several thousand radiolarians were examined from each sample.

? Lithomelissa mitra Bütschli (?) of Chen, 1975, Pl. 8, Figs. 4 and 5. ? Lithomelissa sphaerocephalis Chen, 1975, Pl. 8, Figs. 1 and 2.

? Pseudodictyophimus sp. cf. gracilipes of Bjørklund, 1976a, Pl. 16, Figs. 1-5.

Pseudodictyophimus group of Mullineaux and Westberg-Smith, 1986, Pl. 2, Fig. 14.

Unnamed plagoniid of Mullineaux and Westberg-Smith, 1986, Pl. 2, Fig. 16.

Description. Cephalis of variable size, although generally fairly large. Cephalis is approximately hemispherical and is often subdivided into three lobes by shallow vertical furrows running between cephalic suture and apical horn. Cephalic lattice wall varies between open latticework with irregular pores of medium size and thin, circular bars to relatively hyaline wall with rough surface and small scattered pores. Large, eccentric, three-bladed apical horn and shorter three-bladed lateral spine extending from cephalic suture. Thorax weakly to moderately flared, with lattice-wall of medium-to-small irregular pores and thin circular bar, and with a ragged termination. Three large three-bladed feet extend through middle of thoracic wall in wide flare.

Differs from Triplidium of Bjørklund (1976a) in its smooth cephalic surface, more broadly flared basal feet, small thoracic pores. Most similar to L. mitra sensu Chen (1975), but feet are more highly flared and thorax less well-developed than in L. mitra.

Measurements.

\begin{tabular}{lccll} 
& \multicolumn{5}{c}{$\begin{array}{c}\text { Angle of } \\
\text { F to Axis } \\
\end{array}$} & CeD & $\left(^{\circ}\right)$ & FL & TW \\
\hline Number & 14 & 14 & 13 & 14 \\
Mean & 44.6 & 53.4 & 54.5 & 69.8 \\
Std.Dev. & 9.8 & 7.3 & 18.3 & 15.7 \\
Coeff. Var. & 21.9 & 13.7 & 33.6 & 22.5 \\
Minimum & 30 & 40 & 25 & 45 \\
Maximum & 70 & 70 & 90 & 97
\end{tabular}

Occurrence. Few to common in Oligocene. Rare specimens seen in early Miocene.

Nassellarian gen. et. sp. indet. \#1. (Plate 2, Fig. 3)

Description. Small, thumb-shaped flattened hemispherical cephalis with medium-to-large irregular pores, thin bars. From one to three long thin spines extend from upper part of cephalis, and additional spines extend laterally and downward from open mouth of cephalis. Cephalic and basal spines connected at base of cephalis in typical nassellarian median bar. When present, thorax forms short flared skirt with ragged termination, has large irregular or subcircular pores, thin bars. Occurrence. Rare and sporadic in early Miocene and Oligocene in Site 647. This species is also present in Oligocene and Miocene sediments of the Antarctic (Sections 113-689B-12, CC, 113-693A-29, CC, and 113-693A31, CC, Lazarus, pers. obs., 1987).

\section{Velicuculus $\mathrm{sp}$.}

(Plate 2, Figs. 4 and 5)

? Velicuculus oddgurneri Bjørklund, 1976a, Pl. 19, Figs. 6-9.

Poor preservation prevents detailed analysis of this species in Leg 105 material. A form similar, and perhaps equal to, $V$. oddgurneri also was seen in the Oligocene and Miocene of the Antarctic, while Velicuculus or Lampromitra-like forms are seen in Antarctic sediments as far back as the Campanian (Sites 278 and 689, Lazarus, pers. obs., 1987). The relationships between these forms, other members of Velicuculus (as defined by Riedel and Campbell, 1952) and Lampromitra (e.g., $L$. coronata) are not clear.

Cycladophora tetracantha (Bjørklund and Kellogg, 1972), n. comb. (Plate 2, Figs. 6 and 7).

Theocalyptra tetracantha Bjørklund and Kellogg, 1972, Bjørklund, 1976a, Pl. 22, Figs. 15-17. 


\begin{tabular}{|c|c|c|c|c|c|c|c|c|c|c|c|c|c|c|c|c|c|c|c|c|c|c|c|c|c|c|c|c|c|c|c|c|}
\hline 1 & $\begin{array}{l}8 \\
6 \\
6 \\
4 \\
8 \\
\end{array}$ & $\begin{array}{l}2 \\
1 \\
1 \\
\end{array}$ & $\begin{array}{l}2 \\
3 \\
2\end{array}$ & $\begin{array}{l}2 \\
1\end{array}$ & & $\begin{array}{l}2 \\
1 \\
2 \\
1 \\
1 \\
\end{array}$ & $\begin{array}{l}6 \\
8 \\
1 \\
4 \\
\end{array}$ & $\begin{array}{l}3 \\
2\end{array}$ & $\begin{array}{l}3 \\
1\end{array}$ & 3 & & $\begin{array}{ll}12 \\
1 \\
1\end{array}$ & $\begin{array}{l}2 \\
2 \\
4 \\
\bullet \\
1\end{array}$ & $\begin{array}{l}2 \\
1 \\
4\end{array}$ & $\begin{array}{l}\bullet \\
1 \\
\end{array}$ & $\begin{array}{l}6 \\
4 \\
4 \\
8\end{array}$ & 2 & $\begin{array}{l}2 \\
2 \\
2\end{array}$ & 1 & $\begin{array}{ll}\bullet & 3 \\
1 & \\
2 & 1 \\
- & \end{array}$ & $\begin{array}{ll}3 & 1 \\
0 & \\
1 & 1\end{array}$ & 1 & 3 & $\begin{array}{l}2 \\
3 \\
4\end{array}$ & $\begin{array}{ll}4 & 5 \\
3 & 3 \\
4 & 6 \\
1 & 2 \\
6 & 4\end{array}$ & $\begin{array}{ll}5 & 3 \\
3 & 4 \\
6 & 4 \\
2 & 6 \\
4 & 2 \\
\end{array}$ & $\begin{array}{ll}3 & 3 \\
4 & 4 \\
4 & 4 \\
6 & 1 \\
2 & 2 \\
\end{array}$ & \begin{tabular}{l|l}
3 & \\
4 & \\
4 & \\
1 & \\
2 & 8 \\
\end{tabular} & $\begin{array}{l}8 \\
6 \\
8 \\
4 \\
8\end{array}$ & $\begin{array}{l}4 \\
2 \\
1 \\
4 \\
6\end{array}$ & $\begin{array}{l}4 \\
1 \\
4 \\
4 \\
6\end{array}$ & $\begin{array}{l}3 \\
4 \\
4 \\
4 \\
6\end{array}$ \\
\hline $\begin{array}{ll}4 & 2 \\
2 & 1 \\
2 & \\
2 & \end{array}$ & $\begin{array}{l}7 \\
5 \\
6 \\
6\end{array}$ & $\begin{array}{l}2 \\
2 \\
1\end{array}$ & $\begin{array}{l}8 \\
8 \\
8 \\
8\end{array}$ & $\begin{array}{l}4 \\
5 \\
3\end{array}$ & $\begin{array}{l}1 \\
2\end{array}$ & $\begin{array}{l}4 \\
6 \\
6 \\
3\end{array}$ & $\begin{array}{l}5 \\
6 \\
7 \\
6 \\
1 \\
\end{array}$ & $\begin{array}{l}1 \\
4 \\
2\end{array}$ & $\begin{array}{l}1 \\
1 \\
2\end{array}$ & $\begin{array}{l}2 \\
2 \\
1\end{array}$ & 2 & & 2 & $\begin{array}{l}2 \\
3 \\
1\end{array}$ & $\begin{array}{l}1 \\
2 \\
2\end{array}$ & $\begin{array}{l}4 \\
4 \\
5 \\
3\end{array}$ & $\begin{array}{l}\bullet \\
2 \\
\bullet \\
\bullet\end{array}$ & $\begin{array}{l}2 \\
3 \\
5 \\
3\end{array}$ & $\begin{array}{l}4 \\
1\end{array}$ & 1 & 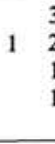 & $\begin{array}{l}3 \\
2 \\
1 \\
1\end{array}$ & \begin{tabular}{l|l}
1 & 1 \\
1 & 3 \\
3 & 5 \\
1 & 1
\end{tabular} & $\begin{array}{ll}1 & 1 \\
3 & 2 \\
5 & 6 \\
1 & 2\end{array}$ & $\begin{array}{ll}1 & 3 \\
2 & 3 \\
6 & 5 \\
2 & 2\end{array}$ & $\begin{array}{ll}3 & 6 \\
3 & 2 \\
5 & 2 \\
2 & \end{array}$ & $\begin{array}{ll}6 & \\
2 & 4 \\
2 & 4 \\
& 1\end{array}$ & \begin{tabular}{l|l}
4 & \\
4 & 8 \\
1 &
\end{tabular} & $\begin{array}{l}6 \\
6 \\
8 \\
6\end{array}$ & $\begin{array}{l}3 \\
4 \\
2 \\
4\end{array}$ & $\begin{array}{l}4 \\
4 \\
6 \\
5 \\
1 \\
\end{array}$ & $\begin{array}{l}3 \\
4 \\
3 \\
6\end{array}$ \\
\hline 1 & $\begin{array}{l}2 \\
1\end{array}$ & & $\begin{array}{l}2 \\
2 \\
2\end{array}$ & & & & & & & & & & & & & & & & & & & & & & & 1 & & & $\begin{array}{l}1 \\
3 \\
4 \\
2\end{array}$ & & 4 & 1 \\
\hline
\end{tabular}

Description. Conical thorax having little or no upper-thorax/lowerthorax differentiation, medium-sized subspherical cephalis having small partially filled circular pores. Thorax moderately flared; regular-to-flat, uninflated outline; pores rounded, hexagonal; bars thin, circular. Thorax termination ragged in incomplete specimens, marked by strongly flared basal spines in some specimens. Two apical horns, three-bladed, one more axially located, larger, and with apical thorns in most specimens. Second apical horn smaller, projects at angle from near cephalic suture.

In the recent revision of cycladophorids by Lombari and Lazarus (1988), the scope of Theocalyptra is restricted to only those forms having extremely flat, flared thoracic architecture. C. tetracantha clearly does not possess this type of thorax. Instead, it possess all diagnostic characteristics of Cycladophora (Lombari and Lazarus, 1988) and thus is transferred to this latter genus.

Measurements.

\begin{tabular}{lccccc} 
& CeD & TL & TW at Base & Basal PD & BW \\
\hline Number & 12 & 12 & 12 & 12 & 12 \\
Mean & 24.8 & 95.8 & 97.3 & 16.5 & 2.9 \\
Std.Dev. & 2.5 & 13.9 & 20.5 & 3.3 & 0.7 \\
Coeff. Var. & 10.0 & 14.5 & 21.0 & 20.3 & 22.9 \\
Minimum & 22 & 75 & 64 & 10 & 2 \\
Maximum & 30 & 120 & 142 & 21 & 4
\end{tabular}

Occurrence. Rare to few, Oligocene to early Miocene.

\section{Cycladophora sp. B}

(Plate 2, Fig. 8).

Diplocyclas sp. A group of Petrushevskaya and Kozlova, 1972, Chen, 1975, Pl. 7, Figs. 4 and 5.

Description. Conical thorax with rounded shoulders near cephalic suture, nearly parallel middle region, and moderately flared basal row of pores. Thorax pores medium-sized, irregular to rounded polygonal in shape. Basal row of pores in complete specimens relatively large, polygonal. Basal termination of regularly spaced spines composing partial row of lattice-wall, but not marked by basal ring or peristome. Bars medium-to-narrow, circular. Hemispherical cephalis partially embedded in thorax with small irregular pores. Single major cylindrical axial apical horn, variously developed but lacking apical thorns. Thinner cylindrical secondary spines project from cephalic suture outward and downward.

Note: Diplocyclas was synonomized with Cycladophora by Lombari and Lazarus (1988).

Measurements.

\begin{tabular}{lcllccccc} 
& CeD & TL & TW & $\begin{array}{c}\text { Upper } \\
\text { TPD }\end{array}$ & $\begin{array}{c}\text { Basal } \\
\text { PD }\end{array}$ & BW & $\begin{array}{c}\text { Apical } \\
\text { horn L }\end{array}$ & $\begin{array}{c}\text { Lateral } \\
\text { SL }\end{array}$ \\
\hline Number & 9 & 10 & 10 & 10 & 10 & 10 & 7 & 7 \\
Mean & 18.9 & 57.0 & 48.8 & 7.9 & 13.6 & 2.7 & 30.3 & 19.0 \\
Std.Dev. & 3.0 & 12.9 & 7.4 & 1.4 & 3.4 & 1.2 & 11.3 & 7.2 \\
Coeff. Var. & 16.0 & 22.7 & 15.1 & 17.3 & 25.3 & 42.9 & 37.4 & 37.8 \\
Minimum & 14 & 40 & 40 & 6 & 9 & 1 & 12 & 10 \\
Maximum & 23 & 77 & 60 & 10 & 18 & 4 & 45 & 30
\end{tabular}

Occurrence. Rare to common, Oligocene. This species is also seen in the early Oligocene of the Antarctic (113-689B-12, CC, Lazarus, pers. obs., 1987).

\section{Ceratocyrtis mashae (?) Bjørklund, 1976a}

(Plate 2, Figs. 9 and 10)

Ceratocyrtis mashae Bjørklund, 1976a, Pl. 17, Figs. 1-5.

?Ceratocyrtis cuccularis (Ehrenberg) group of Dzinoridze et al., 1978, Pl. 26, Fig. 12, Pl. 41, Figs. 14-16.

Ceratocyrtis sp. aff. C. cuccularis (Ehrenberg) of Dzinoridze et al., 1978, Pl. 41, Fig. 21; Petrushevskaya, 1975, Pl. 11, Fig. 2.

?Ceratocyrtis (?) campanula (Clark and Campbell), Dzinoridze et al., 1978, Pl. 26, Fig. 13.

Ceratocyrtis sp. aff. Helotholus histricosa Jørgensen of Dzinoridze et al., 1978, Pl. 41, Fig. 13.

Ceratocyrtis sp. of Dzinoridze et al., 1978, Pl. 41, Fig. 20.

Ceratocyrtis group of Mullineaux and Westberg-Smith, 1986, Pl. 2, Fig. 12.

?Sethophormin group of Mullineaux and Westberg-Smith, 1986, Pl. 2, Fig. 17. 
Description. Small cephalis and large, slightly to moderately flared thorax, slightly inflated, and with recurved terminal section. Base terminated in complete specimens by irregular peristome. Cephalic pores large, irregular; cephalis with short apical and lateral horns. Thoracic pores large, regular; bars medium width, thick, framed. Numerous lattice-wall spines arising from nodes on both cephalis and thorax.

The current taxonomic status of these and similar forms is rather unsatisfactory, as many different names have been introduced into the literature, most without adequate differential diagnosis or consideration of the rather substantial amount of morphologic variation that exists within species. We suspect that a comparative study would demonstrate that most are merely junior synonyms. The species encountered in Site 647 material is similar to specimens described as C. mashae and C. robustus by Bjørklund (1976a) from the Norwegian Sea. However, it is not clear how Bjørklund's species differ from earlier species as used by the other authors cited in the synonomy above. We had difficulty distinguishing between Bjørklund's two species, which may reflect only the arbitrary division of continuous variation on the basis of size. The thoracic width of the specimens seen here are within the range of $C$. mashae, and as Bjørklund (1976a) assigns Site 116 North Atlantic material to C. mashae, this assignment was adopted here. Chen (1975) described a similar form (Sethoconus sp.) from the Antarctic. Chen's species, however, is not equal to the form described here, as his species has a smoother outer wall surface, generally lacks external cephalic spines, and typically terminates in an inwardly directed basal lip.

Measurements.

\begin{tabular}{lccc} 
& CeD & TW & TotL \\
\hline Number & 14 & 14 & 14 \\
Mean & 30.2 & 127.3 & 138.9 \\
Std.Dev. & 4.7 & 18.7 & 21.1 \\
Coeff. Var. & 15.7 & 14.7 & 15.2 \\
Minimum & 20 & 100 & 104 \\
Maximum & 38 & 163 & 192
\end{tabular}

Occurrence. Rare to common, Oligocene to early Miocene.

Nassellarian Genus et. sp. indet. \#2

(Plate 2, Figs. 11 and 12)

cf. Euscenium (?) corynephorum Jørgenson, Bjørklund, 1976a, Pl. 7, Figs. 1-4. cf. Cladoscenium tricolpium (Haeckel, 1882), Bjørklund, 1976a, Pl. 7, Figs. 5-8.

Description. Forms with primary nassellarian spines and loose meshwork of thin bars that form irregular polygonal pores. Sporadically present in Oligocene samples, but too rare and poorly preserved to warrant detailed analysis.

Peridium spp.

(Plate 2, Figs. 13-16)

Lithomelissa macroptera Ehrenberg, Dzinoridze et al., 1978, Pl. 29, Figs. 14 and 15.

Lithomelissa sp. aff. Dictyophimus sphaerocephalus Haeckel of Dzinoridze et al., 1978, Pl. 29, Fig. 16.

Lithomelissa (?) sp. aff. L. haeckeli Bütschli of Petrushevskaya, 1975, Pl. 9, Figs. 24-26.

Lophophaena macrencephala Clark and Campbell group, Dzinoridze et al., 1978, Pl. 29, Fig. 20, Pl. 32, Fig. 36.

Lophophaena sibirica (Gorbovetz) group of Dzinoridze et al., 1978 (in part), Pl. 32, Fig. 33.

cf. Lophophaena (?) capito Ehrenberg group of Petrushevskaya, 1975, Pl. 9, Fig. 21.

Lophophaena group of Mullineaux and Westberg-Smith, 1986 (in part), Pl. 2, Fig. 13b.

Lophophaenoma sp. G of Petrushevskaya, 1971, Petrushevskaya, 1975, Pl. 9, Fig. 22.

Lophophaenoma sp. of Petrushevskaya, 1975, Pl. 9, Fig. 23.

Arachnocorallium spp. of Petrushevskaya, 1975, Pl. 9, Figs. 17-19, Westberg-Smith and Riedel, 1984, Pl. 4, Fig. 2, Mullineaux and Westberg-Smith, 1986, Pl. 2, Fig. 11.

Description. Very large cephalis of irregular globular shape. Some specimens have a secondary, rough-surfaced hyaline covering over lattice-wall. Short, moderately flared thorax with irregular termination.
Thorax not present on all specimens. Lattice-wall of thorax has medium-to-small, irregular pores; thin, circular bars; nodes indistinct. One or occasionally more three-bladed horns extend apically from cephalis.

This group includes several forms, some of which may be distinct species. Ontogenetic variation in the degree of thoracic development, variable silicification of the cephalic outer wall surface, and variable preservation all make species-level analysis of Leg 105 material difficult. Current assignment to Peridium is tentative. The (poor figures) specimens of $A$. tumulosa given by Bjørklund (1976a) may also fall within this group.

Measurements.

\begin{tabular}{lrrr} 
& CeD & PD & BW \\
\hline Number & \multicolumn{1}{c}{33} & \multicolumn{1}{l}{33} & \multicolumn{1}{l}{33} \\
Mean & 43.8 & 4.4 & 3.0 \\
Std. Dev. & 9.4 & 1.6 & 1.3 \\
Coeff. Var. & 21.5 & 37.3 & 45.6 \\
Minimum & 27 & 1 & 1 \\
Maximum & 66 & 7 & 8
\end{tabular}

Occurrence. Few to common, latest Eocene through early Miocene.

$$
\begin{gathered}
\text { Antarctissa robusta } \\
\text { (Plate 1, Figs. 20-22) }
\end{gathered}
$$

Antarctissa robusta Petrushevskaya, 1975, Pl. 11, Figs. 21 and 22.

?Antarctissa capita Popofsky group of Petrushevskaya, 1975, Pl. 11, Fig. 24.

?Antarctissa equiceps Campbell and Clark group of Petrushevskaya, 1975, Pl. 11, Figs. 23 and 25.

Antarctissa antedenticulata Chen, 1975, Pl. 18, Figs. 1 and 2.

Description. Approximately equal-sized cephalis and thorax. Overall dimensions of shell are smaller than any forms assigned to Peridium, and dimensions of shell show very little variation among specimens. Irregular hemispherical cephalis, scattered small infilled pores with hyaline surface. Thorax compressed to equant, pores small, circular, scattered. Bars thin, very wide, shell surface fairly smooth. Thorax not flared, slightly inflated in center. No external feet or spines seen.

The early Oligocene of the Antarctic has a related, but different species of Antarctissa. The Antarctic species (which has not yet been described) has a less distinct cephalic suture, a longer thorax, and larger, often unfilled pores in the thoracic lattice-wall and cephalis.

\section{Measurements.}

\begin{tabular}{lcc} 
& CeD & TL \\
\hline Number & 11 & 11 \\
Mean & 36.1 & 29.2 \\
Std. Dev. & 3.1 & 8.5 \\
Coeff. Var. & 8.5 & 29.1 \\
Minimum & 32 & 15 \\
Maximum & 43 & 44
\end{tabular}

Occurrence. Fairly common in Core 105-647A-13 (early Miocene), rare in Core 105-647A-14, and absent in the Oligocene.

Lithomelissa sp. B

(Plate 2, Figs. 19 and 20)

cf. Lithomelissa stigi Bjørklund, 1976a, Pl. 15, Figs. 12-17.

cf. Lithomelissa sp. of Bjørklund, 1976a, Pl. 15, Figs. 9-11.

cf. Lophophaena group of Mullineaux and Westberg-Smith, 1986 (in part), Pl. 2, Figs. 13a, 13c-13e.

cf. Ceratocyrtis amplus (Popofsky), Petrushevskaya, 1975, P1. 11, Figs. 3-6.

?Ceratocyrtis sp. R of Petrushevskaya, 1975, Pl. 11, Fig. 12.

Description. Medium-sized, compressed hemispherical cephalis with medium-to-small irregular pores and thin circular bars. Eccentric apical horn, stout lateral spine from cephalic suture. Apical spine sometimes branched. Thoracic lattice-wall similar to cephalis. Thorax weakly flared, terminated by hyaline region at base. Ribs embedded in thorax wall are extended in many specimens into short stout spines projecting from base and thorax wall near base. 
Lithomelissa has a fairly simple morphology and thus few characters for analysis; it also shows considerable variation in characters from specimen to specimen. Thus, taxonomic subdivision of the genus is difficult, and many of the species previously described are impossible to recognize with any degree of reliability. A full comparative analysis of this group is needed but is beyond the scope of this study.

Measurements.

\begin{tabular}{lccl} 
& CeD & TL & TW \\
\hline Number & 22 & 22 & 22 \\
Mean & 35.4 & 73.0 & 83.7 \\
Std.Dev. & 6.8 & 16.4 & 14.5 \\
Coeff. Var. & 19.3 & 22.5 & 17.3 \\
Minimum & 27 & 55 & 56 \\
Maximum & 50 & 124 & 119
\end{tabular}

Occurrence. Rare to common in Oligocene to early Miocene of Site 647. Also seen in the Antarctic in the late Oligocene (113-690C-6, CC, Lazarus, pers. obs., 1987).

Dictyophimus sp.

(Plate 2, Figs. 17 and 18)

Description. Small, hemispherical cephalis with small scattered circular pores, partially or entirely infilled. Moderately inflated upper thorax, short subcylindrical lower thoracic segment. Three prominent cylindrical or three-bladed feet that detach from thorax wall at juncture of upper and lower thorax. Termination of thorax is ragged. Thoracic pores medium-sized, elliptical to subpolygonal. Bars medium-to-narrow, circular.

Measurements.

\begin{tabular}{lcll} 
& CeD & TL & TW \\
\hline Number & \multicolumn{1}{c}{10} & 10 & 10 \\
Mean & 18.7 & 41.2 & 55.9 \\
Std.Dev. & 2.5 & 11.0 & 5.9 \\
Coeff. Var. & 13.1 & 26.7 & 10.6 \\
Minimum & 15 & 22 & 47 \\
Maximum & 23 & 56 & 64
\end{tabular}

Occurrence. Rare to common in Oligocene to early Miocene.

Pterocanium sp. A

(Plate 3, Figs. 1 and 2)

cf. Pterocanium charybdeum (Müller), Lazarus et al., 1985, Figs. 1-4. cf. Pterocanium korotnevi (Dogiel) group of Lazarus et al., 1985, Pl. 18, Figs. 1-5.

Description. Large globular thorax having heavily framed subcircular pores, subspherical, heavily silicified cephalis, moderately flared, curved, three-bladed feet. Thorax is more globular and heavily silicified than $P$. charybdeum, yet lacks long, outwardly curved feet of $P$. korotnevi and related forms, such as Lychnocanium grande.

Occurrence. Rare to common in Oligocene and early Miocene.

Pterocanium sp. B

(Plate 3, Figs. 3 and 4)

Description. Characterized by a small, triangular thorax with moderately thin, comparatively smooth bars.

Occurrence. Rare to few in Oligocene and early Miocene.

\section{(?)Cyclampterium pegetrum}

(Plate 6, Figs. 5 and 12)

?Cyclampterium pegetrum Sanfilippo and Riedel, 1970, Pl. 2, Figs. 810, 1971, Pl. 2D, Figs. 13 and 14, Pl. 3B, Figs. 1 and 2.

?Cyclampterium longiventer Chen, 1975, Pl. 10, Fig. 7.

cf. Cyclampterium milowi Riedel and Sanfilippo, 1971, Pl. 7, Figs. 8 and 9, Chen, 1975, Pl. 2, Figs. 4 and 5.

cf. Thyrsocyrtis sp. Petrushevskaya, 1975, Pl. 8, Fig. 10.
Description. Abdomen length, terminal shape, and pore size vary considerably in specimens observed, making assignment to species difficult. Examination of Antarctic material (Lazarus, pers. obs, 1987) suggests that Chen's $C$. longiventer and Petrushevskaya's Thyrsocyrtis sp. are probably the same species. Less clear is whether these forms are synonymous with $C$. pegetrum of Samfilippo amd Riedel. Abdomen length and pore size, the primary characteristics used by Chen to distinguish his new form, vary substantially in the Antarctic material and also vary in specimens of $C$. pegetrum illustrated by Sanfilippo and Riedel. The specimens seen in Site 647 thus could be assigned to either species. The specimens illustrated by Chen as $C$. milowi do not have very well-developed feet, as in the original specimens illustrated by Riedel and Sanfilippo, and are rather similar to his $C$. longiventer.

Occurrence. Generally very rare, with sporadic occurrences throughout the Oligocene and early Miocene.

\section{Nassellarian gen. et. sp. indet. \# 4}

(Plate 6, Figs. 6 and 7)

cf. Dictyopodium sp. aff. D. oxylophus of Chen, 1975, Pl. 4, Figs. 1 and 2

cf. Theocorys anaclasta group of Sanfilippo et al., 1985, Figs. 24, 1a and $1 \mathrm{~b}$.

Description. Medium-sized spherical cephalis with medium-to-small irregular pores partially filled. Apical cylindrical horn and additional parallel cylindrical cephalic spines. Thorax moderately to strongly flared, centrally to distally inflated. Pores medium, irregular, tend to be vertically elongated near cephalic suture. Bars thin, elliptical. Numerous short, randomly distributed, cylindrical lattice-wall spines project from surface of thorax. Thoracic suture moderately constricted, marked by distinct thin internal septum. Abdomen moderately flared, inflated. Lattice-wall similar to thorax, but external lattice-wall spines fewer in number. Base of abdomen similar to thorax. Pores of abdomen vertically elongated near thoracic suture. Incomplete fourth segment observed in two specimens, similar to abdomen. Termination of fourth segment ragged (broken?) in specimens observed. Thin cylindrical spines project outward and distally from middle of thorax and abominal walls.

Virtually identical to Chen's species in homologous portions of the shell, although nature of abdominal termination differs substantially from Chen's species. Chen's specimens possess differentiated feet formed from lattice wall, hence his tentative assignment to Dictyopodium.

Measurements.

\begin{tabular}{lccc} 
& CeD & TL & TW \\
\hline Number & 7 & 7 & 7 \\
Mean & 32.6 & 77.6 & 51.0 \\
Std.Dev. & 3.4 & 6.4 & 6.3 \\
Coeff. Var. & 10.3 & 8.3 & 12.3 \\
Minimum & 27 & 69 & 45 \\
Maximum & 37 & 90 & 63
\end{tabular}

Occurrence. Very rare in Oligocene.

Stichocorys sp. A

(Plate 3, Figs. 8-10)

Description. Medium-to-small spherical cephalis having completely infilled pores, short apical horn in some specimens. Thorax small, hemispherical; pores small, circular; bars medium, circular; rounded nodal elevations. Top of thorax marked by row of large polygonal or wedgeshaped pores. Base of thorax marked by internal septum and slight change in external contour of shell. Abdomen, when present, less heavily silicified, subcylindrical, irregular termination, pores irregular, bars narrow.

Differentiated pores at top of thorax and lightly silicified, cylindrical abdomen distinguish this species from all other Stichocorys. Very little size variation seen in this species. 
Measurements.

\begin{tabular}{lccc} 
& CeD & TL & TW \\
\hline Number & 11 & 11 & 9 \\
Mean & 22.6 & 37.1 & 46.8 \\
Std.Dev. & 2.0 & 2.3 & 1.8 \\
Coeff. Var. & 8.9 & 6.1 & 3.8 \\
Minimum & 19 & 34 & 44 \\
Maximum & 24 & 41 & 51
\end{tabular}

Occurrence. Common in Core 105-647A-14 (early Miocene), rare in Core 105-647A-13. A few single specimens seen in Oligocene samples, which may be from downhole contamination. This species is seen ubiquitously in Miocene sediments of the Atlantic coastal plain and offshore (A. Palmer, pers. comm., 1988).

Stichocorys sp. B (group)

(Plate 3, Figs. 5 and 6)

Lithocampe subligata Stöhr group of Petrushevskaya, 1975, Pl. 14, Figs. 6-9, 12.

Lithocampe punctata Stöhr group of Petrushevskaya, 1975, Pl. 14, Figs. 10 and 13 .

Description. Two, three, or four segmented forms having generally compressed, centrally inflated post-thoracic segments, hemispherical second segment, and medium-to-small spherical, heavily silicified hyaline cephalis. Thick, conical, apical horn in most individuals. Thoracic pores small, circular to irregular; bars medium to thick, circular. Abdominal and post-abdominal lattice-walls similar to that of thorax.

Distinguished from Stichocorys sp. A above by shape and degree of silicification of third segment, by lack of differentiated upper thoracic pores, and by the relatively large size of Stichocorys sp. B. Members of this group bear a great deal of similarity to Cyrtocapsella tetrapera and Eucyrtidium diaphanes, and may well be merely end-members of a morphologic continuum containing all three named species. Given the restricted stratigraphic distribution and biostratigraphic importance of the latter morphs, the current division into separate categories is maintained.

Measurements.

\begin{tabular}{lccc} 
& CeD & TL & AW \\
\hline Number & 11 & 11 & 8 \\
Mean & 24.4 & 54.0 & 73.1 \\
Std.Dev. & 1.7 & 6.1 & 8.8 \\
Coeff. Var. & 7.2 & 11.3 & 12.0 \\
Minimum & 22 & 47 & 58 \\
Maximum & 28 & 64 & 87
\end{tabular}

Occurrence. Very rare in Oligocene, common in the early Miocene.

\section{Cyrtocapsella tetrapera (group)}

(Plate 3, Figs. 7 and 13)

Cyrtocapsella tetrapera Haeckel, Sanfilippo and Riedel, 1970, Pl. 1, Figs. 16-18, Chen, 1975, Pl. 20, Fig. 1.

?Cyrtocapsella cornuta Haeckel, Sanfilippo and Riedel, 1970 (in part), Pl. 1, Fig. 19.

?Cyrtocapsella elongata (Nakaseko), Sanfilippo and Riedel, 1970, Pl. 1, Figs. 11 and 12.

?Cyrtocapsella japonica (Nakaseko), Sanfilippo and Riedel, 1970, Pl. 1, Figs. 13-15.

?Lithocampe (Cyrtocapsella) cylindroides Principi, Petrushevskaya, 1975, Pl. 4, Figs. 14 and 15.

Description. Three- or four-segmented shell. Cephalis small, spherical, hyaline, heavily silicified, bearing short apical horn. Remaining segments fusiform, with strongly constricted basal opening. Outline of shell variable, ranging from smooth ovoid to forms showing abrupt changes in contour between each segment. Sutures marked by internal septa but relatively little external constriction. Lattice-wall for all segments similar. Pores irregular to circular, medium to small; bars medium, elliptical; nodes slightly elevated.

This group includes forms assigned by other authors to several different species, including Cyrtocapsella tetrapera, C. cornuta, and C. ja- ponica. The characters used to make these distinctions (shell outline and segment number) were too variable in this material to permit subdivision into discrete taxa. Note also that this group may be morphologically continuous with Stichocorys sp. B.

Measurements.

\begin{tabular}{llllcclcc} 
& & \multicolumn{9}{c}{$\begin{array}{c}\text { 4th } \\
\text { Segment } \\
\end{array}$} & CeD & TW & AW & W & TL & AL & $\begin{array}{c}\text { 4th } \\
\text { Legment }\end{array}$ \\
\hline Number & 10 & 12 & 12 & 11 & 12 & 12 & 11 \\
Mean & 25.9 & 69.1 & 96.8 & 89.1 & 39.1 & 42.1 & 37.4 \\
Std.Dev. & 3.0 & 6.7 & 10.0 & 13.0 & 7.0 & 10.5 & 7.1 \\
Coeff. Var. & 11.7 & 9.7 & 10.4 & 14.6 & 17.8 & 24.9 & 18.9 \\
Minimum & 22 & 60 & 83 & 70 & 26 & 27 & 25 \\
Maximum & 30 & 85 & 120 & 118 & 51 & 58 & 51
\end{tabular}

Occurrence. Common in Cores 105-647A- 13 and-14, early Miocene.

\section{Eucyrtidium diaphanes \\ (Plate 3, Figs. 11 and 12)}

Eucyrtidium diaphanes Sanfilippo et al., 1973, Pl. 5, Figs. 12-24. cf. Stichocorys johnsonii Caulet, 1986, Pl. 6, Figs. 5 and 6.

Description. Included in this species are specimens having a heavily walled, centrally inflated abdomen, and a distinctive row of large pores at the top of the abdomen. In most other respects, they are indistinguishable from Stichocorys sp. B.

Occurrence. Rare in Cores 105-647A-13 and -14 (early Miocene).

Eucyrtidium sp. A

(Plate 3, Figs. 16 and 17)

Eucyrtidium group of Mullineaux and Wesberg-Smith, 1986, Pl. 3, Fig. 4.

Stichocorys sp. of Bjørklund, 1976a (in part), Pl. 18, Figs. 4-6.

?Eucyrtidium punctatum (Ehrenberg), Caulet, 1986, PI. 5, Fig. 9.

?Eucyrtidium cienkowski group of Westberg-Smith and Riedel, 1984 (in part), Pl. 4, Fig. 13a.

cf. Eucyrtidium sp. of Chen, 1975, P1.7, Figs. 6-8.

cf. Eucyrtidium ceinkowski Haeckel, Chen, 1975, Pl. 15, Fig. 7.

cf. Eucyrtidium sp. of Caulet, 1986, Pl. 5, Fig. 12.

Description. Cephalis small, spherical, hyaline, with short apical horn. Thorax moderately flared cone, little or no inflation. Lattice-wall of thorax and post-thoracic segments similar. Pores medium-to-small, somewhat irregular in shape and alignment; bars medium-to-narrow. Abdomen compressed, weakly flared, slightly inflated. Post-abdominal segments similar in size and shape to abdomen but are unflared (subcylindrical). Sutures between segments marked by external constriction and by well-developed internal septum. Suture lines have tendency to be distorted from typical coplanar nassellarian condition. Maximum width attained near fourth segment; subsequent segments slightly smaller in diameter.

Overall shape of shell similar to $E$. ceinkowski, but differs in irregularity of pore arrangement and lack of obvious vertical ribs. Chen's Eucyrtidium sp. also is similar, but differs in having relatively compressed segments, heavy, ring-like sutures, and relatively large, irregularly shaped pores with heavy bars. Caulet's Eucyrtidium sp. lacks the large, finely pored thorax that is typical for Site 647 material. The specimen illustrated by Caulet as E. punctatum may well be conspecific with the Site 647 species. Caulet's figured specimen clearly is not conspecific with $E$. punctatum of Chen.

Measurements.

\begin{tabular}{lcclll} 
& TotL & MaxW & CeD & TL & AL \\
\hline Number & 10 & 10 & 10 & 10 & 10 \\
Mean & 156.3 & 87.3 & 19.4 & 35.2 & 42.9 \\
Std. Dev. & 27.5 & 13.1 & 3.5 & 3.4 & 11.5 \\
Coeff. Var. & 17.6 & 15.0 & 18.2 & 9.6 & 26.7 \\
Minimum & 100 & 73 & 13 & 28 & 30 \\
Maximum & 187 & 112 & 24 & 40 & 68
\end{tabular}

Occurrence. Rare in Oligocene to early Miocene. 
Calocyclas sp. B

(Plate 3, Figs. 14 and 15)

?Calocyclas sp. of Bjørklund, 1976a, Pl. 22, Figs. 3 and 4.

?Calocyclas sp. of Bjørklund, 1976a, Pl. 22, Figs. 1 and 2.

?Eucyrtidium punctatum (Ehrenberg) group of Westberg-Smith and Riedel, 1984 (in part), Pl. 4, Fig. 15a. cf.Theocyrtis litos (Clark and Campbell), Dzinoridze et al., 1978, Pl. 28, Figs. 2, 6, 7, and 11.

Description. Cephalis small, spherical, hyaline, with cylindical apical horn on well-preserved specimens. Thorax moderately flared, distally inflated, joined to cephalis by faint neck. Thoracic lattice-wall of irregularly arranged small circular pores; bars narrow and moderately thick. Thoracic suture marked by internal septum. Abdomen shape is inverted truncate hemisphere with short basal constriction or neck; pores proximally similar to thorax but becoming much more irregularly spaced distally; bars narrow-to-wide.

Several other forms that seem closely related to this species are seen in the Oligocene, including forms described here as Cyrtocapsella sp. B. There is considerable uncertainty as to the relationships of all these species to each other and to taxa such as Calocyclas semipolita and Cyrtocapsella longithorax from the Antarctic (Petrushevskaya, 1975).

Measurements.

\begin{tabular}{lclcl} 
& CeD & TW & TL & AL \\
\hline Number & 11 & 11 & 11 & 11 \\
Mean & 25.4 & 62.5 & 51.6 & 56.4 \\
Std.Dev. & 4.4 & 12.1 & 7.2 & 17.7 \\
Coeff. Var. & 17.2 & 19.4 & 13.9 & 31.3 \\
Minimum & 18 & 28 & 45 & 30 \\
Maximum & 33 & 76 & 63 & 91
\end{tabular}

Occurrence. Rare in early Miocene and Oligocene.

\section{Lamprocyclas sp. \\ (Plate 4, Figs. 1-3)}

Occurrence. Rare and sporadic in Oligocene and early Miocene.

\section{Calocycletta sp.}

(Plate 4, Fig. 4)

Description. Robust thorax and relatively long, distally tapering abdomen bearing (in one or two relatively well-preserved specimens) terminal teeth. However, in these later cases, the distal tips of the terminal teeth were broken off, making assignment to species impossible.

Occurrence. Rare and sporadic in early Miocene and Oligocene.

Theocyrtis tuberosa (Riedel)

(Plate 4, Figs. 7 and 8)

Theocyrtis tuberosa (Riedel), Sanfilippo et al., 1985, Figs. 32.1a-32.1d.

Occurrence. A single specimen was seen in Sample 105-647A-19-4, $50 \mathrm{~cm}$. Sanfilippo et al. (1985) give the stratigraphic range of this species as latest Eocene to early late Oligocene.

\section{Cyrtopera laguncula Haeckel}

(Plate 4, Figs. 9 and 10)

Cyrtopera laguncula Haeckel, 1887, Pl. 75, Fig. 10.

Occurrence. Chen (1975) and Petrushevskaya (1975) give a Miocene to Holocene age range for this species in the Antarctic, while Bjørklund (1976a) and Dzinoridze et al. (1978) do not record its presence in the Norwegian-Greenland Sea at all. Although never common, the species is present at Site 647 , in all sediments containing radiolarians from early Oligocene through early Miocene.

\section{Cannobotryidae (Haeckel) spp.} (Plate 4, Figs. 5 and 6)

Occurrence. Specimens were too rare and poorly preserved to justify detailed analysis. However, both Centrobotrys Petrushevskaya (1965) and Acrobotrys Haeckel (1881) are present.
Botryostrobus joides Petrushevskaya group

(Plate 4, Figs. 13-16)

Botryostrobus joides Petrushevskaya, 1975, Pl. 10, Fig. 37; Dzinoridze et al., 1978, Pl. 29, Fig. 8; Bjørklund, 1976a, Pl. 23, Figs. 7-14..

?Botryostrobus tumidulus (Bailey) group of Petrushevskaya, 1975 (in part), Pl. 10, Fig. 26

Botryostrobus sp. B of Dzinoridze et al., 1978, Pl. 32, Figs. 28 and 29. ?Eucyrtidium (?) picus Ehrenberg, Dzinoridze et al., 1978, Pl. 29, Fig. 9.

Botryostrobus sp. of Caulet, 1986, Pl. 6, Fig. 2.

Occurrence. This species appears to evolve from a strongly segmented form (Plate 4, Figs. 13 and 14) that dominates in the Oligocene to a form with reduced size and segmentation (Plate 4, Figs. 15 and 16) that becomes the dominant form in the early Miocene. This latter form is substantially different from Petrushevskaya's type material and may eventually require a new species name.

\section{Nassellarian gen. et sp. indet. \#5}

(Plate 4, Figs. 17 and 18)

Description. Cephalis medium-sized, hemispherical to somewhat irregular in shape. Cephalis lattice-wall thin, contains many medium-tosmall circular pores. Single, short, axially located apical horn; roughsurfaced, cylindrical in shape. Thorax of variable size but often rather large, equant to slightly compressed, moderately flared, centrally inflated. Thin lattice-wall of thin bars and medium-to-small circular pores in hexagonal arrangement. Subsequent segments expand slightly in width and are moderately to strongly compressed, centrally inflated, with lattice-wall like that of thorax. Basal termination ragged in all specimens examined. Internal septa present between segments. Central axis of symmetry in many individuals not straight but slightly curved; in these cases, the shell somewhat "banana-shaped."

Occurrence. Rare to few and sporadic in Oligocene and early Miocene.

\section{Cyrtocapsella (?) sp. B (group)}

(Plate 5, Figs. 4-5, 12-13)

cf. Theocorys longithorax Petrushevskaya, 1975, Pl. 8, Fig. 15, Pl. 22 Fig. 2.

cf. Cyrtocapsella isopera Chen, 1975, Pl. 11, Figs. 7-9.

Description. Cephalis medium, subspherical, with scattered small, partially filled, circular pores. Thorax moderately flared, distally inflated (inflation stronger on one side than the other), with a few short spines projecting from the lattice-wall. Pores medium-to-small, circularto-subpolygonal, bars narrow, circular. Thoracic suture ("lumbar stricture") marked by external constriction and by narrow internal septum. Post-thoracic shell of variable length and delineated by one to several constrictions in shell outline. Pores gradually become larger and more irregular than those of thorax; bars remain narrow. Termination of shell irregular.

There are two main subgroups present in this species. Group A (Plate 4, Figs. 12 and 13) is characterized by having a relatively narrow shell and large, polygonal pores, particularly on the thorax. Group B (Plate 4, Figs. 4 and 5) is wider and has rather small circular pores in the thorax. Although some intermediate specimens are seen, most individuals appear to fall into one or the other of these two groups, which may represent two different species. Cyrtocapsella sp. C looks somewhat similar, but has a different shape to the thorax and post-thoracic segments. Differs from C. longithorax in characters of post-thoracic segment. C. longithorax has regular pores in thorax and abdomen (Chen [1975] called C. longithorax, "C. isopera"), a subcylindrical abdominal shape and only rarely has any post-abdominal segments. These are irregular, saclike structures when present. This species also is similar to ?Calocyclas semipolita (Plate 5, Figs. 6 and 7), particularly in the irregularly constricted post-thoracic shell, but differs from this latter form in the features of the thorax.

Measurements (Groups A and B combined).

\begin{tabular}{lcccc} 
& CeD & TW & TL & TotL \\
\hline Number & 21 & 21 & 21 & 21 \\
Mean & 24.6 & 56.4 & 45.6 & 118.0 \\
Std. Dev. & 1.8 & 4.9 & 5.0 & 20.4 \\
Coeff. Var. & 7.3 & 8.7 & 11.1 & 17.3 \\
Minimum & 20 & 48 & 34 & 90 \\
Maximum & 28 & 67 & 54 & 168
\end{tabular}


Occurrence. Rare to abundant in Oligocene, rare to few in early Miocene.

Cyrtocapsella (?) sp. C

(Plate 5, Figs. 10 and 11)

?Lithamphora sp. of Petrushevskaya, 1975, Pl. 10, Fig. 21.

Description. Cephalis medium-sized, hemispherical, scattered small, partially filled, circular pores. Short lateral spine projecting from cephalic suture. Thorax weakly flared to subcylindrical, centrally inflated with nearly flat central region and tapers at both ends. Abdomen cylindrical, moderately compressed. Fragmentary post-abdominal segment usually present. Lattice-wall of thorax and abdomen similar; pores medium, elliptical to polygonal; bars narrow, circular. Thoracic and abdominal sutures marked by faint internal septum.

Distinguished from Cyrtocapsella sp. B by barrel-like shape of thorax, less globular cephalis, more regular pores in lattice-wall of main shell. Petrushevskaya's form may be conspecific, but her photograph is too poor to be certain. Neither these two species, nor for that matter Cyrtocapsella longithorax or ?Calocyclas semipolita, are very similar to other species of Cyrtocapsella and Calocyclas and probably should be placed in a different (new?) genus. Distinctive features include the structure of the lattice-wall, unconstricted termination, and spines projecting from the lattice-wall of the thorax.

Measurements.

\begin{tabular}{lcccl} 
& CeD & TW & TL & TotL \\
\hline Number & \multicolumn{1}{c}{12} & 12 & 12 & 12 \\
Mean & 22.5 & 44.3 & 32.8 & 38.3 \\
Std. Dev. & 2.4 & 2.7 & 4.5 & 11.2 \\
Coeff. Var. & 10.6 & 6.1 & 13.6 & 29.1 \\
Minimum & 17 & 38 & 26 & 23 \\
Maximum & 26 & 47 & 38 & 61
\end{tabular}

Occurrence. Rare to abundant in the Oligocene.

\section{?Calocyclas semipolita}

(Plate 5, Figs. 6 and 7)

?Calocyclas semipolita (?) Clark and Campbell, Chen, 1975 (in part), Pl. 6, Figs. 3, 4, and 6 .

Theoperid, gen. et. sp. indet. of Johnson, 1974, Pl. 2, Figs. 14-17.

Description. C. semipolita is distinguished from Cyrtocapsella sp. B here by the presence in the former of a heavily silicified, hemispherical thorax and more robust abdominal lattice-wall. The specimens observed in Site 647 samples show considerable variation in morphology, with some individuals clearly equivalent to Chen's figured specimens (most closely, his Fig. 4), while others have a less heavily silicified thorax, with more proximal inflation and thus are similar to Cyrtocapsella sp. B. Occurrence. Rare in Oligocene. One specimen only seen in early Miocene (reworked?).

Peripyramis spp.

(Plate 5, Figs. 8 and 9)

Peripyramis circumtexta Haeckel, 1887, Pl. 54, Fig. 5.

Litharachnium group of Mullineaux and Westberg-Smith, 1986, Pl. 3, Fig. 5.

\section{Cornutella spp.}

\section{(Plate 4, Figs. 11 and 12)}

?Cornutella profunda Ehrenberg, Riedel, 1958, Pl. 3, Figs. 1 and 2.

Despite various attempts by previous authors to differentiate species within this genus, no satisfactory species-level taxonomy exists. Therefore, all forms seen were lumped together.

\section{Nassellarian gen. et sp. indet. \#6}

(Plate 5, Fig. 1)

Occurrence. Only one specimen seen.

Nassellarian gen. et sp. indet. \#7 (Plate 5, Figs. 20 and 21)

Carpocanarium group of Mullineaux and Westberg-Smith, 1986, Pl. 3, Fig. 18. cf. Tricolocapsa papillosa (Ehrenberg) group of Petrushevskaya, 1975, Pl. 13, Fig. 13.

Description. Hemispherical cephalis having short apical spine (often missing), centrally inflated elongate thorax with irregular to elliptical pores (long axis tends to be horizontal), bars thick, circular or elliptical in cross section. One large cylindrical lateral spine projects outward and distally from near middle of thorax. Base of thorax marked by thickened lattice-wall bar, but no peristome. The form illustrated by Petrushevskaya is superficially similar to this species, but has a peristome and lacks a lateral spine.

\section{?Artostrobus quadriporus}

(Plate 5, Figs. 16 and 17)

?Artostrobus quadriporus Bjørklund, 1976a, Pl. 23, Figs. 15-21.

?Artostrobus annulatus Bailey, Riedel, 1958, Pl. 4, Fig. 6. Unknown theoperid of Mullineaux and Westberg-Smith, 1986, Pl. 3, Fig. 9b.

Description. Bjørklund's specimens have slightly smaller, less regular pores, less well-developed external spines, and, in contrast to Site 647 material, possess fine secondary spines on the upper part of the shell. These differences are fairly minor, and the Leg 105 material was tentatively assigned to Bjørklund's species. This assignment is tentative because Bjørklund's description of $A$. quadriporus does not state which characteristics distinguish it from other species of Artostrobus (such as A. annulatus Bailey).

Nassellarian gen. et sp. indet. \#8

(Plate 5, Figs. 18 and 19)

Description. Cephalis small, hemispherical, hyaline, with scattered, filled, small circular pores. Prominant cylindrical apical horn. Thorax hemispherical, approximately twice size of cephalis. Pores small, circular, irregularly distributed; bars wide, smooth. Thoracic suture marked by thin internal septum. Abdomen cylindrical to weakly flared, elongate; lattice-wall similar to thorax but less heavily silicified. Two large cylindrial spines project radially from middle of thoracic wall. Termination of shell ragged.

Occurrence. Rare to common in the Oligocene.

Nassellarian gen. et sp. indet. \#9

$$
\text { (text, Fig. 7) }
$$

cf. Lipamella (?) sp. of Kling, 1973 (in part), Pl. 10, Fig. 24.

Description. Medium-sized spherical cephalis havng numerous small circular pores, prominent three-bladed apical horn. Thorax is compressed, moderately flared, distally inflated, connected to cephalis by short neck. Thoracic pores very small, regularly arranged in hexagonal packing, circular to polygonal; bars very narrow. Two prominent, slightly curved, three-bladed spines project radially from middle of thorax wall. Abdomen and post-abdominal segments moderately compressed, subcylindrical (i.e., not flared), slightly centrally inflated with lattice-wall similar to thorax. Narrow septa present between segments.

Similar to Nassellarian sp. C above, but differs in many details. Specimen shown in Kling's figure (1973) has three, not two, lateral spines and smaller pores, but is otherwise similar, although Kling's specimen lacks complete post-thoracic segments.

Measurements. Ceph.D.: $\sim 20 \mu \mathrm{m}$. Th.W.: $\sim 40 \mu \mathrm{m}$. Th.L.: $\sim 25-$ $30 \mu \mathrm{m}$. Ab.L.: $\sim 30 \mu \mathrm{m}$. Ab.W.: $\sim 40 \mu \mathrm{m}$. Ap.H.L.: up to $40 \mu \mathrm{m}$. Thoracic spine L.: up to $80 \mu \mathrm{m}$. (Based on four measured specimens.)

Occurrence. Very rare in the Oligocene.

\section{?Dicolocapsa microcephala}

(Plate 5, Figs. 2 and 3)

?Dicolocapsa microcephala Haeckel, 1887, Pl. 57, Fig. 1; Johnson, 1974, Pl. 6, Fig. 15.

?Lophocorys bicorne, Dzinoridze et al., 1978, Pl. 28, Fig. 12.

cf. Carpocanistrum group A of Westberg-Smith and Riedel, 1984, Pl. 5, Figs. $11 \mathrm{a}$ and $11 \mathrm{~b}$.

cf. Carpocanistrum group of Mullineaux and Westberg-Smith, 1986, Pl. 3, Fig. 10.

Occurrence. Rare in Oligocene and early Miocene. 


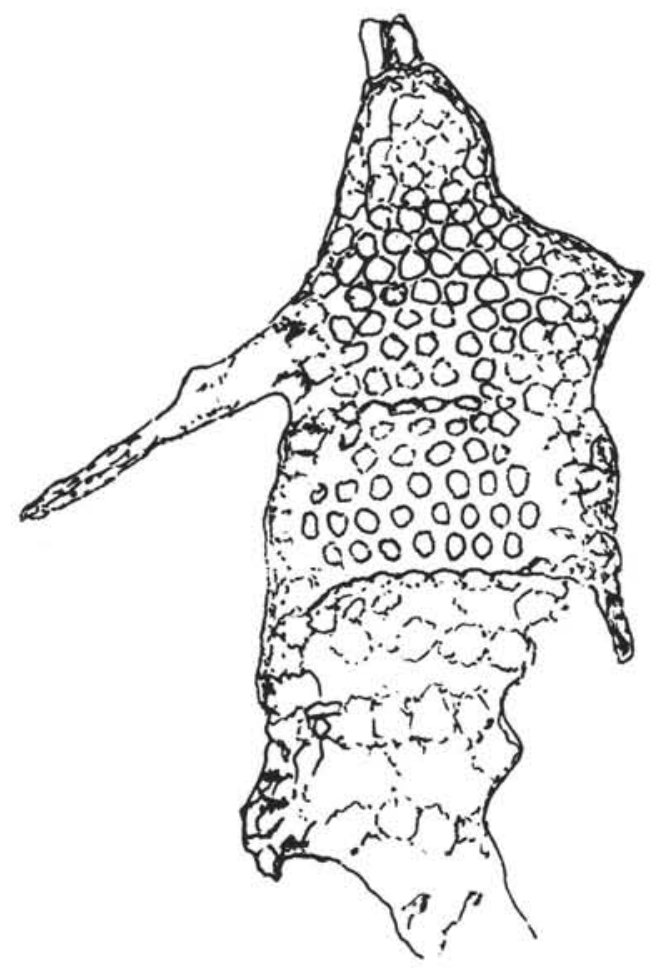

Figure 7. Drawing of a specimen of Nassellarian gen. et sp. indet. \#9, based on a video-print. Sample 105-647A-23-4, $75 \mathrm{~cm}$. Stage coordinates $5.6 / 72.4$.

\section{?Cystophormis brevispina}

(Plate 5, Figs. 14 and 15)

?Cystophormis brevispina (Vinassa), Petrushevskaya, 1975, Pl. 13, Figs. 3-7.

Description. Cephalis strongly compressed, cap partially embedded in thorax, with a few small circular pores. Thorax not flared, centally inflated, with medium circular pores arranged in staggered vertical rows. Bars medium to wide, of moderate thickness. Some specimens have vertical ribs between pore rows. Thorax terminated by circular opening at base of thorax approximately same diameter as cephalis, surrounded by a hyaline peristome. Outline of shell is smooth. The photographs in Petrushevskaya (1975) are too blurred to permit definite comparisons.

Measurements.

\begin{tabular}{lccccc} 
& CeW & CeL & TW & TL & L Peristome \\
\hline Number & 8 & 8 & 10 & 10 & 10 \\
Mean & 28.6 & 18.3 & 72.2 & 64.1 & 30.8 \\
Std.Dev. & 5.4 & 2.6 & 6.9 & 6.8 & 8.2 \\
Coeff. Var. & 18.9 & 14.3 & 9.6 & 10.5 & 26.7 \\
Minimum & 20 & 15 & 63 & 57 & 23 \\
Maximum & 34 & 23 & 86 & 74 & 46
\end{tabular}

Occurrence: In Sections 105-647A-14, CC and -13, CC (early Miocene).

Siphocampe spp. group A

(Plate 6, Figs. 1 and 2)

Lithomitra modeloensis (Campbell and Clark) group of Dzinoridze et al., 1978, Pl. 40, Fig. 7.

Lithomitra imbricata (Ehrenberg) group of Dzinoridze et al., 1978, Pl. 29, Fig. 7.

Lithomitra arachnea (Ehrenberg) group of Petrushevskaya, 1975, Pl. 10, Figs. 10, 13-17.

?Lithomitra (?) sp. of Petrushevskaya, 1975, Pl. 10, Fig. 36.
?Lithomitra nodosaria Haeckel group of Petrushevskaya, 1975, Pl. 10 , Fig. 18.

Siphocampe group of Westberg-Smith and Riedel, 1984, Pl. 6, Fig. 3.

Siphocampe group of Mullineaux and Westberg-Smith, 1986, Pl. 3, Fig. 15.

cf. Botryostrobus group of Mullineaux and Westberg-Smith, 1986, Pl. 3, Figs. $13 \mathrm{a}$ and $13 \mathrm{~b}$.

Nigrini (1977) synonymized Lithomitra with Siphocampe. We were not able to differentiate in the Leg 105 material most of the species of Siphocampe that have been described by previous authors. We recognized only two broad divisions and one distinctive species (S. acephala).

Occurrence. Common to abundant in virtually all samples examined.

\section{Siphocampe spp. group B}

(Plate 6, Figs. 3 and 4)

cf. Lithomitra (?) sp. aff. Theocampe dactylica, Dzinoridze et al., 1978, Pl. 32, Fig. 1.

cf. Dictyoprora pirum, Sanfilippo et al., 1985, Fig. 33.2a and 33.2b.

Occurrence. Transitional morphotypes between Siphocampe spp. groups A and B occur frequently. Rare to few in Oligocene and early Miocene.

Siphocampe acephala

(Plate 6, Figs. 10 and 11)

Siphocampe acephala (Ehrenberg), Nigrini, 1977, Pl. 3, Fig. 5.

cf. Lithomitra sp. P of Dzinoridze et al., 1978 (in part), Pl. 32, Figs. 2 and 3.

cf. Lithomitra (?) elegans Ehrenberg group of Dzinoridze et al., 1978, Pl. 32, Figs. 18-20.

cf. Lithomitra (?) minuta (Clark and Campbell), Dzinoridze et al., 1978 (in part), Pl. 32, Figs. 22 and 23.

Description. This species is characterized by its curved main axis of symmetry (e.g., the thorax and abdomen are not in line), regular pore rows, and rectangular pore shape in many individuals. Some specimens are transitional with ?Dictoprora amphora.

Occurrence. Few to common in Oligocene and early Miocene.

\section{?Dictyoprora amphora \\ (Plate 6, Figs. 8 and 9)}

?Dictyoprora amphora, Sanfilippo et al., 1985, Fig. 33.3.

Lithomitra sp. of Bjørklund, 1976a, Pl. 23, Figs. 1-3.

Lithomitra sp. of Bjørklund, 1976a, Pl. 23, Figs. 4-6.

cf. Lithomitra sp. P of Dzinoridze et al., 1978 (in part), Pl. 29, Fig. 3, PI. 32, Figs. 4-7.

cf. Lithocampe (?) sp. aff. Lithocampe minuta Clark and Campbell, Dzinoridze et al., 1978, Pl. 32, Figs. 16 and 17.

Occurrence. Abundant in virtually all samples.

\section{SPUMELLARIA \\ Druppatractus hastatus \\ (Plate 6, Figs. 13-15)}

Druppatractus hastatus Blueford, 1982, Pl. 6, Figs. 3 and 4. ?Ellipsostylus salebrosus Blueford, 1982, Pl. 7, Figs. 7, 8a, and 8b. Druppatractus sp. Chen, 1975, Pl. 20, Figs. 11 and 12.

Stylosphaera spp. of Nigrini and Lombari, 1984 (in part), Pl. 4, Fig. 4b.

Description. Cortical shell elliptical; pores medium, slightly irregular; bars narrow, framed; nodes elevated. Two large cylindrical spines at axes, of unequal length. Medium-sized medullary shell present in most individuals.

Chen's specimens have slightly more elongate cortical shells, and, according to the measurements given in his text, are also slightly smaller. We do not believe that these differences are of species-level importance. The only difference between $D$. hastatus and $E$. salebrosus, according to Blueford, is the absence in the latter of a medullary shell. The presence of a medullary shell is not a useful taxonomic character on either biologic or practical grounds, as it may be missing because of either ontogenetic variation (see recent review in Anderson [1983]) or dissolution. Thus, E. salebrosus is probably a junior synonym of $D$. hastatus. 
Measurements.

\begin{tabular}{lccccc} 
& CtW & CtL & CtPD & CtBW & SL \\
\hline Number & 12 & 12 & 12 & 12 & 7 \\
Mean & 69.3 & 77.8 & 5.7 & 2.5 & 31.0 \\
Std.Dev. & 2.9 & 2.9 & 0.5 & 0.5 & 5.1 \\
Coeff. Var. & 4.1 & 3.7 & 8.7 & 20.3 & 16.6 \\
Minimum & 67 & 72 & 5 & 2 & 27 \\
Maximum & 74 & 83 & 6 & 3 & 40
\end{tabular}

Occurrence. Rare to few in the Oligocene.

\section{Sphaerostylus cristatus (group)}

(Plate 6, Figs. 16-19)

Sphaerostylus cristatus Blueford, 1982, Pl. 5, Figs. 9 and 10. ?Xiphostylus minimus Mamedov, 1969, Pl. 1, Fig. 1.

Description. Cortical shell spherical with thick walls. Pores very small, circular; bars medium width, very thick. In some specimens, numerous tapered cylindrical spines project from surface of cortical shell. Two large cylindrical spines may be present at axes, unequal in length. One or more medullary shells present. Medullary shells, like spines, are often absent in many specimens.

As used here, this is a large and probably artificial grouping of specimens having similar cortical shells. However, ontogenetic variation and dissolution in Leg 105 material made it difficult to separate distinct species within this group, although the general size, shape, and lattice-wall characters are virtually identical with Blueford's species. As noted by Blueford, many of the specimens in this group are similar to Stylosphaera angelina Campbell and Clark.

Measurements.

\begin{tabular}{llllccl} 
& CtL & CtW & MD & CtPD & CtBW & SL \\
\hline Number & 31 & 31 & 14 & 24 & 24 & 13 \\
Mean & 99.8 & 98.3 & 41.5 & 6.5 & 2.8 & 95.3 \\
Std.Dev. & 17.5 & 16.2 & 12.4 & 1.0 & 1.1 & 24.2 \\
Coeff. Var. & 17.5 & 16.5 & 29.8 & 15.8 & 40.5 & 25.4 \\
Minimum & 95 & 95 & 27 & 5 & 2 & 35 \\
Maximum & 137 & 133 & 70 & 8 & 5 & 130
\end{tabular}

Occurrence. Rare to few in Oligocene and early Miocene.

Sphaerostylus nicholasi

(Plate 6, Figs. 19, 20, and 23)

Sphaerostylus nicholasi Blueford, 1982, Pl. 6, Figs. 5 and 6.

?Axoprunum liostylum (Ehrenberg) group, Petrushevskaya, 1975, Pl. 2, Fig. 22.

Axoprunum sp. aff. Stylacontarium bispiculum Popofsky, Dzinoridze et al., 1978, Pl. 22, Fig. 16.

Stylosphaera group of Mullineaux and Westberg-Smith, 1986 (in part), Pl. 1, Fig. 3b.

?Stylatractus pictus Mamedov, 1969, Pl. 2, Figs. 4 and 4a.

?Axoprunum pierinae (Clark and Campbell), Dzinoridze et al., 1978, Pl. 22, Fig. 19. cf. Stylacontarium bispiculum Popofsky, Chen, 1975, Pl. 21, Figs. 1 and 2.

Description. Large cortical shell, elliptical with slightly flattened sides, circular pores medium-to-large; bars narrow, very thick, framed. Axial spines large, cylindrical, one typically longer than the other but sometimes equal in length. Medullary shell connected to cortical shell by prominent beams in equatorial plane.

Axial spines are not as unequal in Leg 105 material as in Blueford's material, which we judged to be only a minor difference. $S$. bispiculum of Chen (1975), a species seen also in ODP Leg 113 material from the Weddell Sea (Lazarus, pers. obs., 1987) has a more spherical shell and is somewhat larger than the species described here. Druppatractus acquilonius Hays (1970) is a much larger species than the one described here. In overall size and arrangement of supporting beams, this species is similar to Axoprunum stauraxonium Haeckel, described by Hays (1970) from the Pliocene-Pleistocene of the North Pacific. The differences between Blueford's Miocene species and Axoprunum stauraxonium may be too minor to justify retaining two distinct species names, but the Miocene name was used for now until more comparative data are available.
Measurements.

\begin{tabular}{lcccccc} 
& CtL & CtW & MD & CtPD & CtBW & SL \\
\hline Number & 12 & 12 & 5 & 10 & 10 & 6 \\
Mean & 146.1 & 135.3 & 42.6 & 11.8 & 3.6 & 83.5 \\
Std. Dev. & 21.3 & 18.5 & 8.6 & 2.1 & 1.3 & 22.3 \\
Coeff. Var. & 14.6 & 13.7 & 20.2 & 17.8 & 35.1 & 26.7 \\
Minimum & 90 & 83 & 30 & 8 & 2 & 60 \\
Maximum & 167 & 153 & 50 & 15 & 6 & 120
\end{tabular}

Occurrence. Rare to few in Oligocene to early Miocene.

Stylatractid sp. E

(Plate 6, Figs. 21, 22, and 28)

Description. Cortical shell ellipsoidal; pores large, circular; bars very thin; variously developed silicification but often very thick; surface of some specimens rough or with numerous lattice-wall spines projecting from nodes. Two unequally developed, large three-bladed axial spines, occasionally third three-bladed spine projecting from cortical shell at acute angle from smaller of the two axial spines. Medullary shell with thin bars and small circular pores, connected to cortical shell by numerous three-bladed beams distributed throughout region within \pm $20^{\circ}$ of equatorial plane. One axis of medullary shell wall drawn out and extended onto a spine, giving it an ovoid shape. Long axis of medullary shell frequently not colinear with long axis of cortical shell. Incomplete specimens without cortical shell are common.

Ovoid medullary shell similar to Druppatractus irregularis Popofsky in Blueford (1982); but in the species described here it is larger. Cortical shell of the two species also are different.

Measurements.

\begin{tabular}{lcccccc} 
& CtW & CtL & CtPD & CtBW & MD & SL \\
\hline Number & 17 & 17 & 13 & 11 & 10 & 12 \\
Mean & 77.4 & 83.6 & 10.4 & 2.7 & 35.5 & 79.8 \\
Std.Dev. & 12.1 & 12.0 & 2.5 & 1.3 & 3.9 & 22.6 \\
Coeff. Var. & 15.7 & 14.3 & 24.1 & 46.6 & 11.0 & 28.3 \\
Minimum & 68 & 74 & 7 & 2 & 26 & 54 \\
Maximum & 103 & 112 & 15 & 6 & 40 & 130
\end{tabular}

Occurrence. Few to common in Oligocene to early Miocene.

?Lithatractus timmsi

(Plate 6, Figs. 24 and 25)

?Lithatractus timmsi Campbell and Clark, 1944, Pl. 2, Figs. 18-19.

?Druppatractus irregularis Popofsky, Blueford, 1982, Pl. 6, Figs. 7a and $7 \mathrm{~b}$.

?Druppatractus nanus Blueford, 1982, Pl. 7, Figs. 3a-4.

?Ellipsostylus distachyus Blueford, 1982, P1.7, Figs. 5a-6.

Description. Cortical shell spherical to ellipsoidal; pores very small, circular; bars very narrow, thin to very thick and framed; surface of shell often rough. Two large, three-bladed, unequally developed axial spines, one often much larger than the other. Shorter axial spine often projects at an angle to the polar axis. Additional nonaxial three-bladed spines common. Medullary shell, like that of Stylatractid sp. E above, is ovoid, extended along spine, and often not colinear with cortical axis.

This species, or forms similar to it, can be seen in Oligocene and Miocene sediments from the North Pacific and Antarctic as well as in Site 647 from the North Atlantic (Lazarus, pers. obs., 1987). Blueford's species differ in only minor details from $L$. timmsi, and may well be junior synonyms of it, or of $D$. irregularis Popofsky.

Measurements.

\begin{tabular}{lcccccc} 
& CtW & CtL & CtPD & CtBW & MD & SL \\
\hline Number & 11 & 11 & 7 & 7 & 10 & 10 \\
Mean & 79.9 & 86.9 & 5.0 & 1.7 & 33.1 & 95.6 \\
Std. Dev. & 13.3 & 12.6 & 1.2 & 0.8 & 3.9 & 25.4 \\
Coeff. Var. & 16.6 & 14.5 & 23.1 & 44.1 & 11.7 & 26.5 \\
Minimum & 63 & 72 & 4 & 1 & 28 & 65 \\
Maximum & 104 & 110 & 7 & 3 & 40 & 145
\end{tabular}

Occurrence. Rare to few in Oligocene to early Miocene. 
Stylatractid sp. G

(Plate 6, Figs. 26 and 27)

?Stylatractus sp. of Sanfilippo et al., 1985, Fig. 5.4.

?Amphisphaera santhaennae (Campbell and Clark), Petrushevskaya, 1975, Pl. 2, Fig. 21.

cf. Stylatractus spp. of Nigrini and Lombari, 1984, Pl. 4, Fig. 2a and 2b.

Description. Cortical shell ellipsoidal; pores are irregularly arranged, circular, show substantial variation in size but are on average of medium size (typically 6 $8 \mu \mathrm{m})$; bars medium-to-narrow width $(2-3 \mu \mathrm{m})$, moderately thick, framed; surface of shell rough. Two large, three-bladed axial spines of unequal length. Two medullary shells, outer one large and ellipsoidal in shape, inner one about one-half the size of outer one and spherical, although further details are obscured by outer shells.

Distinguished by large outer medullary shell and small, irregular cortical shell pores. Nigrini and Lombari's species have much larger pores and a different cortical shell shape. The illustration of Sanfilippo et al. (1985) is too small to give positive identification (their form was only illustrated for comparison with another species), while the photograph of Petrushevskaya (1975) is too blurred.

Measurements.

\begin{tabular}{lccc} 
& CtW & CtL & MW \\
\hline Number & 13 & 13 & 13 \\
Mean & 118.5 & 137.9 & 74.1 \\
Std.Dev. & 15.5 & 12.2 & 5.1 \\
Coeff. Var. & 13.1 & 8.9 & 6.8 \\
Minimum & 80 & 118 & 68 \\
Maximum & 13 & 157 & 86
\end{tabular}

Occurrence. Rare to few in Oligocene to early Miocene.

\section{Sphaerostylus rosetta}

(Plate 7, Figs. 12 and 17)

Sphaerostylus rosetta Blueford, 1982, Pl. 7, Figs. 1 and 2.

Description. Large, massively silicified cortical shell having delicate rosettes set within thick, wide, protruding frames. A much more strongly silicified form than $S$. neptunus Haeckel. Medullary shell in at least some Leg 105 specimens resembles that of ?Lithatractus timmsi, that is, ovoid-shaped and oriented at angle to cortical shell axis.

Occurrence. Rare to few and sporadic in Oligocene and early Miocene.

\section{Cenosphaera spp. A (group)}

(Plate 7, Figs. 5 and 6)

Group 1 (no photograph)

cf. Rhizosphaera acrocladon Blueford, 1982, Pl. 3, Figs. 5, 6a, and 6b. cf. Spongoplegma anturcticum Haeckel, Chen, 1975, Pl. 22, Figs. 3-4. cf. Spongoplegma sp. of Chen, 1975, Pl. 22, Figs. 1 and 2.

?Haliomma sp. N of Dzinoridze et al., 1978, Pl. 21, Fig. 3.

?Haliomma (?) sp. aff. Cenosphaera eocenica Clark and Campbell,

Dzinoridze et al., 1978, Pl. 21, Fig. 5.

Description. Large cortical shell with medium-sized, irregular pores; medium-to-narrow bars. In many individuals, numerous short latticewall spines arise from bars that subdivide pores and project outward to give spiny outer shell surface. In some specimens, this is so prominent as to form a thick, almost spongy outer layer on outside of shell. Numerous thin radial beams connect cortical shell to irregular lattice-work that forms medullary shell.

The lattice-wall of the main cortical shell is similar to Chen's (1975) Spongoplegma sp. and the various forms illustrated by Dzinoridze et al.(1978), but neither Chen or Dzinoridze et al. mention the spiny extracortical growth commonly seen in Leg 105 material. While similar, Rhizosphaera acroladon has more irregular cortical shell pores, thinner bars, a somewhat bumpy cortical shell surface, and a more organized medullary shell structure.

Group 2

(Plate 7, Figs. 5 and 6)

Description. Includes several related forms that are probably representatives of more than one species. Large spherical cortical shell, often dual-walled with inner shell of medium-sized, irregular pores and outer shell of smaller pores, also irregular in shape, connected by numerous radial beams between nodes of the two lattice-walls. In some specimens, the two shells are so heavily silicified as to form a single, heavy, coarse, spongy shell, or the inner shell is heavily silicified with thick bars and small pores, while the outer shell is reduced to a vestige. Radial beams connect cortical shells to two or more spherical medullary shells of varying size. Medullary shells have medium-sized, polygonally framed pores. One or more short, thick, cylindrical spines project from cortical shell surface. Related to Group 1 only by somewhat similar cortical shell structure and large overall size.

Measurements (Groups 1 and 2 combined).

\begin{tabular}{lccc} 
& CtD & PD* & BW* \\
\hline Number & 12 & 12 & 12 \\
Mean & 190.8 & 15.8 & 4.0 \\
Std. Dev. & 27.1 & 3.7 & 1.0 \\
Coeff. Var. & 14.2 & 23.3 & 23.8 \\
Minimum & 147 & 10 & 3 \\
Maximum & 230 & 20 & 6 \\
* (inner cortical shell). &
\end{tabular}

Occurrence. Rare to few in Oligocene to early Miocene.

$$
\begin{aligned}
& \text { Cenosphaera (?) oceanica } \\
& \text { (Plate 7, Figs. } 7 \text { and 8) }
\end{aligned}
$$

Cenosphaera (?) oceanica Clark and Campbell, Petrushevskaya, 1975, Pl. 1, Figs. 12 and 13, Pl. 31, Fig. 5.

cf. Actinomma (?) californica (Clark and Campbell), Dzinoridze et al., 1978, Pl. 21, Fig. 7.

Occurrence. Rare and sporadic in the Oligocene. Large, thin-walled shell is easily broken, and fragments are much more common than intact, or nearly intact, specimens.

\section{Cenosphaera sp. D}

(Plate 7, Figs. 1 and 2)

cf. Cenosphaera sp. of Chen, 1975, Pl. 7, Figs. 1 and 2.

Description. Medium-to-small, single, spherical, cortical shell (diameter $110-120 \mu \mathrm{m}$ ) having medium-to-small circular pores set closely together between narrow bars but in very thick frames. Shell surface slightly rough due to frames. Chen's species is similar, but much larger (200 $\mu \mathrm{m}$ in diameter) and has an even thicker shell wall.

Occurrence. Few in early Miocene, one or two single occurrences in the Oligocene (downhole contamination?).

\section{?Cenosphaera (?) mariae}

(Plate 7, Fig. 4)

?Cenosphaera (?) mariae Lipman, Dzinoridze et al., 1978, Pl. 21, Fig. 10. Actinommid sp. of Westberg-Smith and Riedel, 1984 (in part), Pl. 2,

Fig. 2.

Description. Thin-walled, small- to medium-sized cortical shell having closely spaced, subcircular pores of various sizes irregularly distributed over surface. One or more medullary shells, about one-half the diameter of the cortical shell, may be present, supported by numerous thin radial beams. Variable size and medullary shell development suggest that this may represent more than one species, but more detailed study needed for definitive analysis.

Occurrence. Rare to common in Oligocene and early Miocene. This species is also seen in Antarctic sediments (Lazarus, pers. obs., 1987).

\section{Collosphaera? sp.}

(Plate 7, Fig. 3)

Collosphaera sp. A of Reynolds, 1980 (in part), Pl. 1, Figs. 1-3.

cf. Cenellipsis bergontianus Carnevale group of Dzinoridze et al., 1978, Pl. 22, Fig. 10.

Description. The haphazard arrangement of the subcircular pores on the shell, with some pores overlapping others, is distinctive and similar to the wall structure of other members of Collosphaera. However, the shell shape is more typical of prunoids. There are some differences between the Leg 105 material and the specimens described by Reynolds from the North Pacific. Reynolds' species appears to have a larger average size, the shell wall in Reynolds' specimens is much thicker than seen 
here, and no specimens were seen with pores as small as those of Reynolds (1980), Pl. 1, Fig. 4.

Measurements.

\begin{tabular}{lccc} 
& CtL & CtW & CtPD \\
\hline Number & 6 & 6 & 6 \\
Mean & 92.8 & 69.3 & 5.5 \\
Std.Dev. & 7.3 & 5.9 & 0.5 \\
Coeff. Var. & 7.8 & 8.5 & 10.0 \\
Minimum & 84 & 58 & 5 \\
Maximum & 103 & 74 & 6
\end{tabular}

Occurrence. Rare in Oligocene and early Miocene. This species also was seen in the Antarctic in the Miocene and Oligocene (Lazarus, pers. obs., 1987).

Actinomma spp. group B

(Plate 7, Figs. 9, 13, 14, 18, and 19)

Heliosoma (?) mirabile Clark and Campbell, Dzinoridze et al., 1978, Pl. 21, Fig. 14.

Thecosphaera diligins Kozlova, Dzinoridze et al., 1978, Pl. 21, Figs. 16 and 17.

Hexaconthium sp. aff. $H$. pachydermum Jørgensen, Dzinoridze et al., 1978, Pl. 22, Fig. 6

cf. Thecosphaera leptococcus Carnevale, Dzinoridze et al., 1978, Pl. 21, Fig. 13.

Hexacontium groups B and C of Mullineaux and Westberg-Smith, 1986, Pl. 1, Fig. 1b and 1c.

Actinommid of Mullineaux and Westberg-Smith, 1986, Pl. 1, Fig. 6a.

Description. Medium-sized cortical shell with uniformly sized and shaped pores. Pore size varies, but is typically medium to medium-large; bars medium to narrow, moderately thick, framed; surface of shell often slightly rough. Secondary shorter lattice-wall spines sometimes present. Rarely, a supra-cortical shell is partially developed at a short distance from the cortical shell surface. Six or more three-bladed spines project from shell, connected by radial beams to two medullary shells. Spines, beams, and medullary shells may be absent.

This taxon is very broad (note the unusually high coefficients of variation in the measured characters) and may contain several different species. Ontogenetic variability in actinommids is known to be high (Bjørklund, 1976b) and valid subdivision of this group may require a detailed analysis of several characters, including morphometrics.

Measurements.

\begin{tabular}{lcccll} 
& CtD & CtPD & CtBW & MD & SL \\
\hline Number & 43 & 38 & 38 & 29 & 30 \\
Mean & 115.4 & 10.2 & 3.0 & 44.7 & 31.9 \\
Std.Dev. & 24.8 & 2.4 & 1.2 & 10.1 & 14.0 \\
Coeff.Var. & 21.5 & 23.9 & 39.5 & 22.5 & 44.0 \\
Minimum & 88 & 7 & 2 & 32 & 18 \\
Maximum & 183 & 16 & 6 & 72 & 70
\end{tabular}

Occurrence. Common to abundant in Oligocene to early Miocene.

\section{Actinomma sp. C}

(Plate 7, Figs. 15 and 20)

cf. Actinomma tanyacantha Chen, 1974, Pl. 1, Figs. 1 and 2.

cf. Actinomma golownini Petrushevskaya, 1975, Pl. 2, Fig. 16.

Description. Medium-sized cortical shell in most specimens with flattened sides, giving it a rounded, cubical shape. Medium-large subcircular pores closely spaced with narrow, rather thin bars. Long threebladed spines project from center of each face of the cube and from each vertex. Spines on cube faces continue inward as three-bladed beams that support medium-small outer medullary shell with polygonal pores and thin bars. A small spherical inner medullary shell may also be present, but details are obscured by outer shells. Small secondary spines may project from surface of cortical shell, and primary three-bladed spines may be distally branched, as in Anomalacantha dentata.

Differs from $A$. golowini (and A. tanyacantha, which is a junior synonym of $A$. golowini) in that this Leg 105 species is smaller, shows more variation in cortical shell shape (the degree of flattening of the sides is variable, and some specimens are nearly spherical), has secondary spines projecting from shell surface in some specimens, and has distal thorns on the main spines in some specimens.

Measurements.

\begin{tabular}{llcc} 
& CtD & MD & CtPD \\
\hline Number & 10 & 8 & 8 \\
Mean & 76.9 & 31 & 8 \\
Std.Dev. & 11.4 & 3 & 0.8 \\
Coeff.Var. & 14.8 & 9.6 & 9.4 \\
Minimum & 61 & 28 & 7 \\
Maximum & 94 & 36 & 9
\end{tabular}

Occurrence. Rare and sporadic in Oligocene and early Miocene.

\section{Anomalacantha dentata \\ (Plate 7, Figs. 23 and 24)}

Heteracantha dentata Mast, Bjørklund, 1976a, Pl. 14, Figs. 10-12. Anomalacantha dentata (Mast) Benson, 1966, Pl. 5, Figs. 10-11.

Occurrence. Rare to few in Oligocene and early Miocene.

Generic name changed by Loeblich and Tappan (1961) because Heteracantha was previously occupied.

Arachnosphaera sp.

(Plate 8, Figs. 8 and 14)

cf. Arachnosphaera dichotoma Jørgensen, Bjørklund, 1976a, Pl. 3, Figs. 5-9.

Description. Small, single spherical (cortical) shell having large polygonal pores and narrow, thin, framed bars. Several thin three-bladed spines projecting from shell surface.

Differs from $A$, dichotoma specimens illustrated by Bjørklund in having a smaller number of larger pores. This species appears to be similar to Anomalacantha dentata described here, but differs primarily in the quantitative development of characters (silicification, spine, pore, and shell size).

Measurements.

\begin{tabular}{lccc} 
& CtD & CtPD & CtBW \\
\hline Number & 10 & 10 & 10 \\
Mean & 49.3 & 11.8 & 2.2 \\
Std.Dev. & 4.3 & 1.5 & 0.8 \\
Coeff. Var. & 8.8 & 13.1 & 38.1 \\
Minimum & 45 & 9 & 1 \\
Maximum & 58 & 14 & 3.5
\end{tabular}

Occurrence. Rare in Oligocene to early Miocene.

Sphaeropyle sp.

(Plate 7, Figs. 10, 11, and 16)

Description. Ellipsoidal (nearly spherical) cortical shell with pylome at one pole of major axis in complete specimens. Pores of cortical shell small, circular, densely scattered over surface, lattice-wall thin. Large, spherical outer medullary shell having medium circular pores and medium-wide, medium thickness bars. Small spherical inner medullary shell. Numerous radial beams project a short distance beyond cortical shell surface.

Measurements.

\begin{tabular}{lccccc} 
& CtL & $\begin{array}{c}\text { Outer } \\
\text { CtW }\end{array}$ & $\begin{array}{c}\text { Outer } \\
\text { MD }\end{array}$ & $\begin{array}{c}\text { Outer } \\
\text { MPD }\end{array}$ & MBW \\
\hline Number & 7 & 7 & 7 & 3 & 3 \\
Mean & 127.4 & 110.1 & 81.7 & 8.0 & 2.7 \\
Std.Dev. & 11.1 & 18.9 & 4.2 & 3.0 & 1.2 \\
Coeff. Var. & 8.7 & 17.2 & 5.1 & 37.5 & 43.3 \\
Minimum & 112 & 82 & 76 & 5 & 2 \\
Maximum & 142 & 130 & 88 & 11 & 4
\end{tabular}

Occurrence. Rare to few in Oligocene to early Miocene. 
Heliodiscus ? spp.

(Plate 7, Figs. 21 and 22)

cf. Heliodiscus asteriscus Haeckel; Nigrini and Lombari, 1984, Pl. 5, Fig. 4.

Phacodiscid group of Mullineaux and Westberg-Smith, 1986, Pl. 1, Fig. 8

Heliodiscus sp. A of Petrushevskaya, 1975, Pl. 1, Fig. 16.

Periphaena dupla (?) group of Petrushevskaya, 1975, Pl. 1, Figs. 14 and 15.

Occurrence. Rare in Oligocene and early Miocene.

\section{Spumellarian gen. et sp. indet. \#1}

(Plate 7, Figs. 27 and 28)

Description. Five coplanar three-bladed spines radiate from the surface of a small, pentangular, lozenge-shaped cortical shell, with two additional three-bladed spines projecting perpendicularly from the center of the two faces of the cortical shell. Cortical shell pores medium, irregular; bars narrow, thin. There is a loose mesh or strutwork inside the cortical shell, but no distinct medullary shell. Corresponds to no genus or species in figures from any high-latitude DSDP radiolarian report, nor to any Haeckelian taxon.

Measurements.

\begin{tabular}{lcccl} 
& CtD & CtPD & CtBW & SL \\
\hline Number & 15 & 15 & 15 & 10 \\
Mean & 46.1 & 6.6 & 1.5 & 27.2 \\
Std.Dev. & 3.1 & 0.9 & 0.7 & 14.5 \\
Coeff. Var. & 6.7 & 13.8 & 48.8 & 53.4 \\
Minimum & 42 & 5 & 1 & 15 \\
Maximum & 53 & 8 & 3 & 60
\end{tabular}

Occurrence. Rare in Oligocene. Similar forms also were seen in the early Oligocene of the Antarctic (Site 689, Lazarus, pers. obs., 1987).

\section{Spumellarian gen. et sp. indet. \#2}

(Plate 7, Figs. 25 and 26)

Description. A form similar to Spumellarian gen. et sp. indet. \#1 above, but slightly larger and having a shell in the shape of an octahedron; thus, has six spines at the vertices.

Occurrence. Very rare in the Oligocene; one doubtful specimen from Core 105-647A-14 (early Miocene), which may be reworked.

\section{Euchitonia ? spp.}

(Plate 8, Figs. 3 and 9)

Preservation of these forms was too poor to identify species.

Occurrence. Rare in early Miocene.

\section{Spongocore spp.}

$$
\text { (Plate 8, Figs. } 1 \text { and 2) }
$$

Spongocore group of Mullineaux and Westberg-Smith, 1986, Pl. 1, Fig. 13.

Occurrence. Rare to common in Oligocene and early Miocene.

$$
\begin{aligned}
& \text { Amphitholus (?) sp. A } \\
& \text { (Plate 8, Figs. } 4 \text { and 10) }
\end{aligned}
$$

Description. Multishelled tholonid with three concentric lobate shells. Lobate expression varies from strongly developed innermost shell to nearly smooth outlined ellipsoidal outermost shell. Cortical and outer medullary shell lattice-walls of medium-to-small, circular-to-irregular pores; narrow, medium-to-thin bars. Several thin radial beams connect cortical shell to medullary shells, do not project much beyond surface of cortical shell in specimens observed. Incomplete specimens lacking cortical shell are common. Orientation of long axes of medullary and cortical shells may or may not be colinear (possibly because of different orientations of the specimens).

\section{Measurements.}

\begin{tabular}{lccccc} 
& CtL & $\begin{array}{c}\text { Outer } \\
\text { CtW }\end{array}$ & $\begin{array}{c}\text { Outer } \\
\text { MD }\end{array}$ & $\begin{array}{c}\text { Outer } \\
\text { MPD }\end{array}$ & MBW \\
\hline Number & 17 & 17 & 17 & 15 & 15 \\
Mean & 102.1 & 93.1 & 71.5 & 9.0 & 2.5 \\
Std.Dev. & 16.7 & 25.5 & 13.2 & 3.6 & 1.1 \\
Coeff. Var. & 16.4 & 27.4 & 18.4 & 40.1 & 43.0 \\
Minimum & 75 & 43 & 58 & 6 & 1 \\
Maximum & 140 & 147 & 112 & 20 & 4
\end{tabular}

Occurrence. Few to common in Oligocene to early Miocene. Similar forms are seen in the early Oligocene of the Antarctic (Lazarus, pers. obs., 1987).

Tetrapyle (?) spp.

(Plate 8, Figs. 22 and 23)

Pylonid group of Mullineaux and Westberg-Smith, 1986, Pl. ?, Fig. 2.

Description. Flattened, ellipsoidal, cortical lattice-wall band connected to smaller ellipsoidal medullary bands by girdle bands and by radial beams. In cross section, two major openings in shell, one at either end of long axis of ellipse. Each opening is bisected by a radial beam. Beams also extend slightly beyond surface of shell in some specimens. Lattice-wall pores small, circular-to-irregular; bars narrow and thin. Includes species assigned to several different genera by other authors.

Measurements.

\begin{tabular}{llllccc} 
& CtL & CtW & ML & MW & CtPD & CtBW \\
\hline Number & 10 & 10 & 10 & 10 & 9 & 9 \\
Mean & 71.1 & 56.8 & 32.4 & 20.0 & 5.7 & 1.7 \\
Std.Dev. & 13.0 & 12.4 & 10.5 & 7.7 & 1.5 & 0.8 \\
Coeff. Var. & 18.3 & 21.8 & 32.5 & 38.4 & 26.5 & 43.8 \\
Minimum & 55 & 42 & 23 & 12 & 3 & 1 \\
Maximum & 93 & 76 & 54 & 38 & 8 & 3
\end{tabular}

Occurrence. Few to common in Oligocene to early Miocene.

Lithelius (?) spp. group A

(Plate 8, Figs. 5, 6, 11, and 12)

Lithelius sp. cf. L. alveolina Haeckel of Dzinoridze et al., 1978, Pl. 24, Fig. 13.

cf. Pylospira group of Mullineaux and Westberg-Smith, 1986 (in part), Pl. 2, Fig. 5b.

Description. Single or double spiraled shell having at most only a few turns and with spirals in many specimens terminating in smooth ellipsoidal cortical shell having flattened sides. Pores small-to-medium, uniform, circular; bars thin, narrow.

In Antarctic Miocene material, forms with smooth cortical shells are distinct from forms with open spirals. This distinction could not be determined in the Leg 105 material, possibly due to poor preservation. Several other lithelid morphotypes were seen that were similar to this species, but differed in size, pore characteristics, or shape. They probably represent different species. Additional specimens should be examined to establish this, while more detailed observations of individual specimens also are necessary to rule out artifactual differences due to different specimen orientations.

Measurements.

\begin{tabular}{lclcc} 
& CtL & CtW & CtPD & CtBW \\
\hline Number & 12 & 12 & 11 & 11 \\
Mean & 67.0 & 57.7 & 6.3 & 15 \\
Std.Dev. & 4.8 & 11.2 & 1.2 & 0.7 \\
Coeff. Var. & 7.2 & 19.5 & 19.0 & 47.3 \\
Minimum & 60 & 42 & 5 & 1 \\
Maximum & 75 & 75 & 8 & 3
\end{tabular}

Occurrence. Rare to common in Oligocene to early Miocene. 
Prunopyle (?) sp. A

(Plate 8, Fig. 7)

Ommatodiscus haeckeli Stöhr group of Petrushevskaya, 1975 (in part), Pl. 3, Fig. 12.

Lithelius sp. cf. L. spiralis Haeckel, Dzinoridze et al., 1978, Pl. 24, Fig. 12.

cf. Lithelius minor Jorgensen, Mullineaux and Westberg-Smith, 1986, Pl. 2, Fig. 4a and $4 \mathrm{~b}$.

cf. Prunopyle hayesi Chen, 1975, Pl. 9, Figs. 3-5.

Description. Elipsoidal shell composed of closely spaced spirals of lattice-wall and numerous radiating beams. Lattice-wall pores small; bars narrow, medium thickness. Shells generally do not possess pylome or terminal cortical shell. Spacing between spirals increases only slightly with increasing diameter. Pores are smaller than in $P$. hayesi and radial pattern of dark and light bands characteristic of $P$. hayesi are not as distinct.

Measurements.

TotL Distance between spirals

\begin{tabular}{lcc}
\hline Number & 11 & 11 \\
Mean & 118.2 & 8.8 \\
Std.Dev. & 36.4 & 2.1 \\
Coeff. Var. & 30.8 & 23.7 \\
Minimum & 68 & 6 \\
Maximum & 208 & 14
\end{tabular}

Occurrence. Few to common in Oligocene to early Miocene.

Prunopyle (?) spp. group B

(Plate 8, Figs. 15-18)

Lithocarpium spp. of Dzinoridze et al., 1978 (all species listed in this genus).

?Larcopyle group of Mullineaux and Westberg-Smith, 1986, Pl. 2, Fig. 3.?

Lithocarpium fragilis (Stöhr), Petrushevskaya, 1975, Pl. 4, Figs. 2-4.

Description. Ellipsoidal shell having irregular internal spirals and pylome at one pole. Surface of shell covered with small irregular pores, bars thin and narrow. Size and elongation of shell vary substantially.

Subgroup 1

(Plate 8, Figs. 16-18)

Description. Elongate, small-shelled form. Shape of shell more strongly elliptical than in Prunopyle sp. A or in other related taxa, including Lithelius sp. A. The generlc placement of this species and all other prunoid and lithelid species is tentative because of the uncertainties that exist in the generic taxonomy of these forms.

Subgroup 2

(Plate 8, Fig. 15)

Description. Weakly ellipsoidal (i.e., nearly circular) flattened disks. Pores are often coarser and pylome usually marked by cleft in outline rather than protruding tube.

Measurements (Subgroups 1 and 2 combined).

\begin{tabular}{lcc} 
& TotL & TotW \\
\hline Number & 15 & 15 \\
Mean & 140.1 & 102.9 \\
Std.Dev. & 40.3 & 41.6 \\
Coeff. Var. & 28.7 & 40.5 \\
Minimum & 94 & 58 \\
Maximum & 220 & 180
\end{tabular}

Occurrence. Few to common in Oligocene to early Miocene.

\section{Prunopyle spp. group C}

(Plate 8, Figs. 13 and 19)

Pylospira group of Mullineaux and Westberg-Smith, 1986 (in part), Pl. 2, Fig. 5a.

Description. Coiled prunoids lacking distinctive structures. A catchall category that needs further work.

Occurrence. Abundant in most samples examined.
Spongodiscus spp.

(Plate 8, Figs. 24 and 25)

Spongodiscus group of Mullineaux and Westberg-Smith, 1986, Pl. 1, Fig. 12.

Spongopyle group of Mullineaux and Westberg-Smith, 1986, Pl. 1, Fig. $7 \mathrm{a}$ and $7 \mathrm{~b}$.

?Spongodiscus sibericus Gorbovetz, 1971, Fig. 2.

Description. Spongy disks, usually seen in fragmentary form. Some may have irregular internal spirals.

Occurrence. Usually abundant throughout section.

?Porodiscus spp,

(Plate 8, Figs. 20 and 21)

Various species assigned to Porodiscus and Stylodictya by other authors. As is true of the spongdiscids, the current species-level taxonomy of these forms is unsatisfactory and should be reviewed and modified to be useful.

\section{ACKNOWLEDGMENTS}

We thank the Captain and crew of the JOIDES Resolution, without whom this study would not have been possible, the ODP staff (particularly Brad Clement) for deadline stretching, Mike Kaminski for many enjoyable discussions, Kozo Takahashi for photographic advice, Gethard Bohrmann and Rudy Stein for access to unpublished data, and Barbara Mohr, for last-minute assistance in manuscript preparation. We also thank Amanda Palmer and an anonymous reviewer for suggestions to improve the manuscript. This work was supported under NSF grant DPP83-17087 and a grant from ODP/USSAC.

\section{REFERENCES}

Anderson, O. R., 1983. Radiolaria: New York (Springer-Verlag).

Benson, R. N., 1966. Recent Radiolaria from the Gulf of California [Ph.D. dissert.] Univ. of Minnesota, Minneapolis.

Bjørklund, K. R., 1976a. Radiolaria from the Norwegian Sea, Leg 38 of the Deep Sea Drilling Project. In Talwani, M., Udintsev, G., et al., Init. Repts. DSDP, 38: Washington (U.S. Govt. Printing Office), 1101-1168.

1976b. Actinomma haysi, n. sp., its Holocene distribution and size variation in Atlantic Ocean sediments. Micropaleontology, 23(1):114-126.

Bjørklund, K. R., and Kellogg, D. E., 1972. Five new Eocene radiolarian species from the Norwegian Sea. Micropaleontology, 18(3):386396.

Blueford, J., 1982. Miocene actinommid radiolaria from equatorial $\mathrm{Pa}$ cific. Micropaleontology, 28:189-213.

Borisenko, N. I., 1960a. New radiolarians from the Paleocene deposits of the Kubanj. Trans., All Un. Sci. Res. Inst. Oil Gas, 4:199-207. 1960b. The radiolarians of the lower and middle Eocene of Western Kubanj. Trans., All Un. Sci. Res. Inst. Oil Gas, 4:219-231.

Campbell, A., and Clark, B. L., 1944. Miocene radiolarian faunas from southern California. Geol. Soc. Am. Spec. Pap. 51.

Caulet, J. P., 1986. Radiolarians from the Southwest Pacific. In Kennett, J. P., von der Borch, C. C., et al., Init. Repts. DSDP, 90: Washington (U.S. Govt. Printing Office), 835-862.

Chen, P. H., 1974*. Some new Tertiary radiolarians from deep-sea sediments. Micropaleontology, 20(4):480-492. (*Mailed spring 1975after Petrushevskaya, 1975).

, 1975. Antarctic Radiolaria. In Hayes, D., Frakes, L., et al., Init. Repts. DSDP, 28: Washington (U.S. Govt. Printing Office), 437-514.

Dzinoridze, R. N., Jousé, A. P., Koroleva-Golikova, G. S., Kozlova, G. E., Nagaeva, G. S., Petrushevskaya, M. G., and Strelnikova, N. I., 1978. Diatom and radiolarian Cenozoic stratigraphy, Norwegian Basin, DSDP Leg 38. In Talwani, M., Udintsev, G., et al., Init. Repts. DSDP, Suppl. to Vol. $38,39,40$, and 41: Washington (U.S. Govt. Printing Office), 289-428.

Goll, R. M., 1968. Classification and phylogeny of the Cenozoic trissocyclidae (radiolaria) in the Pacific and Caribbean basins, part I. $J$. Paleontol., 42(6):1409-1432.

,1969. Classification and phylogeny of Cenozoic trissocyclidae (radiolaria) in the Pacific and Caribbean basins, part II. J. Paleontol., 43(2):322-339. 
1976. Morphological intergradation between modern populations of Lophospyris and Phormospyris (trissocyclidae, radiolaria). Micropaleontology, 22:379-418.

Goll, R. M., and Bjørklund, K. R., 1971. Radiolaria in surface sediments of the North Atlantic Ocean. Micropaleontology, 17(4):434454.

Gorbovetz, A. N., 1971. New data on middle Eocene radiolarians from the southern area of west Siberian plain. In New Data on the Microfauna and Microflora of the Western Siberian Plain: Moscow (Ministry of Geology, USSR, Region. Geol. and the Method of Geol. Mapping), 4:34-37.

Haeckel, E., 1881. Entwurf eines Radiolarien-Systems auf Grund von Studien der Challenger-Radiolarien. Jenaische Zeitschr. Naturwiss., $15: 418-472$.

1887. Report on the Radiolaria collected by H.M.S. Challenger during the years 1873-76. Rept. Voyage Challenger, Zool., 18.

Hays, J. D., 1970. Stratigraphy and evolutionary trends of radiolaria in North Pacific deep-sea sediments. Geol. Soc. Am. Mem., 126:185218.

Jørgensen, E., 1900. Protophyten und Protozoen in Plankton von der norwegischen Westküste. Bergens Mus. Arb., 1899:51-95. 1905. The protist plankton and the diatoms in bottom samples. Bergens Mus. Skrift, 1(1):49-151 and 195-225.

Johnson, D. A., 1974. Radiolaria from the eastern Indian Ocean, Deep Sea Drilling Project, Leg 22. In Von der Borch, C. C., Sclater, J. G., et al., Init. Repts. DSDP, 22: Washington (U.S. Govt. Printing Office), 521-575.

Kennett, J. P., 1982. Marine Geology: Englewood Cliffs, NJ (Prentice Hall).

Kling, S. A., 1973. Radiolaria from the eastern North Pacific, Deep Sea Drilling Project, Leg 18. In Kulm, L. D., von Huene, R., et al., Init. Repts. DSDP, 18: Washington (U.S. Govt. Printing Office), 617671.

Kozlova, G. E., and Gorbovets, A. N., 1966. Radiolarii verkhnemelovkh i verkhne-eozenovykh otlozhenii Zapadno-Sibirkoi nizmennosti, nedra. Vses. Neft. Nauchno-is sled. Geol.-Razu Inst., 248. 159.

Krasheninnikov, A. V., 1960. Some Radiolarians of the lower and middle Eocene of the Western Pre-Caucasus. In Sazonov, N. T., and Shchutskaya, E. K. (Eds.), Trans. All Un. Pet. Sci. Res. Inst. Geolog. Surv., 16:271-301.

Lazarus, D. B., 1983. Speciation in pelagic Protista and its study in the planktonic microfossil record: a review. Paleobiology,9(4):327-340.

Lazarus, D. B., Scherer, R., and Prothero, D. R., 1985. Evolution of th radiolarian species-complex Pterocanium: a preliminary survey. $J$. Paleontol, 59:183-220.

Lipman, R. Kh., 1950. The radiolarians of the Eocene of Kyzyl-Kumov. Trans., All Un. Geolog. Sci. Res. Inst., 1:51-65.

Loeblich, A. R., and Tappan, H., 1961. Remarks on the systematics of the Sarcodina (Protozoa) renamed homonyms and new and validated genera. Proc., Biolog. Soc. Washington, 74:213-234.

Lombari, G., and Lazarus, D. B., 1988. Neogene cycladopohorid radiolarians from North Atlantic, Antarctic, and North Pacific deep-sea sediments. Micropaleontology, 34(2):97-135.

Mamedov, N. A., 1969. New representatives of Eocene radiolarians in Axzerbaidzhan. In (Eds.) Fossil and Recent Radiolarians: Lvov (Lvov Geol. Soc.) 94-101.

Moore, T. C., Jr., 1973. Method of randomly distributing grains for microscopic examination. J. Sediment. Petrol, 43:904-906.
Mullineaux, L. S., and Westberg-Smith, M. J., 1986. Radiolarians as paleoceanographic indicators in the Miocene Monterey Formation, upper Newport Bay, California. Micropaleontology, 32(1):48-70.

Nigrini, C. A., 1977. Tropical Cenozoic Artostrobiidae (Radiolaria). Micropaleontology, 23:241-269.

Nigrini, C. A., and Lombari, G., 1984. A guide to Miocene Radiolaria. Cushman Found. Foram. Res., Spec. Publ., 22.

Petrushevskaya, M. G., 1965. Pecularities of the construction of the skeleton of radiolarians Botryoidae (order Nassellaria). Trans. Inst. Zool., Acad. Sci. U.S.S.R., 35:79-117.

1971. Radiolaria in the plankton and recent sediments from the Indian Ocean and the Antarctic. In Funnell, B. M., and Riedel, W. R. (Eds.), The Micropaleontology of Oceans: Cambridge (Cambridge Univ. Press)

1975. Cenozoic radiolarians of the Antarctic, Leg 29, Deep Sea Drilling Project. In Kennett, J. P., Houtz, R. E., et al., Init. Repts. DSDP, 29: Washington (U.S. Govt. Printing Office), 541676.

Petrushevskaya, M. G., and Bjørklund, K. R., 1974. Radiolarians in Holocene sediments of the Norwegian-Greenland Sea. Sarsia, 57: 33-46.

Petrushevskaya, M. G., and Kozlova, G. E., 1972. Radiolaria: Leg 14, Deep Sea Drilling Project. In Hayes, D. E., Pimm, A. C., et al., Init. Repts. DSDP, 14: Washington (U.S. Govt. Printing Office), 495-648.

Reynolds, R. A., 1980. Radiolarians from the western North Pacific, Leg 57, Deep Sea Drilling Project. In Scientific Party, Init. Repts. DSDP, 56, 57 (Pt. 2): Washington (U.S. Govt. Printing Office), 735-770.

Riedel, W. R., 1958. Radiolaria in Antarctic sediments. Repts. B. A. N. Z. Antarctic Res. Exped., B-6(10):218-254.

Riedel, W. R., and Campbell, A. S., 1952. A new Eocene radiolarian genus. J. Paleontol., 26(4):667-669.

Riedel, W. R., and Sanfilippo, A., 1971. Cenozoic radiolaria from the western tropical Pacific, Leg 7. In Winterer, E. L., Riedel, W. R., et al., Init. Repts. DSDP, 7(Pt. 2): Washington (U.S. Govt. Printing Office), 1529-1672.

Sanfilippo, A., Burckle, L. H., Martini, E., and Riedel, W. R., 1973. Radiolarians, diatoms, silicoflagellates and calcareous nannofossils in the Mediterranean Neogene. Micropaleontology, 19(2):209-234.

Sanfilippo, A., and Riedel, W. R., 1970. Post-Eocene "closed" theoperid radiolarians. Micropaleontology, 16:446-462.

Sanfilippo, A., Westberg-Smith, M. J., and Riedel, W. R., 1985. Cenozoic Radiolaria. In Bolli, H. M., Saunders, J. B., and Perch-Nielson, K. (Eds.), Plankton Stratigraphy: Cambridge (Cambridge Univ. Press), 63-712.

Seibold, E., and Berger, W. H., 1982. The Sea Floor: Berlin, Hiedelberg, New York (Springer-Verlag).

Srivastava, S. P., Arthur, M., et al., 1987. Proc. ODP, Init. Repts., 105: College Station, TX (Ocean Drilling Program).

Westberg-Smith, M. J., and Riedel, W. R., 1984. Radiolarians from the Western Margin of the Rockall Plateau: Deep Sea Drilling Project Leg 81. In Roberts, D. G., Schnitker, D., et al., Init. Repts. DSDP, 81: Washington (U.S. Govt. Printing Office), 479-502.

Date of initial receipt: 14 September 1987

Date of acceptance: 19 February 1988

Ms 105B-125 
APPENDIX

Coarse-Fraction Abundances for Sites 646 and 647

\begin{tabular}{|c|c|c|c|c|c|c|c|c|}
\hline \multirow{2}{*}{\multicolumn{2}{|c|}{$\begin{array}{c}\text { Sample } \\
\text { interval }(\mathrm{cm})\end{array}$}} & \multirow{3}{*}{$\begin{array}{c}\text { Lithics } \\
\mathrm{A}\end{array}$} & \multicolumn{2}{|c|}{ Diatoms } & \multirow{3}{*}{$\begin{array}{c}\begin{array}{c}\text { Silico- } \\
\text { flagellates }\end{array} \\
\text { R }\end{array}$} & \multirow{3}{*}{$\begin{array}{c}\begin{array}{c}\text { Sponge } \\
\text { spicules }\end{array} \\
\mathrm{A}\end{array}$} & \multicolumn{2}{|c|}{ Radiolarians } \\
\hline & & & Pennates & Centrics & & & Abundance & Preservation \\
\hline $105-646 \mathrm{~A}-$ & $1 \mathrm{H}-1,13-15$ & & A & C & & & A & F \\
\hline & $1 \mathrm{H}-2,10-12$ & C & A & A & $\mathrm{R}$ & C & C & P \\
\hline & $1 \mathrm{H}-3,13-15$ & A & C & C & $\mathrm{R}$ & A & C & F \\
\hline & $1 \mathrm{H}-4,13-15$ & A & $\mathrm{R}$ & C & R & C & F & - \\
\hline & $24-1,48-50$ & C & C & F & $\mathbf{R}$ & A & A & F \\
\hline & $2 \mathrm{H}-2,48-50$ & A & $\mathbf{R}$ & $\mathrm{R}$ & $\mathrm{R}$ & F & R & - \\
\hline & $2 \mathrm{H}-3,48-50$ & A & $\mathbf{R}$ & R & $\mathbf{R}$ & C & F & P \\
\hline & $2 \mathrm{H}-4,48-50$ & A & R & $\mathrm{R}$ & R & A & A & P \\
\hline & $2 \mathrm{H}-5,48-50$ & A & C & $\mathrm{F}$ & $\mathbf{R}$ & A & C & F \\
\hline & $2 \mathrm{H}-6,49-51$ & A & $\mathrm{R}$ & C & R & A & A & F \\
\hline & $2, \mathrm{CC}$ & & & & & A & C & G \\
\hline & $3 \mathrm{H}-1,51-59$ & A & A & A & R & A & C & $\mathrm{F}$ \\
\hline & $3 \mathrm{H}-2,57-59$ & A & $\mathbf{R}$ & F & $\mathrm{R}$ & F & C & F \\
\hline & $3 \mathrm{H}-3,57-59$ & A & R & R & R & F & F & F \\
\hline & $3 \mathrm{H}-4,57-59$ & A & $R$ & A & $R$ & C & C & G \\
\hline & $3 \mathrm{H}-5,60-62$ & A & $\mathrm{R}$ & R & $\mathrm{R}$ & A & A & G \\
\hline & 3, CC & - & - & $\mathrm{R}$ & - & C & F & F \\
\hline & $4, \mathrm{CC}$ & - & - & - & & C & F & G \\
\hline & $5, \mathrm{CC}$ & - & - & A & - & C & C & G \\
\hline & $6, \mathrm{CC}$ & - & - & - & & R & - & - \\
\hline & $7, \mathrm{CC}$ & - & - & - & - & R & $\mathrm{R}$ & $P$ \\
\hline & $8, \mathrm{CC}$ & - & - & - & - & A & - & - \\
\hline & 9, CC & - & - & - & - & C & C & G \\
\hline & $10, \mathrm{CC}$ & - & - & $\mathbf{R}$ & - & C & - & - \\
\hline & $11, \mathrm{CC}$ & - & - & R & - & A & $\mathrm{F}$ & G \\
\hline 105-646B- & $1 \mathrm{H}-1,15-17$ & A & $\mathrm{R}$ & A & $\mathrm{R}$ & A & A & G \\
\hline & $1 \mathrm{H}-2,15-17$ & A & $\mathrm{R}$ & A & R & F & C & P \\
\hline & $1 \mathrm{H}-3,15-17$ & A & $\mathrm{R}$ & F & $\mathbf{R}$ & C & C & F \\
\hline & $1 \mathrm{H}-4,15-17$ & A & $\mathrm{R}$ & $\mathrm{F}$ & R & A & C & P \\
\hline & $1 \mathrm{H}-5,15-17$ & A & $\mathrm{R}$ & C & $\mathbf{R}$ & A & C & F \\
\hline & $1 \mathrm{H}-6,15-17$ & A & $\mathrm{R}$ & c & $\mathrm{R}$ & A & A & $\mathbf{P}$ \\
\hline & $1, \mathrm{CC}$ & A & & & & A & C & G \\
\hline & $2 \mathrm{H}-3,15-17$ & C & A & F & $\mathrm{R}$ & A & C & P \\
\hline & $2 \mathrm{H}-4,15-17$ & A & C & F & R & A & A & F \\
\hline & $2 \mathrm{H}-5,15-17$ & A & A & C & $\mathbf{R}$ & A & A & F \\
\hline & $2 \mathrm{H}-6,15-17$ & A & R & $\mathrm{R}$ & $\mathbf{R}$ & F & F & - \\
\hline & $2, \mathrm{CC}$ & & & & & F & $\mathrm{R}$ & G \\
\hline & $3 \mathrm{H}-1,56-58$ & A & $\mathbf{R}$ & F & $\mathbf{R}$ & C & F & - \\
\hline & $3 \mathrm{H}-2,56-58$ & A & $\mathbf{R}$ & C & $\mathbf{R}$ & A & C & $\mathrm{P}$ \\
\hline & $3 \mathrm{H}-3,56-58$ & A & $\mathbf{R}$ & A & $\mathrm{R}$ & F & F & P \\
\hline & $3 \mathrm{H}-4,56-58$ & C & A & F & $\mathbf{R}$ & A & A & $\mathrm{P}$ \\
\hline & $3 \mathrm{H}-5,56-58$ & A & R & $\mathrm{F}$ & $\mathrm{R}$ & $\mathrm{F}$ & F & - \\
\hline & $3 \mathrm{H}-6,56-58$ & A & A & A & $\mathbf{R}$ & A & C & G \\
\hline & $3, \mathrm{CC}$ & A & A & & & A & A & G \\
\hline & $4 \mathrm{H}-2,30-32$ & A & F & $\mathrm{F}$ & $\mathbf{R}$ & A & A & $\mathrm{P}$ \\
\hline & $4 \mathrm{H}-3,30-32$ & A & $\mathrm{R}$ & $\mathrm{R}$ & $\mathbf{R}$ & $\mathrm{F}$ & $\mathrm{R}$ & - \\
\hline & $4 \mathrm{H}-4,30-32$ & A & R & $\mathbf{R}$ & $\mathbf{R}$ & C & C & $\mathrm{P}$ \\
\hline & $4 \mathrm{H}-5,30-32$ & A & C & C & $\mathrm{R}$ & A & A & P \\
\hline & 4, CC & - & C & $\overline{-}$ & - & A & A & E \\
\hline & $5, \mathrm{CC}$ & - & - & $\mathrm{F}$ & - & C & $\mathbf{R}$ & G \\
\hline & $6, \mathrm{CC}$ & - & - & - & - & $\mathrm{R}$ & - & - \\
\hline & 7, CC & - & - & - & - & $\mathrm{F}$ & - & - \\
\hline & $9, \mathrm{CC}$ & - & - & - & - & A & A & G \\
\hline & $10, \mathrm{CC}$ & - & - & - & - & A & A & G \\
\hline & $11, \mathrm{CC}$ & - & - & - & - & C & F & F \\
\hline & $12-2,11-13$ & A & $\mathrm{R}$ & $\mathrm{R}$ & $\mathrm{R}$ & C & $\mathrm{R}$ & - \\
\hline & $12-5,22-24$ & A & $\mathrm{R}$ & $\mathrm{R}$ & $\mathbf{R}$ & A & $\mathbf{R}$ & - \\
\hline & $12, \mathrm{CC}$ & - & - & - & - & A & $\mathrm{R}$ & P \\
\hline & $13-2,61-63$ & A & R & $\mathrm{R}$ & $\mathrm{R}$ & $\mathbf{R}$ & $\mathrm{R}$ & $\mathbf{R}$ \\
\hline & $13-5,88-90$ & A & R & $\mathrm{R}$ & R & C & F & P \\
\hline & $13, \mathrm{CC}$ & & & & & C & R & F \\
\hline & $14-2,64-66$ & A & $\mathrm{R}$ & $\mathbf{R}$ & $\mathrm{R}$ & $\mathrm{F}$ & $\mathrm{R}$ & - \\
\hline & $14-5,81-83$ & A & $\mathbf{R}$ & $\mathbf{R}$ & $\mathbf{R}$ & C & $\mathbf{R}$ & - \\
\hline & $14, \mathrm{CC}$ & - & - & - & - & $\mathbf{R}$ & - & - \\
\hline & $16, \mathrm{CC}$ & - & - & $\mathbf{R}$ & - & C & C & G \\
\hline & $17, \mathrm{CC}$ & - & - & - & - & C & F & G \\
\hline & $18-1,144-146$ & A & $\mathrm{R}$ & $\mathbf{R}$ & $\mathbf{R}$ & $\mathrm{R}$ & $\mathbf{R}$ & - \\
\hline & $18-2,44-46$ & A & $\mathbf{R}$ & $\mathrm{R}$ & $\mathrm{R}$ & F & F & - \\
\hline & $18-3,85-87$ & A & $\mathrm{R}$ & R & $\mathrm{R}$ & $\mathrm{F}$ & R & - \\
\hline & $18, \mathrm{CC}$ & - & - & - & - & C & $\mathbf{R}$ & G \\
\hline & $19, \mathrm{CC}$ & - & - & - & - & A & F & G \\
\hline & $20-2,7-9$ & A & $\mathbf{R}$ & $\mathbf{R}$ & $\mathbf{R}$ & C & F & $\mathrm{P}$ \\
\hline & $20-5,108-110$ & A & $\mathbf{R}$ & $\mathrm{R}$ & $\mathbf{R}$ & C & C & G \\
\hline & $20, \mathrm{CC}$ & - & - & - & - & $\mathbf{R}$ & $\mathbf{R}$ & $\mathrm{F}$ \\
\hline & $21-2,118-120$ & A & $\mathrm{R}$ & $\mathbf{R}$ & $\mathbf{R}$ & C & C & F \\
\hline & $21-4,118-120$ & A & $\mathrm{R}$ & $\mathrm{R}$ & $\mathrm{R}$ & $\mathrm{F}$ & F & - \\
\hline
\end{tabular}


Appendix (continued).

\begin{tabular}{|c|c|c|c|c|c|c|c|c|}
\hline \multirow{2}{*}{\multicolumn{2}{|c|}{$\begin{array}{c}\text { Sample } \\
\text { interval }(\mathrm{cm})\end{array}$}} & \multirow[b]{2}{*}{ Lithics } & \multicolumn{2}{|c|}{ Diatoms } & \multirow{2}{*}{$\begin{array}{l}\text { Silico- } \\
\text { flagellates }\end{array}$} & \multirow{2}{*}{$\begin{array}{l}\text { Sponge } \\
\text { spicules }\end{array}$} & Radic & arians \\
\hline & & & Pennates & Centrics & & & Abundance & Preservation \\
\hline $105-646 \mathrm{E}$ & $3-21, C C$ & & & A & - & A & A & E \\
\hline (Cont.) & $22-2,7-9$ & A & $\mathbf{R}$ & $\mathrm{F}$ & $\mathrm{R}$ & $\mathrm{F}$ & $\mathbf{R}$ & - \\
\hline & $22-6,844-86$ & A & $\mathrm{R}$ & $\mathrm{F}$ & $\mathrm{R}$ & A & $\mathrm{F}$ & - \\
\hline & $22, \mathrm{CC}$ & & & C & - & A & A & G \\
\hline & $23-2,8-10$ & A & $\mathbf{R}$ & C & $\mathbf{R}$ & $\mathrm{C}$ & $\mathbf{F}$ & - \\
\hline & $23-5,122-124$ & A & $\mathbf{R}$ & $\mathbf{R}$ & $\mathbf{R}$ & A & C & G \\
\hline & $23, \mathrm{CC}$ & - & - & $\mathrm{F}$ & - & A & A & G \\
\hline & $25, \mathrm{CC}$ & - & F & F & - & C & A & G \\
\hline & $26-2,20-22$ & A & $\mathrm{R}$ & $\mathrm{F}$ & $\mathbf{R}$ & C & C & G \\
\hline & $26-5,125-127$ & A & $\mathrm{R}$ & $\mathbf{R}$ & $\mathbf{R}$ & $\mathrm{F}$ & F & - \\
\hline & $26, \mathrm{CC}$ & - & - & - & - & $\mathrm{C}$ & $\mathrm{F}$ & F \\
\hline & $28, \mathrm{CC}$ & - & - & F & - & A & $\mathrm{F}$ & P \\
\hline & $29-2,14-16$ & A & $\mathrm{R}$ & $\mathbf{R}$ & $\mathbf{R}$ & $\mathrm{F}$ & $\mathrm{F}$ & - \\
\hline & $29-5,88-90$ & A & $\mathrm{F}$ & R & $\mathrm{R}$ & A & C & $\mathbf{P}$ \\
\hline & $29, \mathrm{CC}$ & - & - & $\mathrm{F}$ & - & A & A & G \\
\hline & $30-2,73-75$ & A & C & $\mathrm{R}$ & $\mathbf{R}$ & C & F & - \\
\hline & $30-5,63-65$ & A & C & R & $\mathrm{R}$ & $\mathrm{R}$ & $\mathrm{F}$ & - \\
\hline & $31-2,10-12$ & A & $\mathrm{R}$ & $\mathbf{R}$ & $\mathbf{R}$ & C & $\mathbf{R}$ & - \\
\hline & $31-6,76-78$ & A & R & $\ddot{R}$ & R & $\mathrm{C}$ & $\mathrm{F}$ & - \\
\hline & $31, \mathrm{CC}$ & & & $\mathrm{F}$ & & A & A & $\mathrm{F}$ \\
\hline & $32-2,58-60$ & A & $\mathbf{R}$ & R & $\mathrm{R}$ & A & $\mathrm{F}$ & - \\
\hline & $32-6,98-100$ & A & $\mathrm{C}$ & $\mathrm{R}$ & $\mathrm{R}$ & C & $\mathrm{F}$ & - \\
\hline & $32, \mathrm{CC}$ & & & $\mathrm{F}$ & & C & C & $\mathrm{F}$ \\
\hline & $33-2,4-6$ & A & $\mathrm{R}$ & $\mathrm{R}$ & $\mathrm{R}$ & $\mathrm{F}$ & $\mathbf{R}$ & - \\
\hline & $33-5,129-131$ & A & $\mathrm{R}$ & $\vec{F}$ & $\mathrm{R}$ & A & $\mathrm{C}$ & G \\
\hline & $33, \mathrm{CC}$ & - & - & - & - & C & $\mathrm{R}$ & $\mathbf{P}$ \\
\hline & $34, \mathrm{CC}$ & - & - & $\mathrm{R}$ & - & A & A & F \\
\hline & $35-2,9-11$ & A & $\mathbf{R}$ & R & $\mathbf{R}$ & C & $\mathrm{F}$ & - \\
\hline & $35-3,8-10$ & A & $\mathrm{R}$ & R & R & $\mathbf{R}$ & $\mathrm{F}$ & - \\
\hline & $36-2,3-7$ & A & $\mathrm{R}$ & $\mathrm{F}$ & R & $\mathrm{R}$ & $\mathrm{R}$ & - \\
\hline & $36-6,138-140$ & A & $\mathrm{R}$ & $\mathbf{R}$ & $\mathrm{R}$ & $\mathrm{F}$ & $\mathbf{R}$ & - \\
\hline & $36, \mathrm{CC}$ & - & - & - & - & - & - & - \\
\hline & 37 & A & $\mathrm{R}$ & $\mathrm{R}$ & $\mathbf{R}$ & $\mathbf{R}$ & $\mathbf{R}$ & - \\
\hline & $37-2,16-18$ & A & $\mathrm{R}$ & $\mathrm{R}$ & $\mathrm{R}$ & $\mathbf{R}$ & $\mathrm{R}$ & - \\
\hline & $37, \mathrm{CC}$ & - & - & - & - & - & - & - \\
\hline $105-647 A$ & $-12-2,8-10$ & A & $\mathbf{R}$ & $\mathrm{R}$ & $\mathbf{R}$ & $\mathrm{R}$ & $\mathrm{F}$ & - \\
\hline & $12-4,69-71$ & A & $\mathrm{F}$ & $\mathrm{F}$ & R & $\mathrm{F}$ & $\mathrm{F}$ & - \\
\hline & $13-2,102-104$ & A & F & C & $\mathrm{R}$ & $\mathrm{F}$ & $\mathrm{F}$ & - \\
\hline & $13-4,91-93$ & A & $\mathrm{R}$ & $\mathrm{C}$ & R & C & A & G \\
\hline & $14-2,145-147$ & A & $\mathrm{R}$ & A & $\mathrm{C}$ & A & A & $\mathrm{F}$ \\
\hline & $14-2,7-9$ & A & $\mathrm{R}$ & C & $\mathrm{R}$ & A & C & $\mathrm{F}$ \\
\hline & $15-2,16-18$ & $\mathrm{~F}$ & $\mathrm{R}$ & C & $\mathrm{R}$ & $\mathrm{C}$ & A & $\mathrm{P}$ \\
\hline & $15-3,65-67$ & C & C & A & $\mathrm{R}$ & A & A & G \\
\hline & $16-2,54-59$ & $\mathrm{~F}$ & $\mathrm{~F}$ & $\mathrm{C}$ & $\mathrm{R}$ & A & A & G \\
\hline & $17-1,107-112$ & $\mathrm{R}$ & $\mathrm{R}$ & A & $\mathrm{F}$ & A & A & G \\
\hline & $17-2,116-121$ & $\mathrm{~F}$ & $\mathbf{R}$ & $\mathrm{F}$ & $\mathrm{R}$ & A & A & E \\
\hline & $17-3,45-50$ & $\mathrm{~F}$ & $\mathrm{R}$ & A & R & A & A & G \\
\hline & $17-4,88-93$ & $\mathrm{R}$ & $\mathrm{R}$ & C & $\mathrm{R}$ & A & A & G \\
\hline & $17-5,99-105$ & $\mathrm{R}$ & $\mathrm{R}$ & A & $\mathrm{R}$ & A & A & $\mathbf{P}$ \\
\hline & $17-6,25-30$ & $\mathrm{R}$ & $\mathrm{R}$ & A & $\mathrm{F}$ & A & A & G \\
\hline & $18-1,70-75$ & $\mathrm{C}$ & R & C & R & C & A & $\mathbf{P}$ \\
\hline & $18-2,78-82$ & $\mathrm{R}$ & R & $\mathrm{F}$ & $\mathrm{F}$ & A & A & G \\
\hline & $19-1,96-100$ & R & $\mathrm{R}$ & A & $\mathrm{R}$ & A & A & G \\
\hline & $19-2,105-110$ & $\mathrm{~F}$ & $\mathrm{R}$ & C & $\mathrm{R}$ & A & A & E \\
\hline & $19-2,48-50$ & $\mathrm{R}$ & $\mathrm{R}$ & $\mathbf{R}$ & $\mathrm{R}$ & C & C & - \\
\hline & $19-3,112-116$ & R & $\mathrm{F}$ & A & $\mathrm{F}$ & A & A & E \\
\hline & $19-4,115-119$ & $\mathrm{C}$ & $\mathrm{F}$ & A & $\mathbf{R}$ & A & A & E \\
\hline & $19-4,50-52$ & $\mathrm{~F}$ & $\mathrm{R}$ & $\mathrm{R}$ & $\mathrm{R}$ & C & A & G \\
\hline & $19-5,26-30$ & R & $\mathrm{F}$ & A & $\mathrm{R}$ & A & A & G \\
\hline & $19-6,117-121$ & $\mathrm{R}$ & $\mathrm{R}$ & A & $\mathrm{C}$ & A & A & E \\
\hline & $19-6,50-52$ & $\hat{R}$ & $\mathrm{R}$ & $\mathrm{R}$ & $\mathbf{R}$ & $\mathrm{F}$ & A & G \\
\hline & $20-1,48-50$ & $\mathrm{R}$ & $\mathrm{R}$ & $\mathrm{R}$ & $\mathrm{R}$ & $\mathrm{C}$ & A & G \\
\hline & $20-1,91-94$ & R & $\mathrm{R}$ & A & C & C & A & G \\
\hline & $20-2,90-94$ & $\mathrm{~F}$ & $\mathrm{R}$ & A & $\mathrm{C}$ & A & A & G \\
\hline & $20-3,52-54$ & $\mathrm{~F}$ & R & C & $\mathrm{R}$ & $\mathrm{F}$ & $\mathrm{C}$ & $P$ \\
\hline & $20-3,90-94$ & C & R & $\mathrm{F}$ & $\mathrm{F}$ & C & A & $\mathrm{P}$ \\
\hline & $20-4,84-89$ & C & $\hat{R}$ & A & $\mathrm{R}$ & C & A & G \\
\hline & $20-5,50-52$ & F & $\mathrm{R}$ & $\mathrm{F}$ & $\mathrm{R}$ & C & A & G \\
\hline & $20-5,80-92$ & R & $\mathrm{F}$ & A & F & A & A & G \\
\hline & $21-1,13-16$ & R & $\mathrm{R}$ & A & $\mathrm{R}$ & A & A & E \\
\hline & $21-1,48-50$ & $\mathrm{C}$ & $\mathrm{R}$ & $\mathrm{R}$ & $\mathrm{R}$ & C & A & G \\
\hline & $21-2,13-16$ & $\mathrm{~F}$ & R & A & $\mathrm{R}$ & A & A & G \\
\hline & $21-3,13-16$ & $\mathrm{R}$ & $\hat{F}$ & A & $\mathrm{R}$ & A & A & E \\
\hline & $21-3,48-50$ & $\mathrm{~F}$ & $\mathrm{R}$ & A & $\mathrm{R}$ & $\mathrm{F}$ & A & $\mathrm{P}$ \\
\hline & $23-1,57-59$ & R & $\mathrm{R}$ & $\mathrm{R}$ & $\mathrm{R}$ & R & C & G \\
\hline & $23-1,97-100$ & $\mathrm{R}$ & $\mathrm{R}$ & A & $\mathrm{R}$ & A & A & E \\
\hline & $23-2,95-98$ & $\ddot{R}$ & $\ddot{R}$ & $\mathrm{~A}$ & R & A & A & G \\
\hline
\end{tabular}


Appendix (continued).

\begin{tabular}{|c|c|c|c|c|c|c|c|c|}
\hline \multirow{2}{*}{\multicolumn{2}{|c|}{$\begin{array}{c}\text { Sample } \\
\text { interval }(\mathrm{cm})\end{array}$}} & \multirow[b]{2}{*}{ Lithics } & \multicolumn{2}{|c|}{ Diatoms } & \multirow{2}{*}{$\begin{array}{l}\text { Silico- } \\
\text { flagellates }\end{array}$} & \multirow{2}{*}{$\begin{array}{l}\text { Sponge } \\
\text { spicules }\end{array}$} & \multicolumn{2}{|c|}{ Radiolarians } \\
\hline & & & Pennates & Centrics & & & Abundance & Preservation \\
\hline \multirow{50}{*}{$\begin{array}{l}105-647 \\
\text { (Cont.) }\end{array}$} & A-23-3, 89-91 & $\mathrm{R}$ & $\mathrm{R}$ & $\mathrm{R}$ & $\mathrm{F}$ & A & A & E \\
\hline & $23-4,75-78$ & $\mathrm{~F}$ & $\mathrm{R}$ & A & $\mathrm{F}$ & A & A & E \\
\hline & $23-5,66-69$ & R & $\mathrm{R}$ & C & R & $\mathrm{F}$ & A & E \\
\hline & $24-2,46-49$ & $\mathrm{R}$ & $\mathrm{R}$ & A & $\mathrm{F}$ & C & C & G \\
\hline & $24-2,83-85$ & $\mathrm{R}$ & $\mathrm{R}$ & $\mathrm{R}$ & $\mathbf{R}$ & C & A & G \\
\hline & $24-3,62-65$ & $\mathrm{R}$ & F & A & $\mathrm{R}$ & A & A & G \\
\hline & $24-4,31-34$ & $\mathrm{R}$ & $\mathrm{R}$ & A & $\mathrm{F}$ & A & A & G \\
\hline & $24-4,86-88$ & $\mathrm{~F}$ & $\mathrm{R}$ & C & $\mathrm{R}$ & $\mathrm{F}$ & A & G \\
\hline & $25-1,107-110$ & $\mathrm{R}$ & $\mathrm{R}$ & A & $\mathrm{R}$ & A & A & E \\
\hline & $25-2,107-110$ & $\mathrm{R}$ & $\mathrm{R}$ & A & $\mathrm{R}$ & A & A & G \\
\hline & $25-3,107-110$ & $\mathbf{R}$ & $\mathrm{F}$ & A & $\mathrm{F}$ & A & A & F \\
\hline & $25-3,48-50$ & $\mathrm{~F}$ & $\mathrm{R}$ & $\mathrm{R}$ & R & A & A & G \\
\hline & $25-4,107-110$ & $\mathrm{R}$ & $\mathrm{R}$ & A & $\mathrm{F}$ & A & A & E \\
\hline & $25-5,107-110$ & $\mathrm{R}$ & - & A & $\mathrm{C}$ & A & A & G \\
\hline & $25-5,48-50$ & F & $\mathrm{R}$ & $\mathrm{R}$ & $\mathbf{R}$ & A & A & G \\
\hline & $28-1,105-108$ & $\mathrm{R}$ & $\mathrm{R}$ & F & $\mathrm{R}$ & - & F & - \\
\hline & $28-2,105-108$ & A & $\mathbf{R}$ & C & $\mathbf{R}$ & $\mathrm{F}$ & F & - \\
\hline & $28-3,102-105$ & F & $\mathrm{R}$ & $\mathrm{R}$ & $\mathbf{R}$ & R & $\mathrm{C}$ & F \\
\hline & $28-4,105-108$ & C & $\mathrm{R}$ & C & $\mathbf{R}$ & C & F & - \\
\hline & $30-1,107-111$ & $\mathrm{~F}$ & $\mathrm{R}$ & $\mathrm{R}$ & $\mathrm{R}$ & $\mathrm{R}$ & $\mathbf{R}$ & - \\
\hline & $30-2,25-29$ & C & $\mathrm{R}$ & $\mathbf{R}$ & $\mathbf{R}$ & $\mathrm{R}$ & $\mathrm{R}$ & - \\
\hline & $30-3,110-114$ & A & $\mathrm{R}$ & $\mathrm{F}$ & $\mathrm{R}$ & C & $\mathrm{R}$ & - \\
\hline & $30-4,107-111$ & C & $\mathrm{R}$ & F & $\mathbf{R}$ & $\mathrm{R}$ & $\mathbf{R}$ & - \\
\hline & $30-5,18-22$ & A & $\mathrm{R}$ & $\mathrm{F}$ & $\mathbf{R}$ & $\mathbf{R}$ & $\mathbf{R}$ & - \\
\hline & $30-6,105-106$ & F & $\mathrm{R}$ & $\mathbf{R}$ & $\mathrm{R}$ & $\mathrm{R}$ & $\mathrm{R}$ & - \\
\hline & $30-7,33-37$ & A & $\mathrm{R}$ & $\mathrm{F}$ & $\mathrm{R}$ & $\mathbf{R}$ & $\mathrm{R}$ & - \\
\hline & $31-1,132-136$ & A & $\mathrm{R}$ & C & $\mathrm{R}$ & $\mathbf{R}$ & $\mathrm{R}$ & - \\
\hline & $31-2,34-37$ & A & $\mathrm{R}$ & $\mathrm{R}$ & $\mathrm{R}$ & $\mathbf{R}$ & $\mathbf{R}$ & - \\
\hline & $32-1,89-93$ & C & $\mathrm{R}$ & $\mathbf{R}$ & $\mathbf{R}$ & $\mathbf{R}$ & C & $\mathrm{F}$ \\
\hline & $32-2,20-24$ & A & $\mathrm{R}$ & F & $\mathrm{R}$ & $\mathrm{R}$ & C & P \\
\hline & $33-2,26-28$ & C & $\mathrm{R}$ & $\mathbf{R}$ & $\mathbf{R}$ & F & $\mathrm{F}$ & $\mathbf{P}$ \\
\hline & $35-1,77-80$ & C & $\mathrm{R}$ & $\mathrm{F}$ & R & R & $\mathrm{R}$ & - \\
\hline & $35-2,77-80$ & A & $\mathrm{R}$ & $\mathrm{F}$ & $\mathrm{R}$ & R & $\mathbf{R}$ & $\mathbf{R}$ \\
\hline & $35-3,77-80$ & C & R & $\mathrm{F}$ & R & $\hat{R}$ & $\mathrm{R}$ & - \\
\hline & $36-1,49-52$ & C & $\mathrm{R}$ & $\mathrm{R}$ & $\mathrm{R}$ & $\mathbf{R}$ & $\mathrm{R}$ & - \\
\hline & $36-2,49-52$ & A & $\mathrm{R}$ & R & $\mathrm{R}$ & $\mathbf{R}$ & $\mathrm{R}$ & - \\
\hline & $36-3,49-52$ & C & $\mathbf{R}$ & F & $\mathbf{R}$ & $\mathrm{R}$ & $\mathrm{R}$ & - \\
\hline & $36-4,49-52$ & A & $\mathrm{R}$ & C & $\mathrm{F}$ & $\mathrm{F}$ & $\mathrm{F}$ & - \\
\hline & $37-2,90-93$ & A & $\mathbf{R}$ & $\mathbf{R}$ & $\mathbf{R}$ & $\mathrm{R}$ & $\mathrm{R}$ & - \\
\hline & $37-3,90-93$ & $\mathrm{C}$ & $\mathrm{R}$ & $\mathrm{F}$ & $\hat{R}$ & $\mathrm{R}$ & $\mathrm{R}$ & - \\
\hline & $37-4,90-93$ & A & R & $\mathrm{R}$ & R & R & $\mathrm{R}$ & - \\
\hline & $38-1,83-86$ & A & C & A & $\hat{R}$ & C & $\mathrm{F}$ & $\mathrm{P}$ \\
\hline & $38-2,84-87$ & A & $\mathrm{R}$ & $\mathrm{F}$ & $\mathrm{R}$ & $\mathrm{R}$ & $R$ & - \\
\hline & $38-3,86-89$ & C & $\mathrm{R}$ & F & $\mathrm{R}$ & $\mathrm{R}$ & $\mathrm{R}$ & - \\
\hline & $38-4,86-89$ & A & $\mathrm{R}$ & $\mathrm{F}$ & R & $\mathrm{R}$ & $\mathrm{R}$ & - \\
\hline & $38-5,87-90$ & $\mathrm{~F}$ & $\mathrm{R}$ & $\mathrm{F}$ & $\mathrm{R}$ & $\mathrm{R}$ & $\mathrm{R}$ & - \\
\hline & $38-6,87-89$ & C & R & $\mathrm{F}$ & $\mathrm{R}$ & $\mathrm{R}$ & $\mathbf{R}$ & - \\
\hline & $39-1,80-83$ & A & $\mathrm{R}$ & $\mathrm{R}$ & $\mathrm{R}$ & $\mathrm{R}$ & F & - \\
\hline & $39-2,77-80$ & A & $\mathrm{R}$ & $\mathrm{R}$ & $\mathrm{R}$ & $\mathrm{R}$ & $\mathrm{R}$ & - \\
\hline & $39-3,81-84$ & A & $R$ & $R$ & $R$ & $\mathrm{R}$ & $\mathbf{R}$ & - \\
\hline
\end{tabular}

Abundance: $\mathrm{A}=$ abundant, $\mathrm{C}=$ common, $\mathrm{R}=$ rare, $\mathrm{F}=$ few. Preservation: $\mathrm{E}=$ excellent, $\mathrm{G}=$ good, $\mathrm{P}=$ poor, $\mathrm{F}=$ fair. 


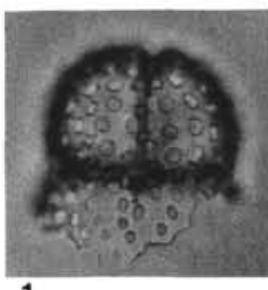

1

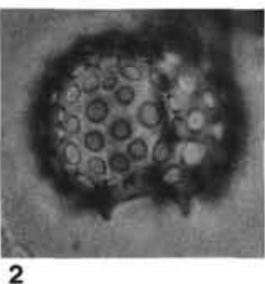

2

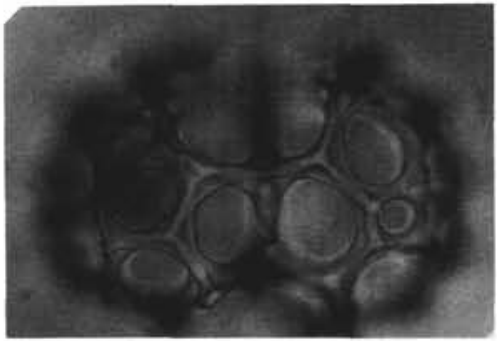

7

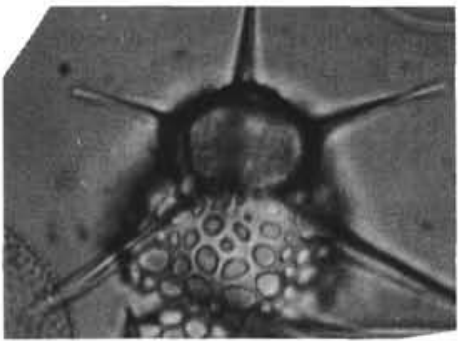

11

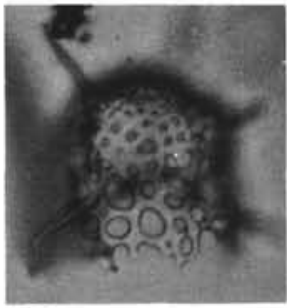

15

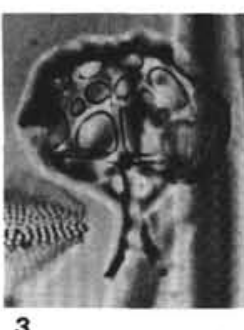

3

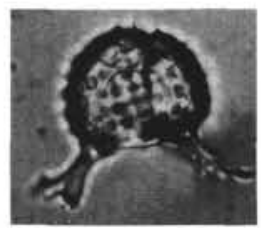

4

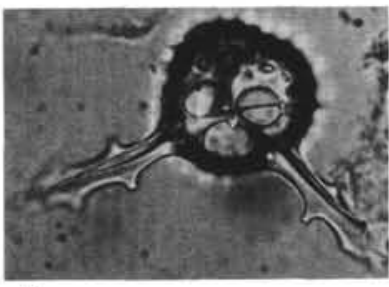

5

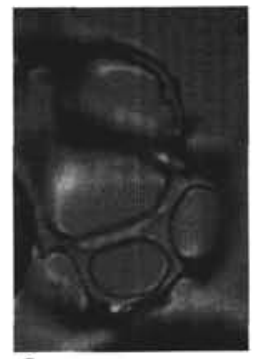

6
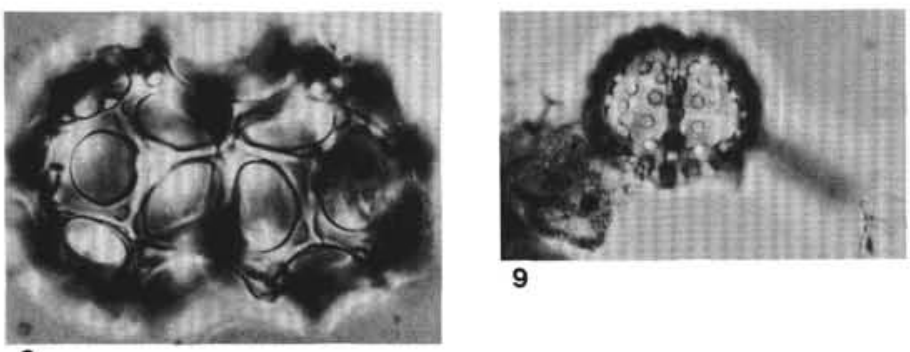

9

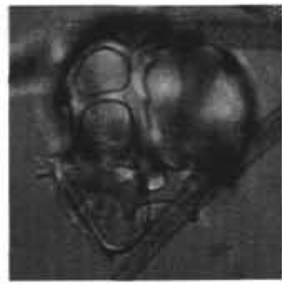

10

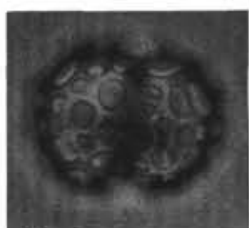

14

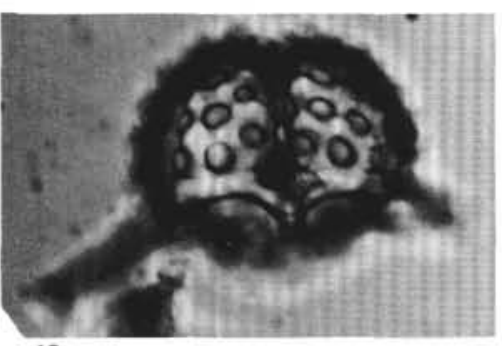

12

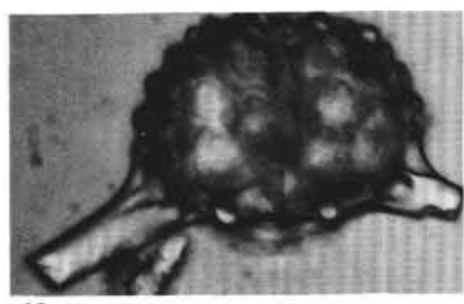

13

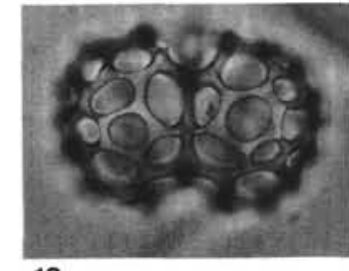

18

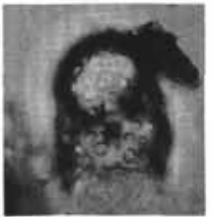

20

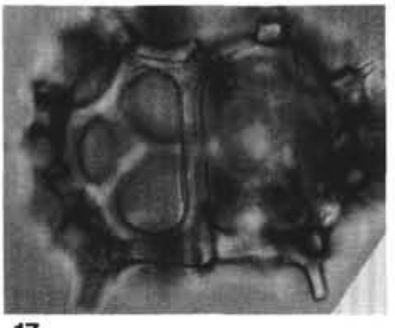

17

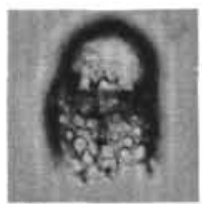

21

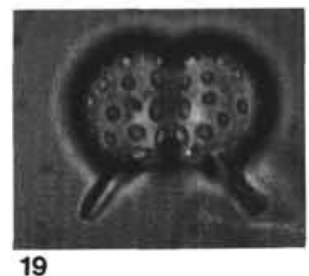

19

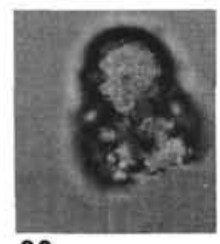

22

Plate 1. 1. Trissocyclid sp. B, 105-647A-14-2, $145 \# 2,5.9 / 91.1,27 \times$. 2. Trissocyclid sp. B, 105-647A-14-2, 145 \#2, 18.6/87.0, 27×. 3. Trissocyclid sp. C gr. 1, 105-647A-20-2, 90 \#2, 6.3/68.8, 27×. 4. Trissocyclid sp. C gr. 2, 105-647A-14-2, 145 \#2, 5.6/69.3, 27×. 5. Trissocyclid sp. C gr. 2, 105-647A-14-2, 7 \#2, 14.3/87.3, 27×. 6. Trissocyclid sp. E, 105-647A-24-2, 46\#2, 10.2/102.5, 17×. 7. Trissocyclid sp. D, 105-647A-13-4, 91 \#3, $7.9 / 79.5,27 \times$. 8. Trissocyclid sp. D, $105-647 \mathrm{~A}-13-4,91 \# 3,6.8 / 75.9,27 \times$. 9. Dorcadospyris sp., 105-647A-14-2, 145 \#2, 10.3/92.0, $17 \times$. 10. Trissocyclid sp. E, 105-647A-17-3, 45 \#3, 4.4/90.3, 27×. 11. Nassellarian gen. et sp. indet. \#3, 105-647A-20-2, 90 \#2. 7.4/89.0, 17×. 12. Dorcadospyris sp., 105-647A-14-2, $145 \# 2,19.3 / 71.5,27 \times$. 13. Dorcadospyris sp., 105-647A-14-2, 145 \#2, 19.3/71.5, 27× . 14. Corythospyris sp., 105-647A-14-2, $145 \# 2,8.0 / 89.2,27 \times$. 15. Nassellarian gen. et sp. indet. \#3, 105-647A-14-2, 145 \#2, 14.2/73.0, 27×. 16. Trissocyclid sp. A, 105-647A-14-2, $145 \# 2,7.9 / 86.0,27 \times$. 17. Trissocyclid sp. A, 105-647A-23-4, $75 \# 1,21.5 / 102.3,27 \times$. 18. Trissocyclid sp. A, 105-647A14-2, 145 \#2, 15.8/102.5, 27×. 19. Corythospyris sp., 105-647A-13-4, 91 \#3, 8.7/85.5, $27 \times$. 20. Antarctissa robusta, 105-647A-13-4, 91 \#3, $13.7 / 76.9,27 \times$. 21. Antarctissa robusta, 105-647A-13-4, $91 \# 3,16.5 / 101.4,27 \times$. 22. Antarctissa robusta, 105-647A-13-4, 91 \#3, 10.1/69.9, $27 \times$. 


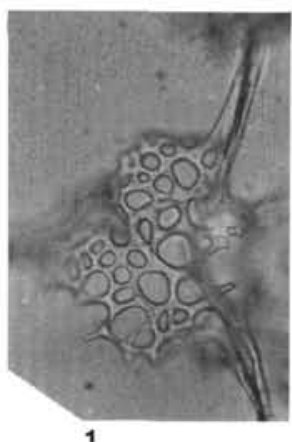

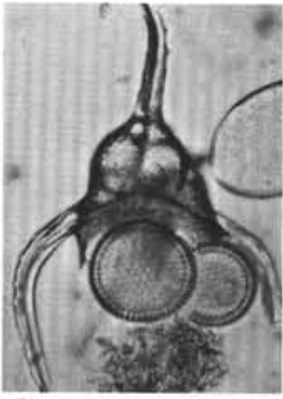

2

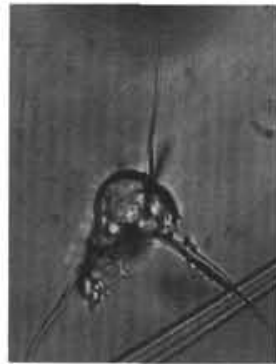

3

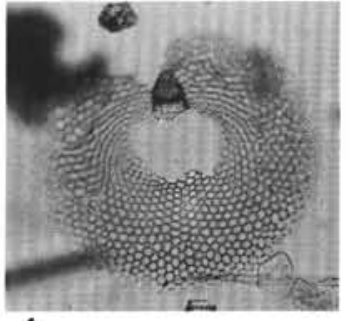

4

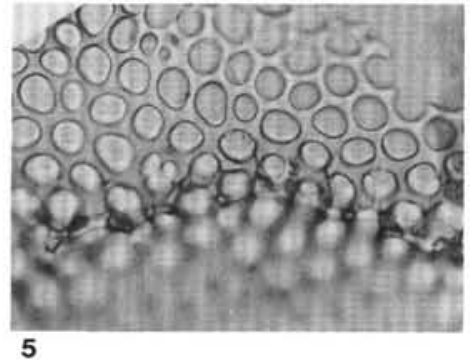

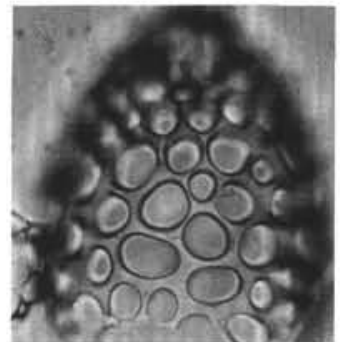

9

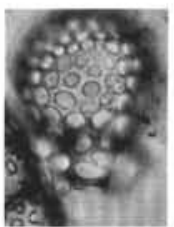

13

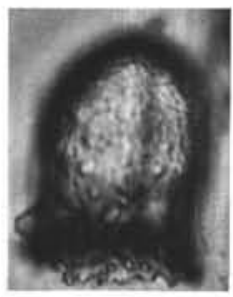

14

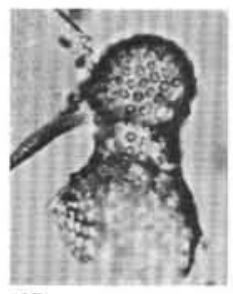

15

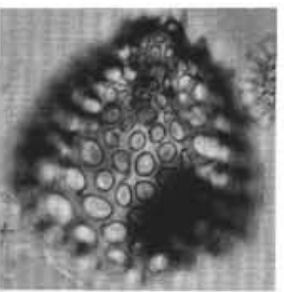

10

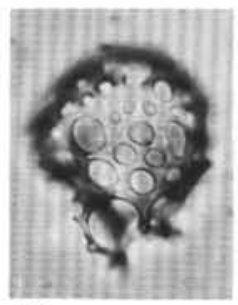

16

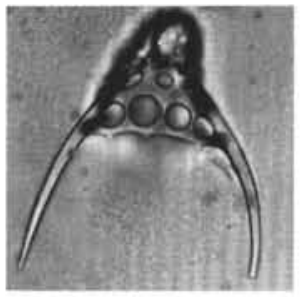

18

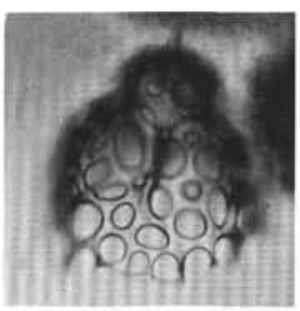

19

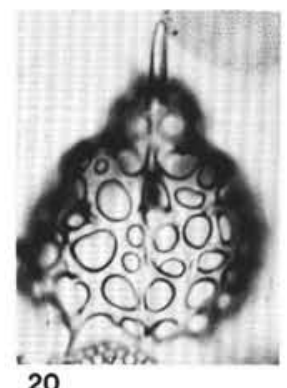

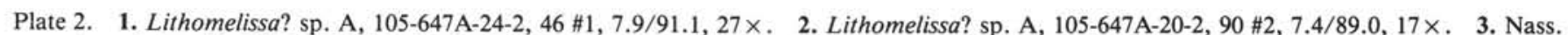

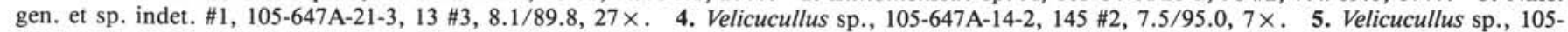

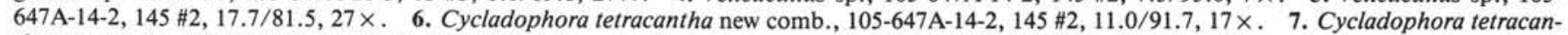

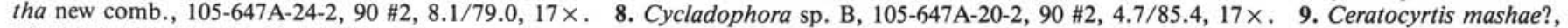

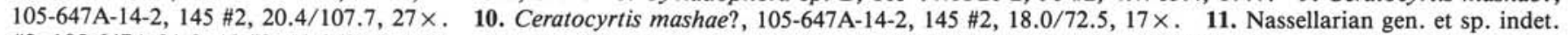

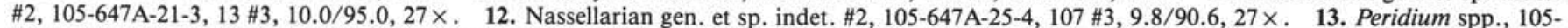

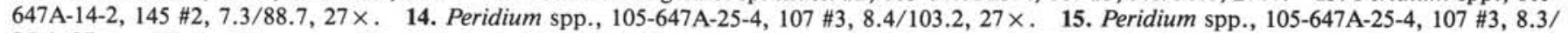

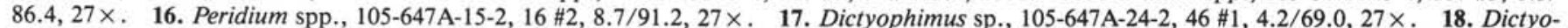

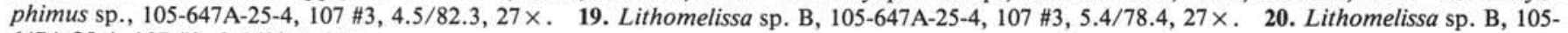
$647 \mathrm{~A}-25-4,107 \# 3,3.5 / 80.5,27 \times$. 


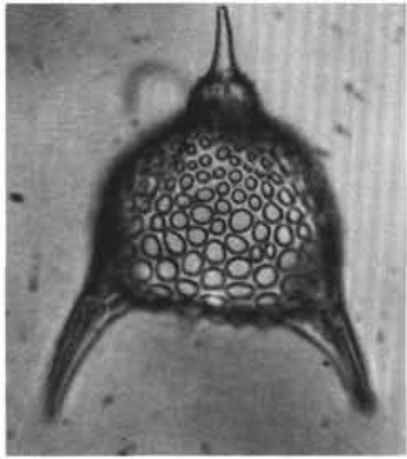

1
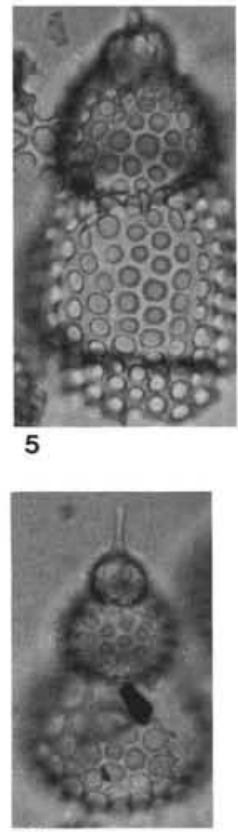

11
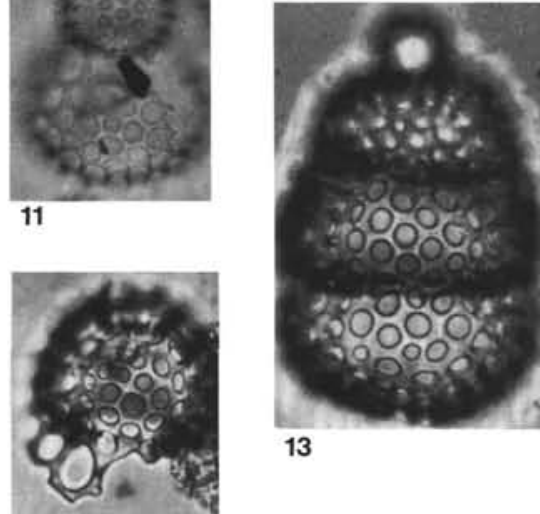

13

2

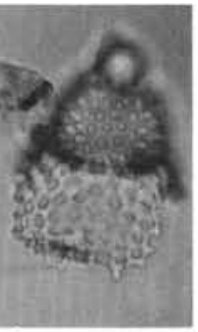

6
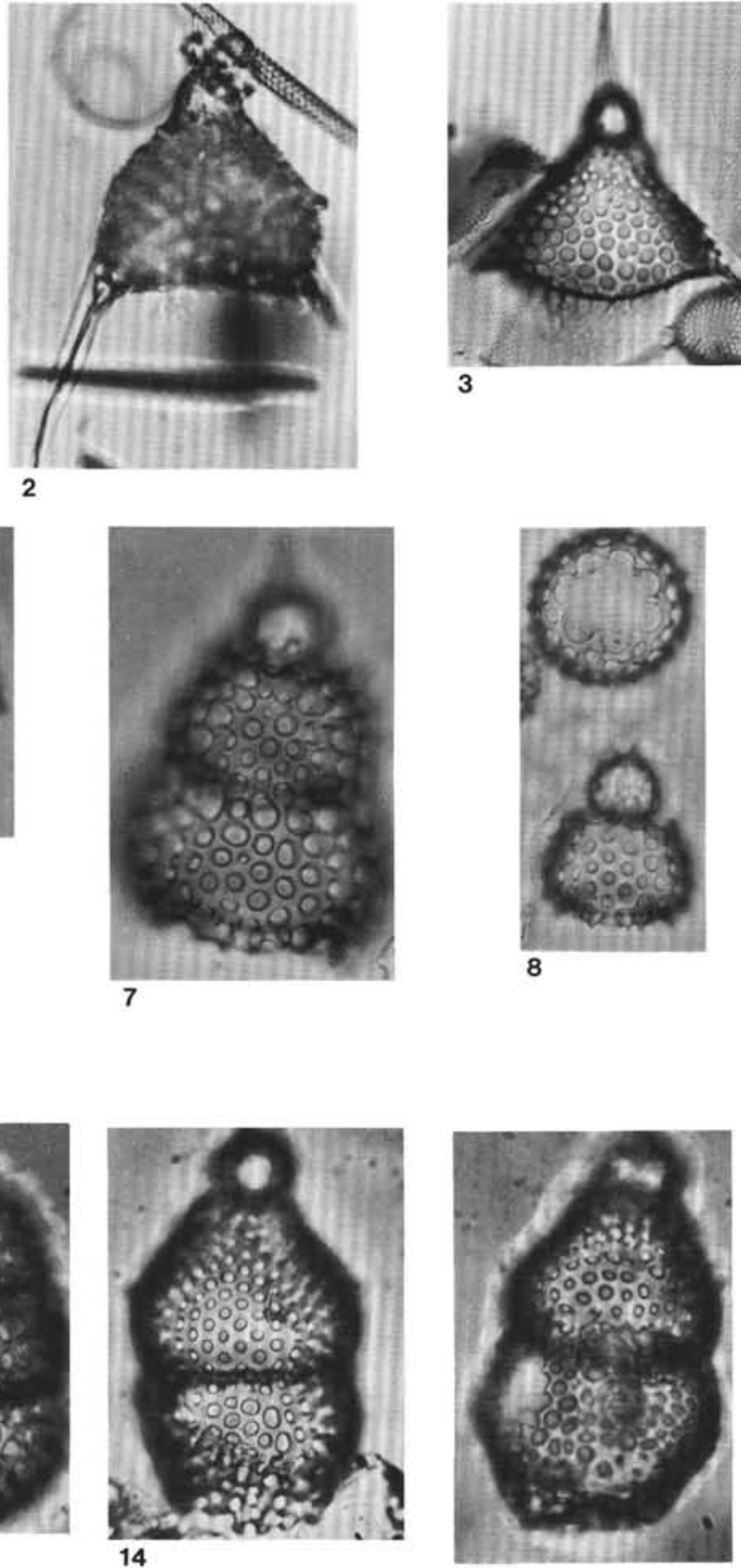
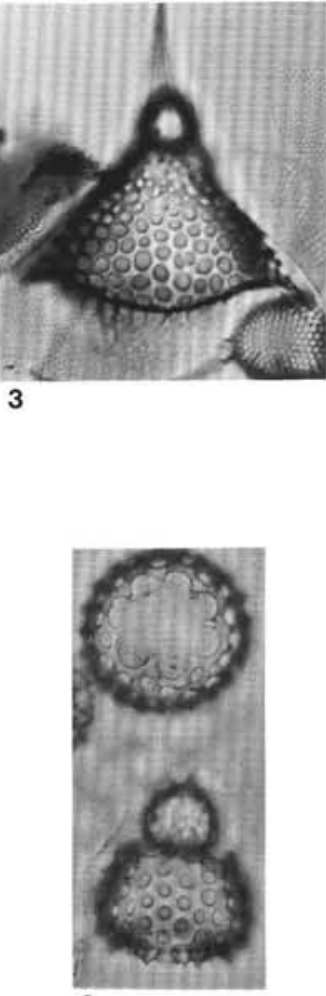

8
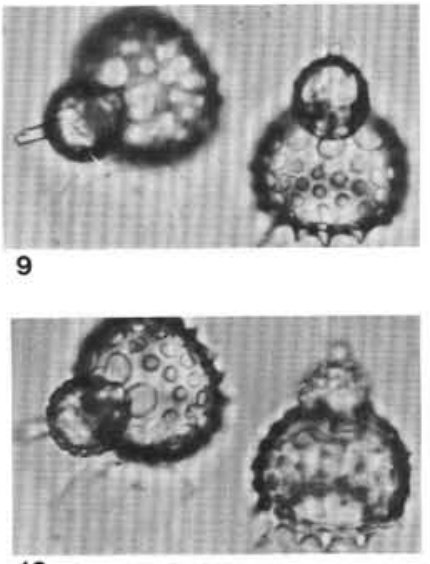

10

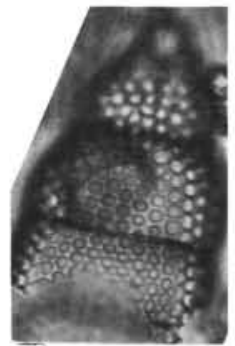

16

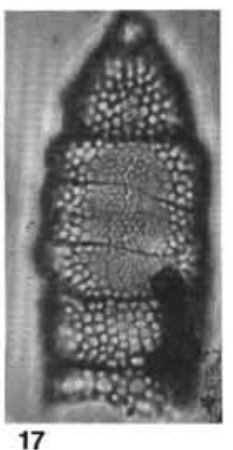

12

Plate 3. 1. Pterocanium sp. A, 647A-23-4, 75 \#1, 19.2/74.0, 17×. 2. Pterocanium sp. A, 647A-24-2, 46 \#2, 3.4/74.0, 17× 3. Pterocanium sp. B, 647A-20-2, 90 \#2, 4.9/75.4, $17 \times$. 4. Pterocanium sp. B, 647A-21-3, 13 \#3, 4.4/66.7, 27×. 5. Stichocorys sp. B (group), 647A-14-2, 7 \#2, 10.6/ $75.3,27 \times$. 6. Stichocorys sp. B (group), 647A-14-2, $145 \# 2,3.8 / 74.0,17 \times$. 7. Cyrtocapsella tetrapera (group), 647A-14-2, 145 \#2, 7.7/85.0, 27×. 8. Stichocorys sp. A, 647A-14-2, $145 \# 2,6.3 / 100.4,27 \times$. 9. Stichocorys sp. A, 647A-14-2, 145 \#2, $12.5 / 90.4,27 \times$. 10. Stichocorys sp. A, 647A$14-2,145 \# 2,12.5 / 90.4,27 \times$. 11. Eucyrtidium diaphanes, 647A-14-2, 7 \#2, 9.3/103.0, 17×. 12. Eucyrtidium diaphanes, 647A-13-4, 91 \#3, 9.0/ 92.4, 17×. 13. Cyrtocapsella tetrapera (group), 647A-13-4, 91 \#3, 18.3/101.5, 17×. 14. Calocyclas sp. B, 647A-13-4, 91 \#3, 9.3/83.3, 27×. 15. Calocyclas sp. B, 647A-14-2, $145 \# 2,2.0 / 101.0,27 \times$. 16. Eucyrtidium sp. A, 647A-21-3, 13 \#3, 2.3/70.2, 17× . 17. Eucyrtidium sp. A, 647A-21-3, 13 \#3, 6.1/103.5, $17 \times$. 


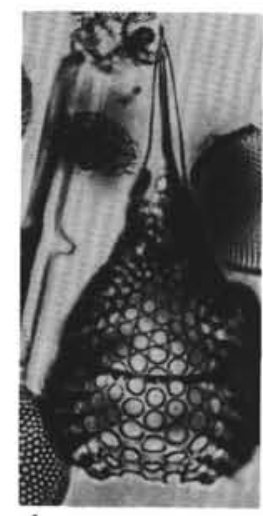

1
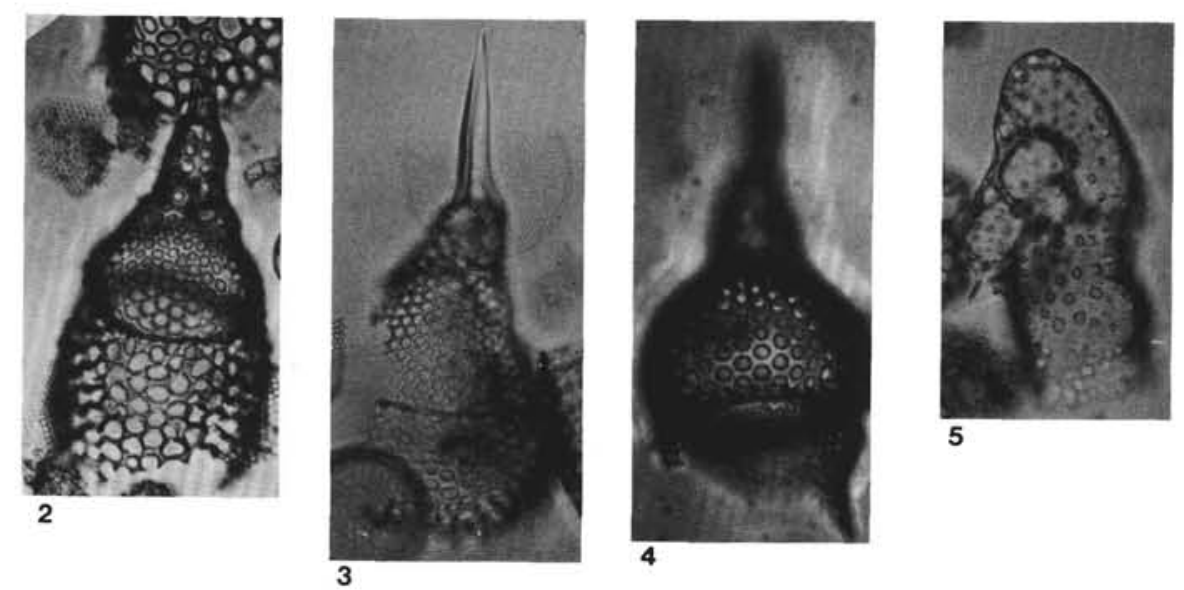

5

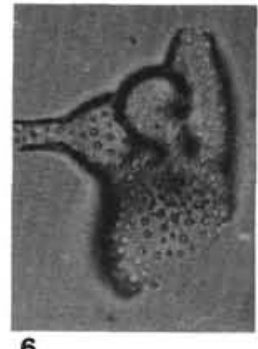

6
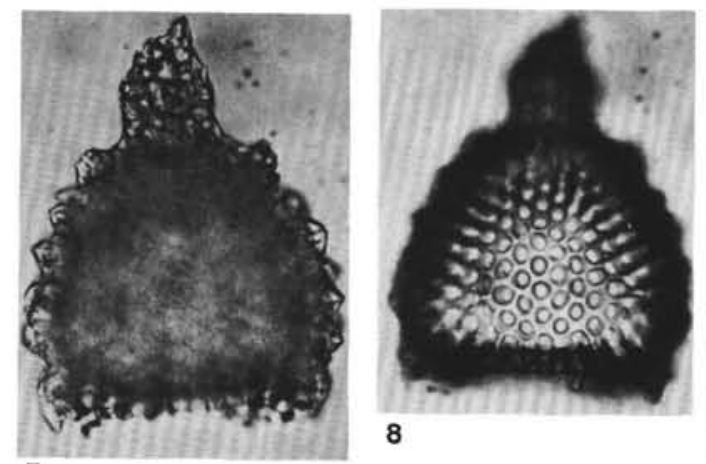

8

7
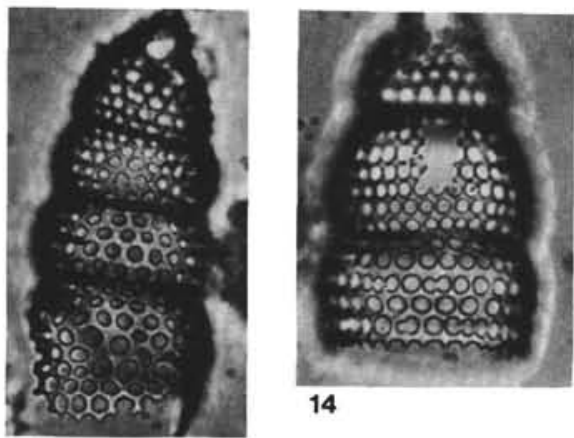

14

13
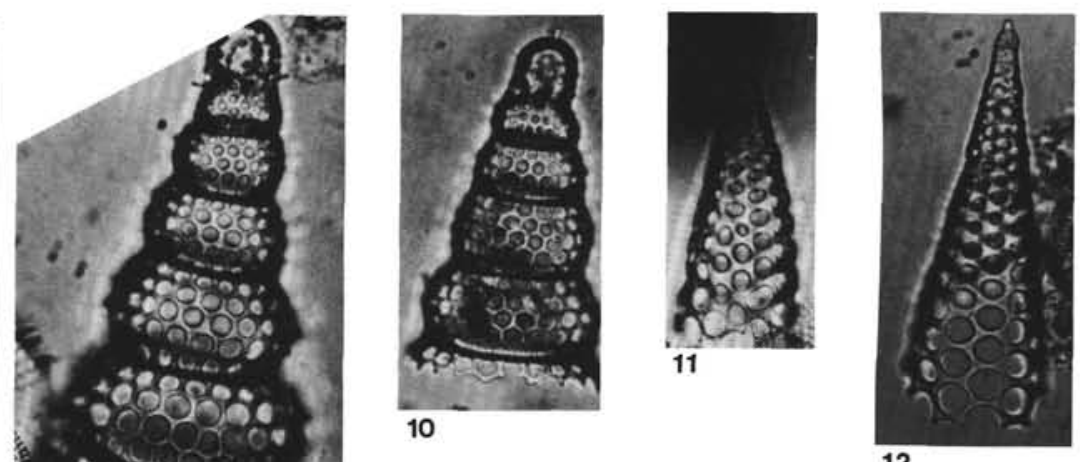

12
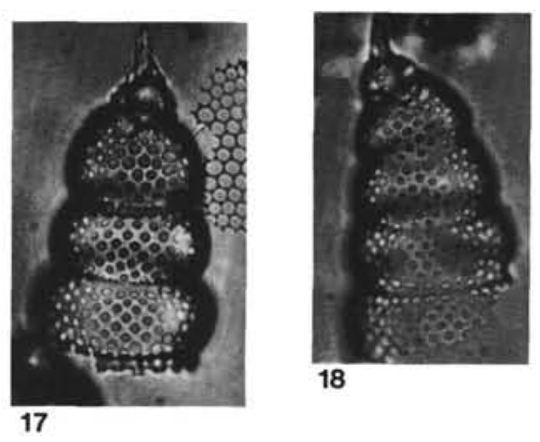

18

Plate 4. 1. Lamprocyclas sp., 105-647A-23-4, 75 31, 22.6/90.3, $27 \times$. 2. Lamprocyclas sp., 105-647A-20-2, 90 \#2, 9.8/68.2, 27×. 3. Lamprocyclas sp., 105-647A-23-4, 75 \#1, 22.6/90.3, 27×. 4. Calocycletta sp., 105-647A-20-2, 90 \#2, 7.9/70.1, 27×. 5. Cannobotryiidae (group), 105$647 \mathrm{~A}-23-4,75 \# 1,21.3 / 89.5,27 \times$. 6. Cannobotryiidae (group), 105-647A-14-2, $145 \# 2,11.6 / 67.1,27 \times$. 7. Theocyrtis tuberosa, 105-647A-19-4, $50 \# 3,21.8 / 103.0,27 \times$. 8. Theocyrtis tuberosa, 105-647A-19-4, $50 \# 3,21.8 / 103.0,27 \times$. 9. Cyrtopera laguncula, 105-647A-20-2, 90 \#2, 8.4/ $74.3,27 \times$. 10. Cyrtopera laguncula, 105-647A-15-2, 16\#2, 8.7/73.0, $27 \times$. 11. Cornutella sp., 105-647A-13-4, 91 \#3, 96./65.3, 27×. 12. Cornutella sp., 105-647A-25-4, $107 \# 3,1.4 / 86.1,27 \times$. 13. Botryostrobus joides (group), 105-647A-25-4, 107 \#3, 1.4/86.1, 27 ×. 14. Botryostrobus joides (group), 105-647A-14-2, $145 \# 2,14.4 / 101.2,27 \times$. 15. Botryostrobus joides (group), 105-647A-14-2, 145 \#2, 17.8/94.7, 27 $\times$. 16. Botryostrobus joides (group), 105-647A-14-2, $145 \# 2,6.4 / 79.3,27 \times$. 17. Nassellarian gen. et sp. indet. \#5, 105-647A-25-4, 107 \#3, 9.9/81.0, 27 $\times$. 18. Nassellarian gen. et sp. indet. \#5, 105-647A-24-2, $46 \# 2,8.5 / 101.6,27 \times$. 

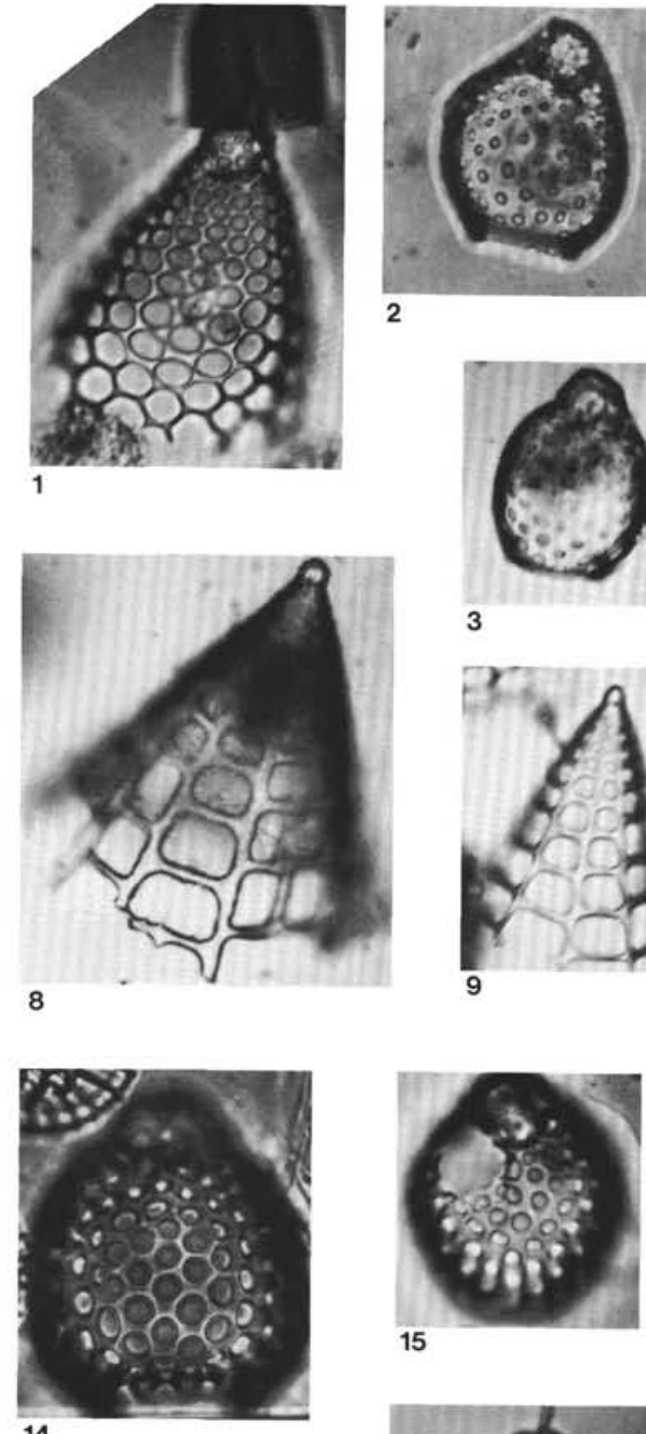

15

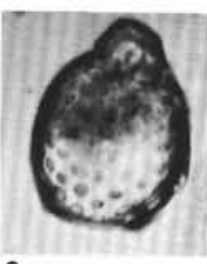

3
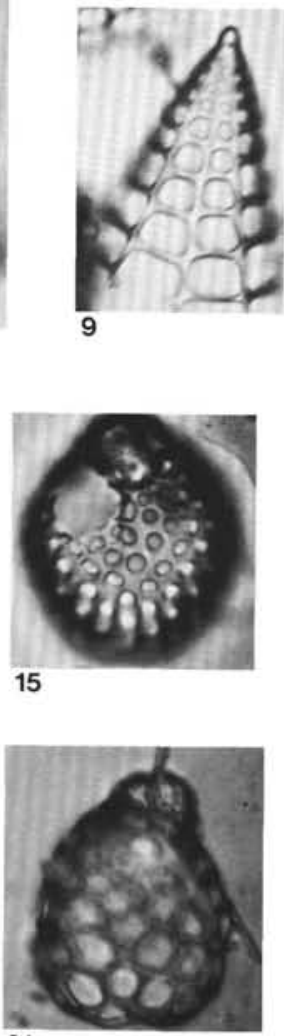

21

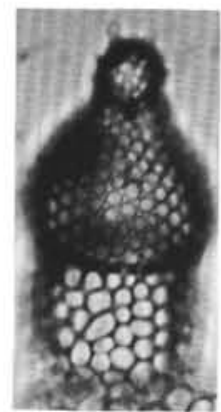

4
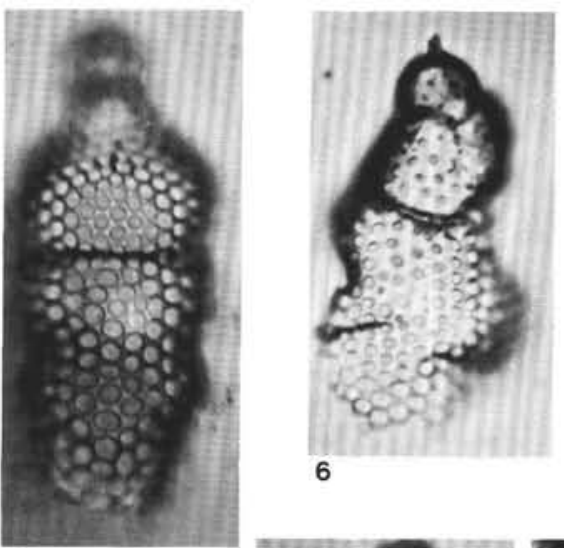

6

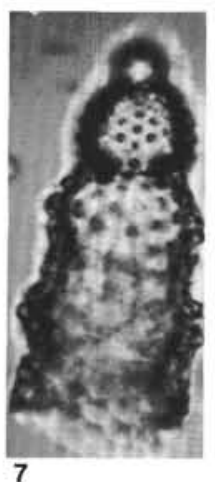

5
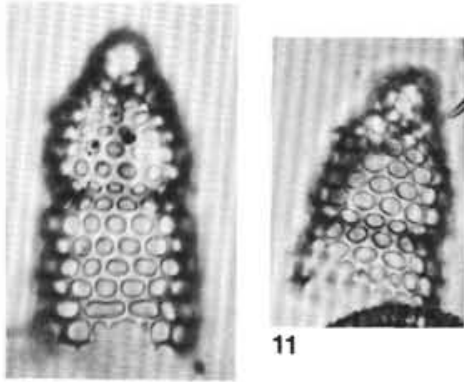

11
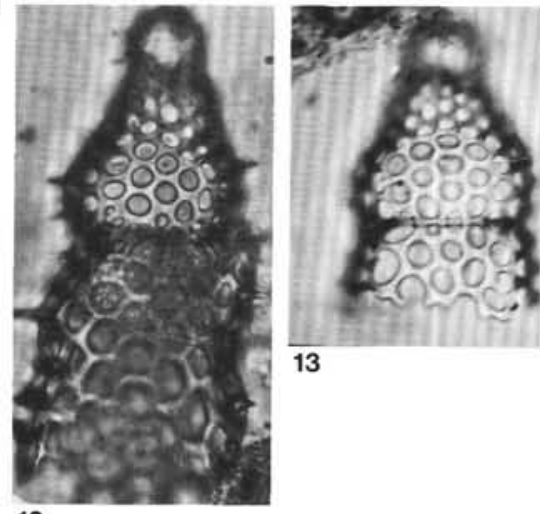

13
10
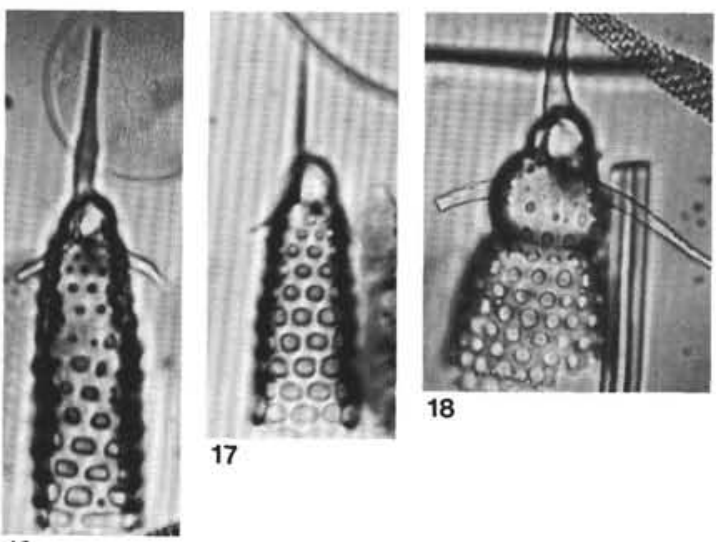

18

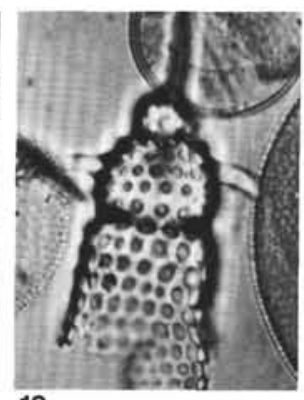

19

20

Plate 5. 1. Nassellarian gen. et sp. indet. \#6, 105-647A-20-2, 90 \#2, 9.9/79.5, 17×. 2. ?Dicolocapsa microcephala, 105-647A-15-2, 16 \#2, 9.6/ 102.5, $27 \times$. 3. ?Dicolocapsa microcephala, 105-647A-14-2, 145 \#2, 4.5/71.3, $27 \times$. 4. Cyrtocapsella sp.B. gr.B, 105-647A-20-2, 90 \#2, 4.8/76.0, $27 \times$. 5. Cyrtocapsella sp.B. gr.B, 105-647A-14-2, $145 \# 2,8.2 / 87.1,27 \times$. 6. ?Calocyclas semipolita (abnormal specimen), 105-647A-25-4, 107 \#3, $6.5 / 81.0,27 \times$. 7. ?Calocyclas semipolita, 105-647A-24-2, 46 \#2, 10.0/98.0, 27×. 8. Peripyramis sp., 105-647A-23-4, 75 \#1, 20.5/101.5, 17× 9. Peripyramis sp., 105-647A-20-2, 90 \#2, 7.4/94.9, 17×. 10. Cyrtocapsella sp. C, 105-647A-24-2, 46 \#2, 10.0/98.0, 27 $\times$. 11. Cyrtocapsella sp. C, 105-647A-25-4, 107 \#3, 75./86.3, 27×. 12. Cyrtocapsella sp. B gr. A, 105-647A-20-2, 90 \#2, 4.6/85.0, 27×. 13. Cyrtocapsella sp. B gr. A, 105647A-14-2, 145 \#2, 6.1/104.9, 27×. 14.?Cystophormis brevispina, 105-647A-14-2, 145 \#2, 5.7/77.8, 27×. 15. ?Cystophormis brevispina, 105$647 \mathrm{~A}-14-2,145$ \#2, 14.2/70.9, $27 \times$. 16. ?Artostrobus quadriporus, 105-647A-25-4, 107 \#3, 6.4/72.2, 27×. 17. ?Artostrobus quadriporus, 105647A-20-2, 90 \#2, 8.6/66.2, 27×. 18. Nassellarian gen. et sp. indet. \#8, 105-647A-21-3, 13 \#3, 1.0/85.9, 27×. 19. Nassellarian gen. et sp. indet. $\# 8,105-647$ A-24-2, $46 \# 2,10.0 / 55.4,27 \times$. 20. Nassellarian gen. et sp. indet. \#7, 105-647A-21-3, 13 \#3, 93./83.2, 27 $\times$. 21. Nassellarian gen. et sp. indet. \#7, 105-647A-21-3, $13 \# 3,4.6 / 85.3,27 \times$. 


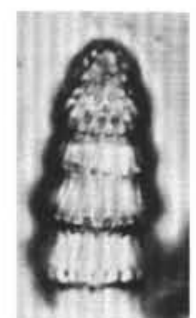

1

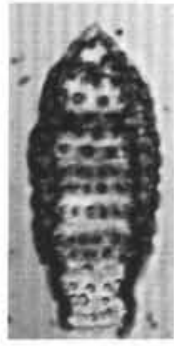

8
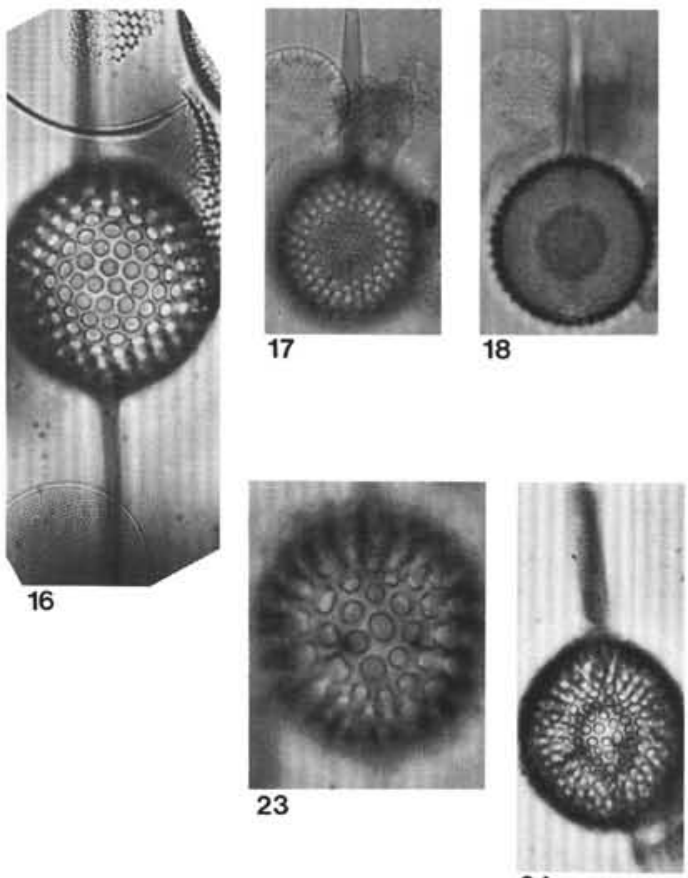

24

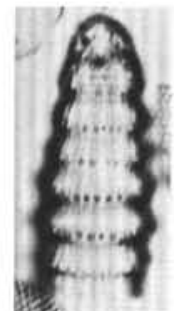

2

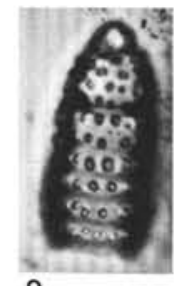

9

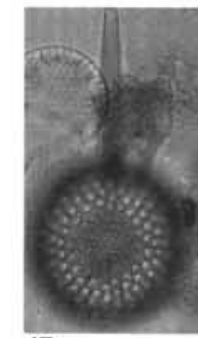

17

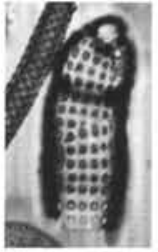

10

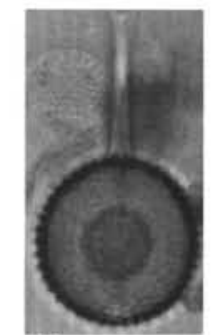

18

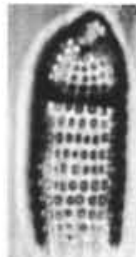

11

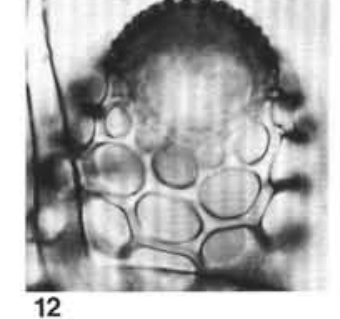

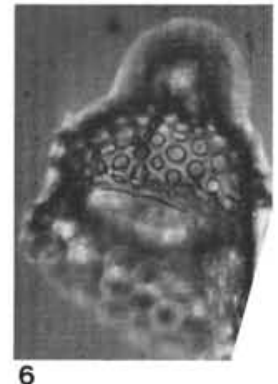

6

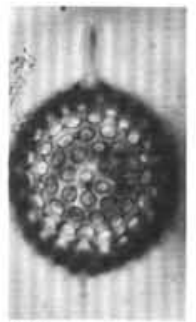

13
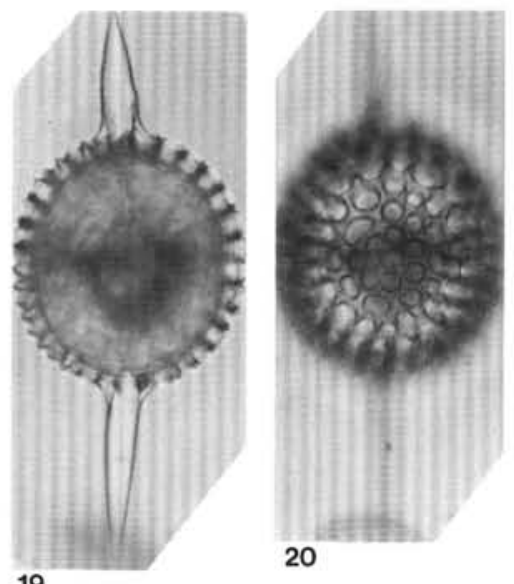

20

19

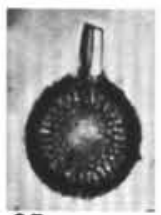

25

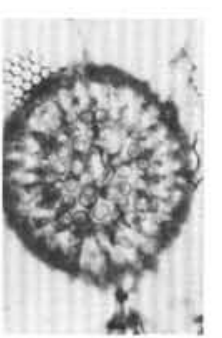

26

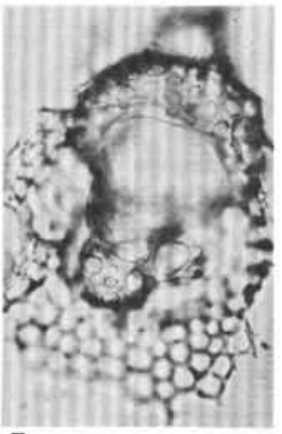

7
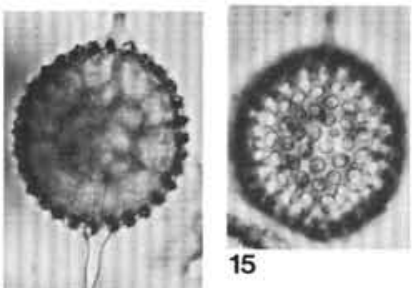

15

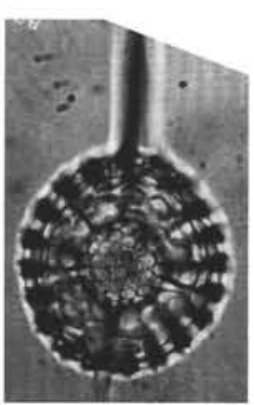

21

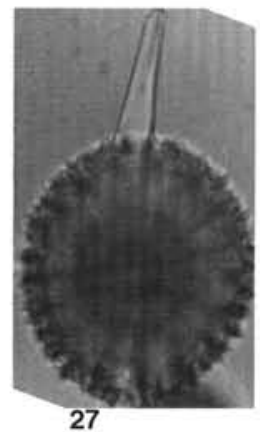

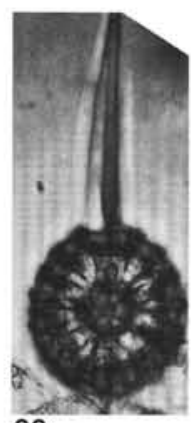

22

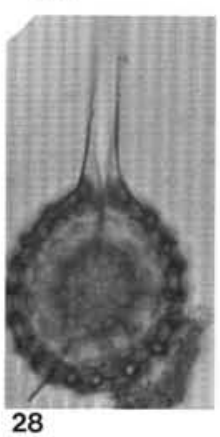

28

Plate 6. 1. Siphocampe spp. group A, 105-647A-20-2, 90 \#2, 7.7/99.7, 20×. 2. Siphocampe spp. group A, 105-647A-25-4, 107 \#3, 4.0/74.0, 20×. 3. Siphocampe spp. group B, 105-647A-20-2, $90 \# 2,8.6 / 66.4,20 \times$. 4. Siphocampe spp. group B, 105-647A-20-2, 90 \#2, 95./75.5, 20×. 5. ?Cyclampterium pegetrum, 105-647A-23-4, $75 \# 1,10.3 / 80.5,12.5 \times$. 6. Nassellarian gen. et sp. indet. \#4, 105-647A-21-3, 13 \#3, 10.5/76.0, 20×. 7. Nassellarian gen. et sp. indet. \#4, 105-647A-21-3, $13 \# 3,1.8 / 99.8,20 \times$. 8. Dictyoprora amphora, 105-647A-21-3, 13 \#3, 8.6/90.1, 20×. 9. Dictyoprora amphora, 105-647A-36-4, 49 \#3, 21.5/77.0, 20×. 10. Siphocampe acephala,105-647A-24-2, 46.1, 4.5/73.7, 20× . 11. Siphocampe acephala, 105-647A-25-4, 107 \#3, 2.0/89.2, 20×. 12. ?Cyclampterium pegetrum, 105-647A-23-4, 75 \#1, 10.3/86.5, 20×. 13. Druppatractus hastatus, 105-647A-17-3, 45 \#3, 6.5/88.3, 20×. 14. Druppatractus hastatus, 105-647A-17-3, 45 \#3,6.5/88.3, 20×. 15. Druppatractus hastatus, 105$647 \mathrm{~A}-19-4,50$ \#3, 17.2/73.2, 20×. 16. Sphaerostylus cristatus (group), 105-647A-25-4, 107 \#3, 5.3/70.1, 20×. 17. Sphaerostylus cristatus (group), 105-647A-17-3, 45 \#3, 3.4/97.4, 12.5×. 18. Sphaerostylus cristatus (group), 105-647A-17-3, 45 \#3, 3.4/97.4, 12.5 $\times$. 19. Sphaerostylus nicholasi, 105-647A-14-2, $145 \# 2,6.0 / 101.4,12.5 \times$. 20. Sphaerostylus nicholasi, 105-647A-20-2, 90 \#2, 2.5/87.3, 12.5×. 21. Stylatractid sp. E, 105-647A-36-4, 49 \#3, 3.9/78.2, 12.5×. 22. Stylatractid sp. E, 105-647A-19-4, 50 \#3, 19.8/73.0, 12.5×. 23. Sphaerostylus nicholasi, 150-647A20-2, 90 \#2, 2.5/87.3, 12.5×. 24. ?Lithatractus timmsi, 105-647A-25-4, 107 \#3, 7.2/85.0, 20×. 25. ?Lithatractus timmsi, 105-647A-13-4, 91 \#3, $19.6 / 75.1,12.5 \times$. 26. Stylatractid sp. G, 105-647A-14-2, $14532,17.4 / 93.2,12.5 \times$. 27. Stylatractid sp. G, 105-647A-14-2, 145 \#2, 8.3/66.0, $12.5 \times$. 28. Stylatractid sp. E, 105-647A-20-2, $90 \# 2,1.8 / 91.5,12.5 \times$. 


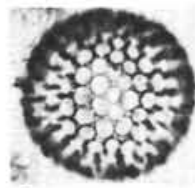

1

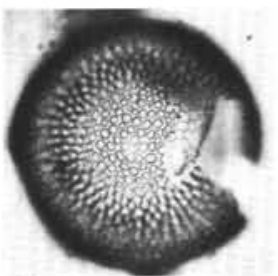

7

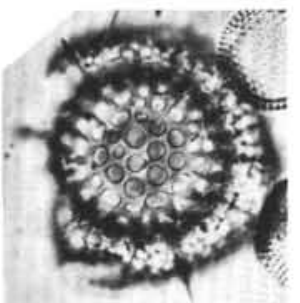

13

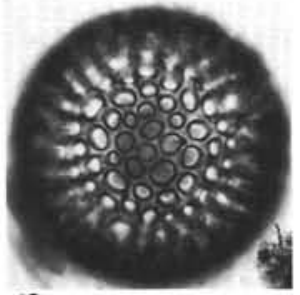

18

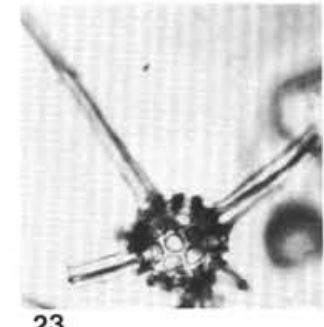

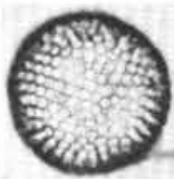

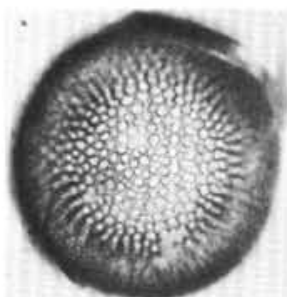

8
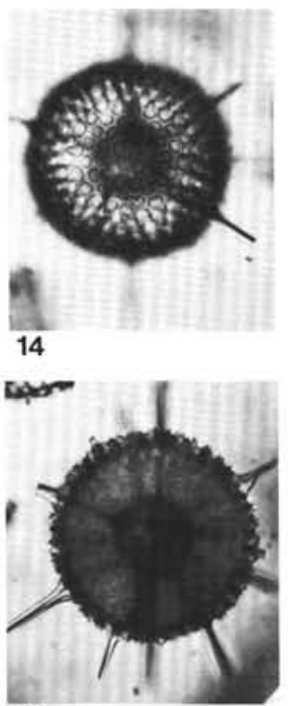

19

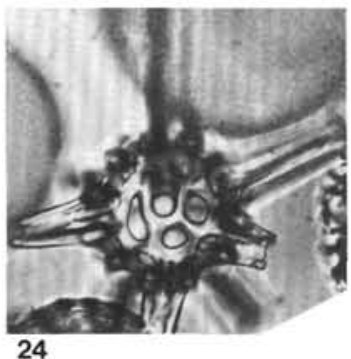

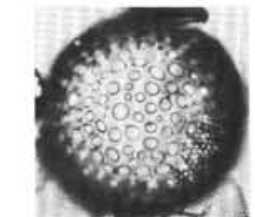

4
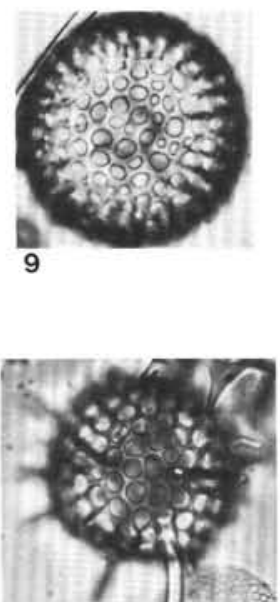

15

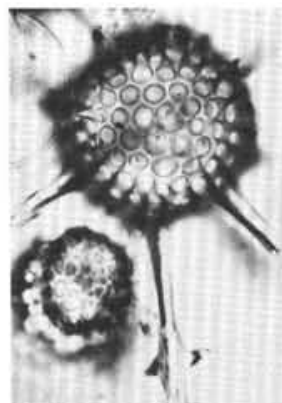

20

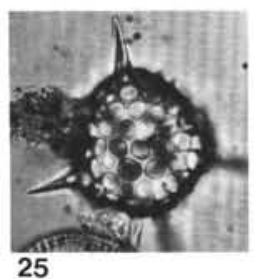

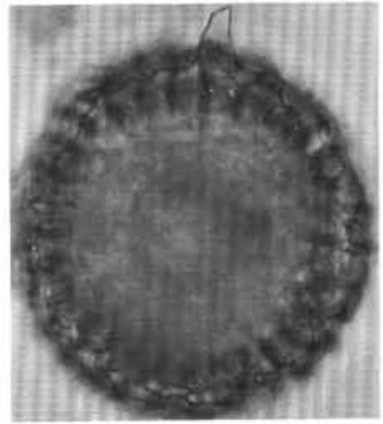

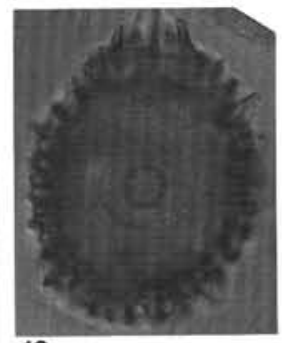

10
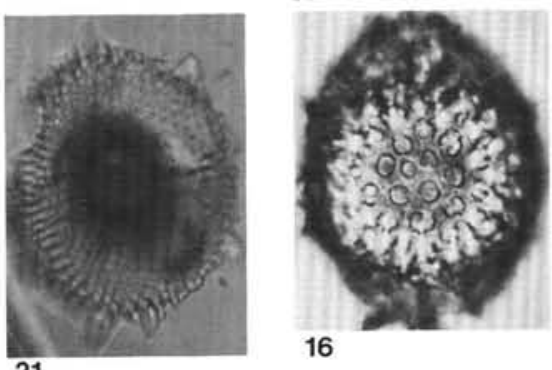

16

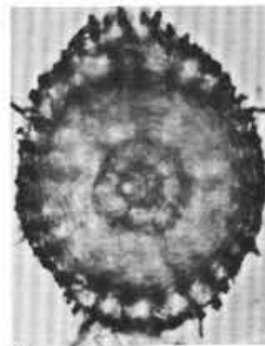

11

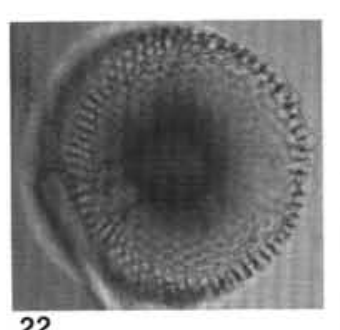

22
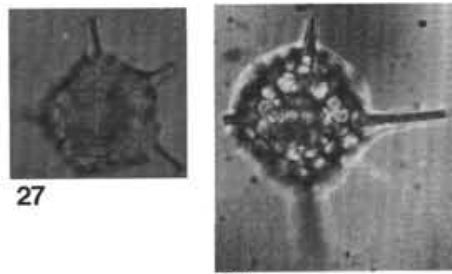

28

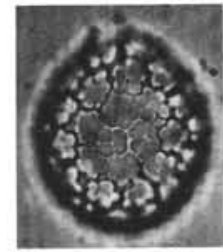

12
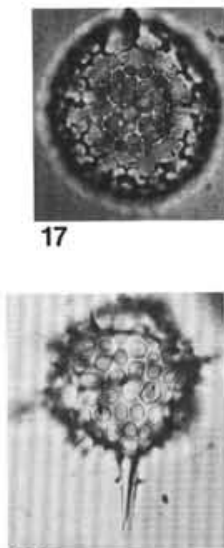

26

Plate 7. 1. Cenosphaera sp. D, 105-647A-13-4, $91 \# 3,5.3 / 69.1,12.5 \times$. 2. Cenosphaera sp. D, 105-647A-14-2, 145 \#2, 21.7/80.0, 12.5 $\times$. 3. Collosphaera? sp., 105-647A-21-3, 13 \#3, 5.9/68.6, 20×. 4. ?Cenosphaera (?) mariae, 647A-21-3, 13 \#3, 6.1/69.0, 12.5×. 5. Cenosphaera sp. A group 2, 105-647A-14-2, $7 \# 1,5.3 / 69.1,12.5 \times$. 6. Cenosphaera sp. A group 2, 105-647A-14-2, 7 \#1, 5.3/69.1, 12.5 $\times$. 7. ?Cenosphaera oceanica, 105647A-13-4, 91 \#3, 19.6/75.1, 12.5×. 8. ?Cenosphaera oceanica, 105-647A-21-,3 13 \#3, 9.4/79.2, 12.5×. 9. Actinomma sp. Gr.B, 105-647A-23-4, 75 $\# 1,19.2 / 78.0,12.5 \times$. 10. Sphaeropyle sp., 105-647A-19-3, 50 \#3, 10.3/69.7, 20×. 11. Sphaeropyle sp., 105-647A-14-2, 145 \#2, 6.8/84.5, 20×. 12. Sphaerostylus rosetta, 105-647A-13-4, $91 \# 3,3.7 / 100.4,20 \times$. 13. Actinomma spp. Gr. B, 105-647A-21-3, 13 \#3, 6.0/79.0, 12.5× . 14. Actinomma spp. Gr. B, 105-647A-23-4, 75 \#1, 69.2/78.0, 12.5×. 15. Actinomma sp. C, 105-647A-21-3, 13 \#3, 9.8/73.0, 20×. 16. Sphaeropyle sp., 105-647A-14-2, $145 \# 2,6.8 / 84.5,20 \times$. 17. Sphaerostylus rosetta, 105-647A-13-4, 91 \#3, 19.4/66.8, 20×. 18. Actinomma spp. Gr. B, 105-647A20-2, 90 \#2, 4.4/74.2, $12.5 \times$. 19. Actinomma spp. Gr. B, 105-647A-20-2, 90 \#2, 4.4/74.2, 12.5×. 20. Actinomma sp. C, 105-647A-20-2, 90 \#2, 7.6/100.7, 20×. 21. Heliodiscus sp., 105-647A-14-2, $145 \# 2,7.5 / 87.3,20 \times$. 22. Heliodiscus sp., 105-647A-14-2, 7 \#2, 12.6/75.2, 20×. 23. Anomalocantha dentata, 105-647A-25-4, 107 \#3, 9.9/89.5, 12.5×. 24. Anomalocantha dentata, 105-647A-25-4, 107 \#3, 5.7/69.3, 20×. 25. Spumellarian gen. et sp. indet. \#2, 105-647A-20-2 90\#2, 76./91.3, 20×. 26. Spumellarian gen. et sp. indet. \#2, 105-647A-24-2, 46 \#1, 2.2/79.4, $20 \times$. 27. Spumellarian gen. et sp. indet. \#1, 105-647A-23-4, $75 \# 1,8.5 / 82.3,20 \times$. 28. Spumellarian gen. et sp. indet. \#1, 105-647A-21-3, 13 \#3, $4.6 / 85.2,20 \times$. 


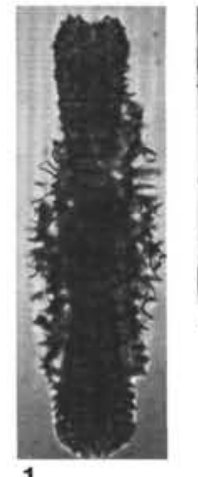

1
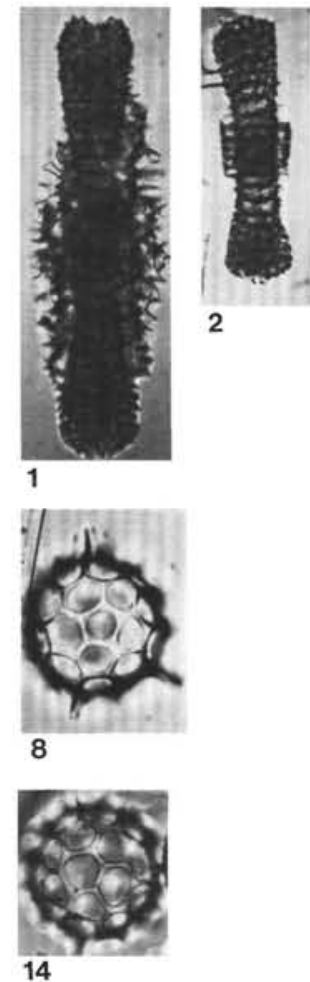

2

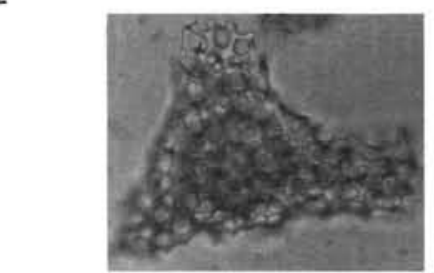

9
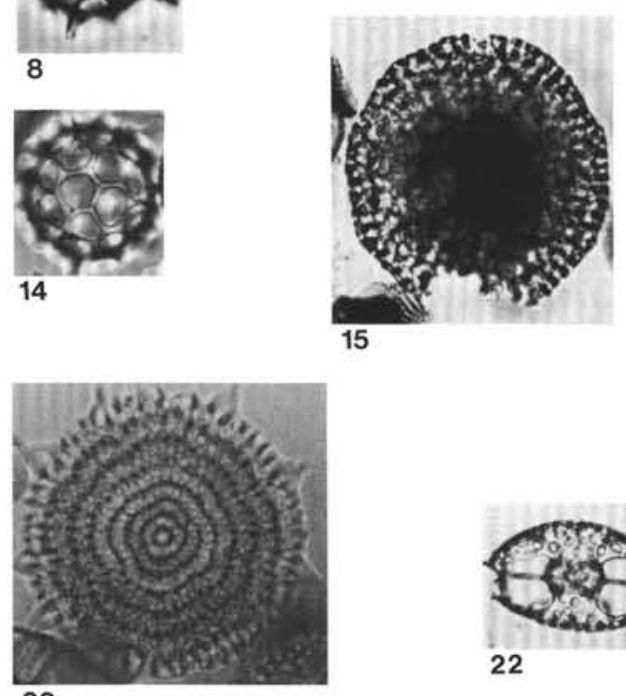

20

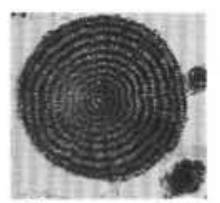

21

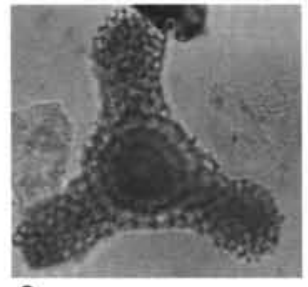

3

22

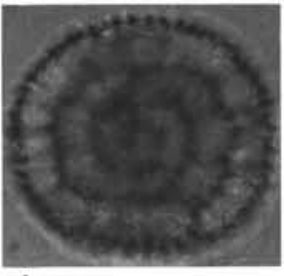

4
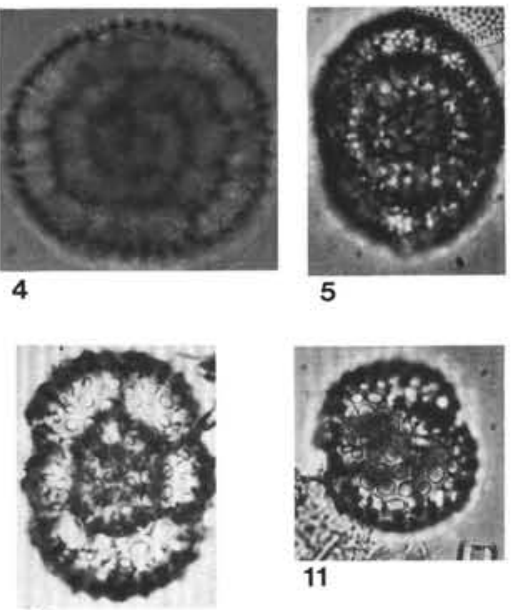

10

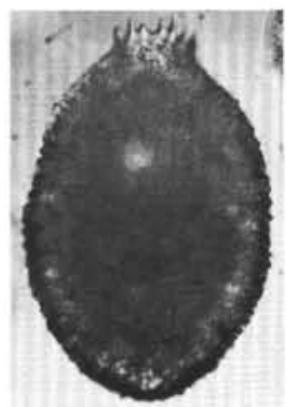

16
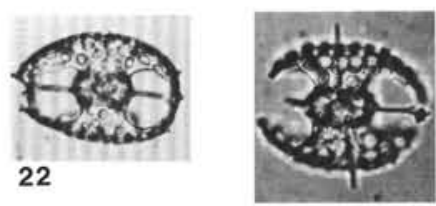

23

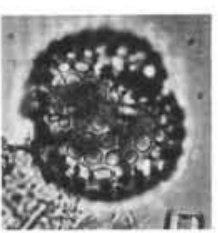

11

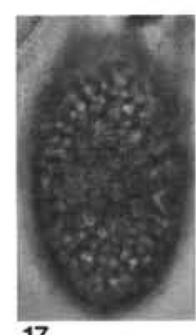

17

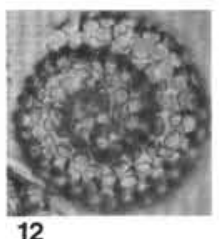

12

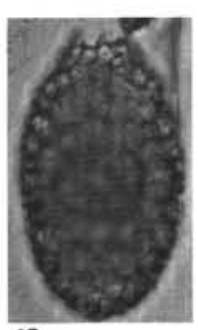

18

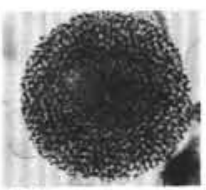

24

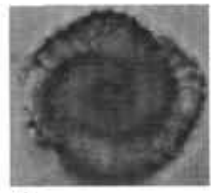

6

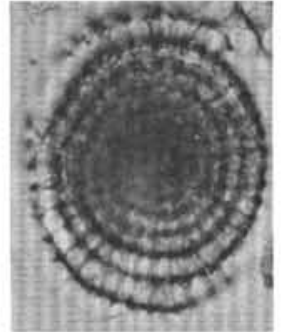

7

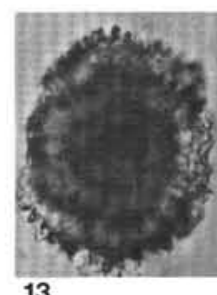

13

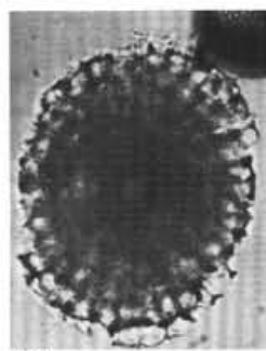

19

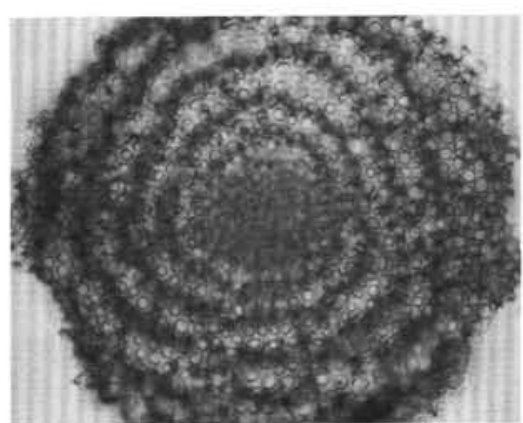

25

Plate 8. 1. Spongocore sp., 105-647A-23-4, $75 \# 1,23.2 / 85.0,20 \times$. 2. Spongocore sp., 105-647A-20-2, 90 32, 10.4/74.2, 12.5 $\times$. 3. Euchitonia? spp., 105-647A-14-2, $145 \# 2,6.6 / 89.0,20 \times$. 4. Amphitholus sp. A, 105-647A-21-3, $13 \# 3,3.0 / 102.2,20 \times$. 5. Lithelius sp. A (group), 105-647A21-3, $13 \# 3,6.3 / 69.8,20 \times$. 6. Lithelius sp. A (group), 105-647A-20-2, $90 \# 2,4.2 / 77.4,20 \times$. 7. Prunopyle sp. A, 105-647A-15-2, 16 \#2, 8.4/70.4, $20 \times$. 8. Arachnosphaera sp., 105-647A-14-2, $145 \# 2,11.4 / 81.0,20 \times$. 9. Euchitonia? spp., 105-647A-14-2, 145 \#2, 6.0/90.0, 20×. 10. Amphitholus sp. A, 105-647A-14-2, 7 \#2, 7.3/92.1, 20×. 11. Lithelius sp. A (group), 105-647A-14-2, 145 \#2, 15.5/83.0, 20×. 12. Lithelius sp. A (group), 105-647A-13-4, 91 \#3, 20.1/65.4, 20×. 13. Prunopyle spp group C, 105-647A-14-2, 145 \#2, 5.4/69.1, 12.5 $\times$. 14. Arachnosphaera sp., 105-647A-21-3, $13 \# 3,2.5 / 88.2,20 \times$. 15. Prunopyle spp. B subgr. $2,105-647$ A-25-4, 107 \#3, 9.8/65.2, 20×. 16. Prunopyle spp. B subgr. 1, 105647 A-15-2, $16 \# 2,8.7 / 80.9,20 \times$. 17. Prunopyle spp. B subgr. 1, 105-647A-25-4, 107 \#3, 7.5/69.0, 12.5×. 18. Prunopyle spp. B subgr. 1 , 105647A-25-4, $107 \# 3,7.5 / 69.0,12.5 \times$. 19. Prunopyle spp. group C, 105-647A-14-2, 145 \#2, 15.7/93.1, 20×. 20. Porodiscus? spp., 105-647A-17-3, $45 \# 2,72.8 / 10.2,20 \times$. 21. Porodiscus? spp., 105-647A-20-2, $90 \# 2,5.1 / 72.0,5 \times$. 22. Tetrapyle sp., 105-647A-23-4, 75 \#1, 2.8/74.5, 20×. 23. Tetrapyle sp., 105-647A-21-3, 13 \#3, 6.2/70.4, 20×. 24. Spongodiscus sp., 105-647A-17-3, 45 \#2, 2.2/78.2, 12.5×. 25. Spongodiscus sp., $105-647 \mathrm{~A}-23-4,75$ \#1, 12.7/86.7, $5 \times$. 